Pacific Northwest

National Laboratory

Operated by Battelle for the

U.S. Department of Energy

\title{
Specification of Selected Performance Monitoring and Commissioning Verification Algorithms for CHP Systems
}

MR Brambley

S Katipamula

October 2006

Prepared for the U.S. Department of Energy

under Contract DE-AC05-76RL01830

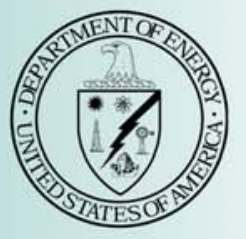




\title{
DISCLAIMER
}

This report was prepared as an account of work sponsored by an agency of the United States Government. Neither the United States Government nor any agency thereof, nor Battelle Memorial Institute, nor any of their employees, makes any warranty, express or implied, or assumes any legal liability or responsibility for the accuracy, completeness, or usefulness of any information, apparatus, product, or process disclosed, or represents that its use would not infringe privately owned rights. Reference herein to any specific commercial product, process, or service by trade name, trademark, manufacturer, or otherwise does not necessarily constitute or imply its endorsement, recommendation, or favoring by the United States Government or any agency thereof, or Battelle Memorial Institute. The views and opinions of authors expressed herein do not necessarily state or reflect those of the United States Government or any agency thereof.

\author{
PACIFIC NORTHWEST NATIONAL LABORATORY \\ operated by \\ BATTELLE \\ for the \\ UNITED STATES DEPARTMENT OF ENERGY \\ under Contract DE-AC05-76RL01830
}

Printed in the United States of America
Available to DOE and DOE contractors from the Office of Scientific and Technical Information, P.O. Box 62, Oak Ridge, TN 37831-0062;
ph: (865) 576-8401
fax: $(865) 576-5728$
email: reports@adonis.osti.gov

\author{
Available to the public from the National Technical Information Service, \\ U.S. Department of Commerce, 5285 Port Royal Rd., Springfield, VA 22161 \\ ph: (800) 553-6847 \\ fax: $(703) 605-6900$ \\ email: orders@ntis.fedworld.gov \\ online ordering: http://www.ntis.gov/ordering.htm
}




\section{Specification of Selected Performance Monitoring and Commissioning Verification Algorithms for CHP Systems}

MR Brambley

S Katipamula

October 2006

Prepared for

the U.S. Department of Energy

under Contract DE-AC05-76RL01830

Pacific Northwest National Laboratory

Richland, Washington 99352 


\section{Acknowledgements}

This work was supported the Distributed Energy Program of the Office of Electricity Delivery and Energy Reliability of the U.S. Department of Energy. The authors wish to thank Mario Sciulli, Program Manager at the National Energy Technology Laboratory, and Debbie Haught, the DOE Program Manager, for their support and guidance in the performance of this work. Members of the project advisory panel also provided valuable input through their review of project plans and reports. Their guidance is critical to the successful performance of this project.

\section{Project Advisory Panel}

Todd Amundson, Bonneville Power Administration

Gordon Bloomquist, Washington State University Extension Program and Northwest CHP Application Center

Michael O’Callaghan, United Technologies Research Center

Joe Haley, UTC Power

Steve Gable, Honeywell

Carlos Haiad, Southern California Edison

Sumit Ray, Trammell Crow

Randy Hudson II, Oak Ridge National Laboratory

Abdi Zaltash, Oak Ridge National Laboratory

Chris Marnay, Lawrence Berkeley National Laboratory 


\section{Executive Summary}

Pacific Northwest National Laboratory (PNNL) is assisting the U.S. Department of Energy (DOE) Distributed Energy (DE) Program by developing advanced control algorithms that provide the basis upon which tools to enhance performance and reliability, and reduce emissions of distributed energy technologies, including combined heat and power (CHP) technologies, could be developed.

The primary objective of this multiyear project is to develop algorithms for combined heat and power systems. These algorithms will ensure optimal performance, increase reliability, and lead to the goal of clean, efficient, reliable and affordable next generation energy systems.

This document provides detailed functional specifications for the algorithms for CHP system performance monitoring and commissioning verification that are applicable to both existing and new CHP systems. The report identifies 7 generic CHP system configurations for which algorithms will be developed from a total of 10 originally identified in the Scope Specification (Katipamula and Brambley 2006). The report then provides specifications for monitoring individual components present in the seven selected CHP configurations. Each specification includes equations for calculating performance metrics and a diagram showing all fixed inputs, measured inputs, and outputs for the algorithms. An analogous specification is also provided for performance monitoring at the system level.

Commissioning and performance verification are then discussed in some detail. A method to model system performance and detect degradations is presented along with equations and an input/output diagram. Verification of commissioning is accomplished essentially by comparing actual measured performance to benchmarks for performance provided by the system integrator and/or component manufacturers. The results of these comparisons are then automatically interpreted to provide conclusions regarding whether the CHP system and its components have been properly commissioned and where problems are found, guidance is provided for corrections.

The report then presents an example of how the monitoring algorithms could be deployed as a stand-alone software package. Scenarios are also provided illustrating how the algorithms could be used for performance monitoring during operation of a CHP system and as a means for verifying proper commissioning of a CHP system during initial start-up or restart. The report concludes by identifying the next steps in the project. 


\section{Variables}

\section{Physical Variable}

Coefficient of performance

Cost

Density

Value-weighted energy utilization factor

Specific enthalpy

Fuel energy flow rate

Heat loss rate

Higher heating value

Lower heating value

Mass flow rate

Power

Pressure

Specific heat

Temperature

Volumetric flow rate

Efficiency

Effectiveness

Electric power

Price

Thermal power

Unit monetary value

\section{Subscripts}

Parameter

\section{Components}

Absorption chiller generator

Absorption chiller

Chiller (electric)

Condenser

Cooling tower

Desiccant system

Evaporator

Fan

Gear box

Heat recovery steam generator

Heat recovery unit

Prime Movers

Micro-turbine

Reciprocating engine

Pump

\section{Notation}

\begin{tabular}{l} 
Notation \\
\hline COP \\
Cost \\
$\rho$ \\
$E U F_{V W}$ \\
$H$ \\
$Q_{\text {Fuel }}$ \\
$L$ \\
$H H V$ \\
LHV \\
$\dot{m}$ \\
$W$ \\
$P$ \\
$c_{p}$ \\
$T$ \\
$\dot{v}$ \\
$\eta$ \\
$\varepsilon$ \\
$W_{\text {Elec }}$ \\
Price \\
$Q_{t h}$ \\
$Y$
\end{tabular}

\section{$\underline{\text { Subscript Notation }}$}

gen
AbChiller
Chiller
cond
$C T$
$D$
evap
Fan
gearbox
HRSG
HRU

Turbine

engine

Pump 
Parameter

Substances

Air

Cooling water

Exhaust gases

Fuel

Hot water

Steam

Water

Flow Direction

Input

Output

Forms of Energy

Electricity

Thermal

Fuel

\section{Other}

Actual value

Commissioning baseline

Discharge

Electric generation

Minimum

Maximum

Suction

Wet bulb

\section{$\underline{\text { Subscript Notation }}$}

A

$c w$

ex

F or Fuel

hotwater

Sor steam

$w$

$i$

o

Elec

th

F or Fuel

$a$

$C x b$

discharge

EE

min

$\max$

suction

$w b$ 


\section{Contents}

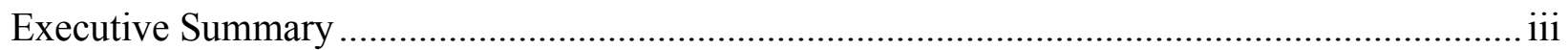

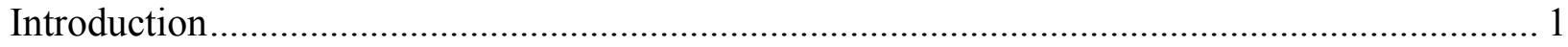

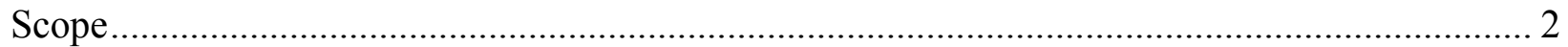

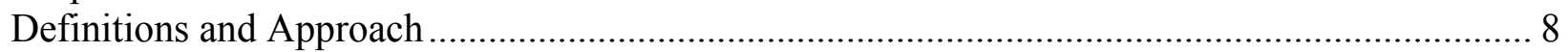

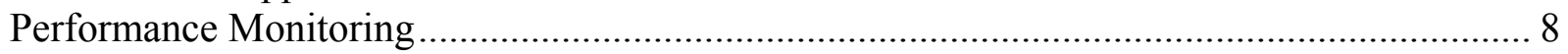

Commissioning Verification......................................................................................... 9

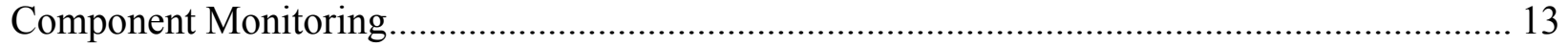

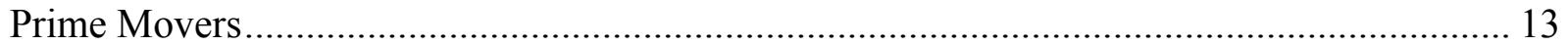

Efficiency of Prime Movers............................................................................................... 13

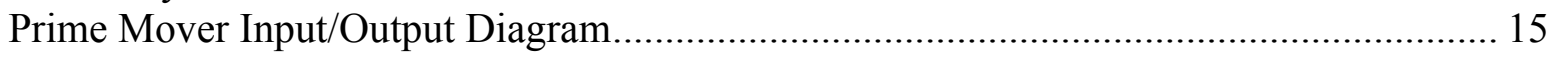

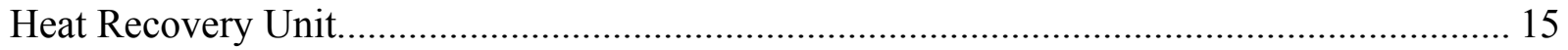

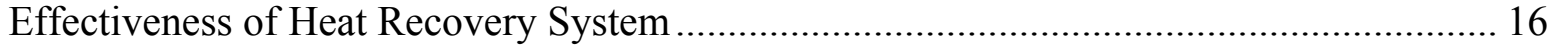

Heat Recovery Unit Input/Output Diagram...................................................................... 19

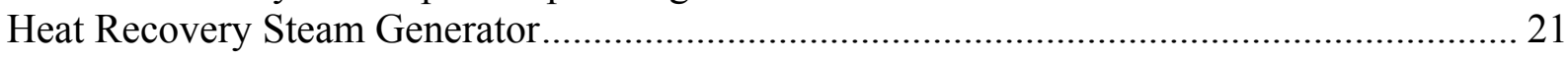

Effectiveness of Heat Recovery Steam Generator................................................................. 22

Heat Recovery Steam Generator Input/Output Diagram .................................................... 23

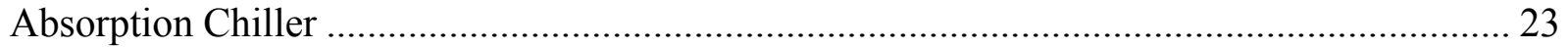

Efficiency of Absorption Chiller .............................................................................. 25

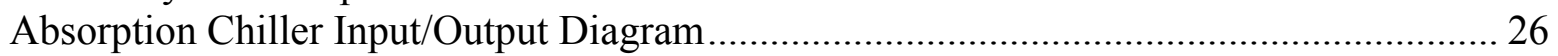

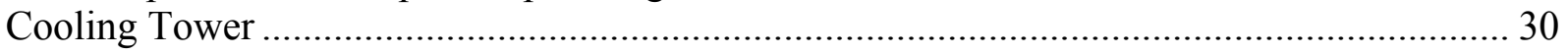

Efficiency of Cooling Towers................................................................................... 30

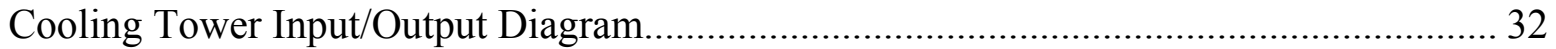

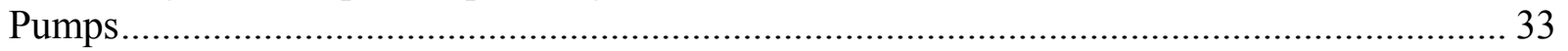

Efficiency of Pumps........................................................................................................... 33

Pump Input/Output Diagram....................................................................................... 34

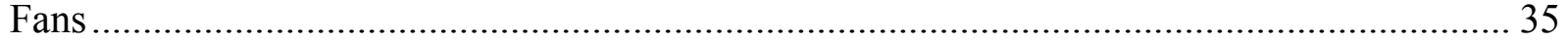

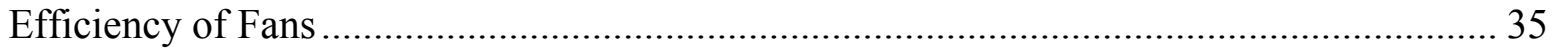

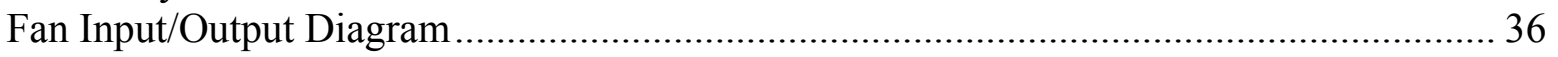

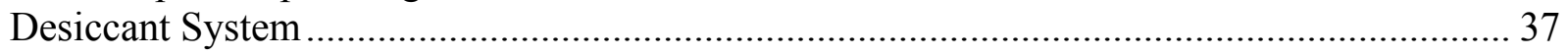

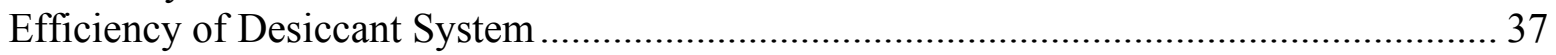

Desiccant System Input/Output Diagram ………...................................................... 38

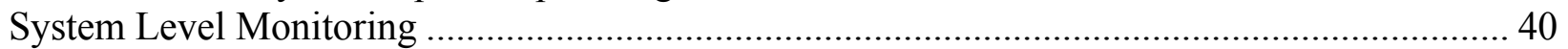

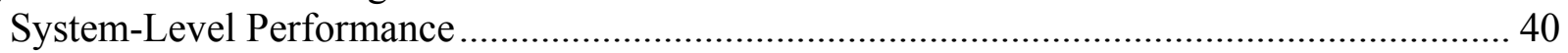

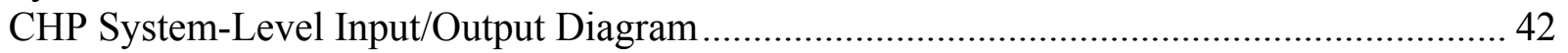

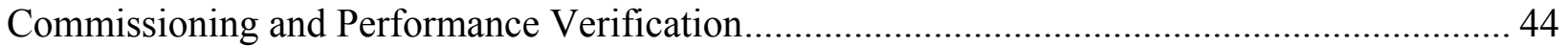

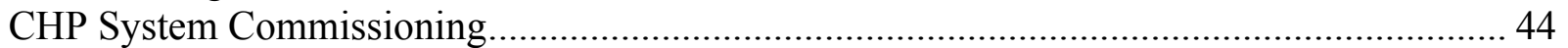

Approach to Commissioning and Performance Verification..................................................... 46

A Bin-Based Method for Baseline Performance ................................................................... 49

Input/Output Diagrams .................................................................................................. 53

Commissioning Verification Input/Output Diagrams.......................................................... 54

Performance Verification Input/Output Diagrams............................................................ 55

CHP Performance Monitoring (PM) and Commissioning Verification (CxV): Algorithm

Deployment Scenario ....................................................................................................... 57

CHP Performance Monitoring and Commissioning Verification: Application Scenarios .......... 59

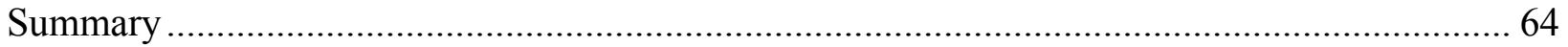




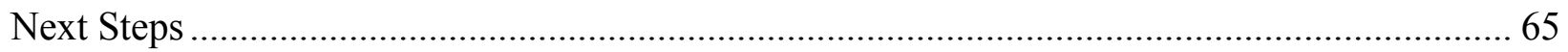

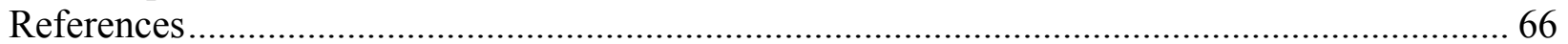




\section{Introduction}

Pacific Northwest National Laboratory (PNNL) is assisting the U.S. Department of Energy (DOE) Distributed Energy (DE) Program by developing advanced control algorithms that would lead to development of tools to enhance performance and reliability, and reduce emissions of distributed energy technologies, including combined heat and power (CHP) technologies ${ }^{1}$.

The primary objective of this multiyear project is to develop algorithms for combined heat and power systems. These algorithms will ensure optimal performance, increase reliability, and lead to the goal of clean, efficient, reliable and affordable next generation energy systems.

As part of the project, in late FY2005, an expert project advisory panel (PAP) was formed to help guide and review progress of the proposed multiyear research effort. The advisory panel included representatives from: 1) Honeywell Labs, 2) United Technologies Research Center (UTRC), 3) Northwest CHP Application Center, 4) Bonneville Power Administration (BPA) and 5) Southern California Edison (SCE). This panel met to review project objectives, scope and plans in December 2005.

The next phase of the project focused on defining the potential breadth of advanced controls for CHP systems and then defined from that the specific scope for this project. The results of that phase are documented in a report titled Advanced CHP Control Algorithms: Scope Specification (Katipamula and Brambley 2006).

The current report documents the next phase of work, providing a detailed functional specification for algorithms for performance monitoring and commissioning verification that are applicable to both existing and new CHP systems. The report identifies the systems for which algorithms will be developed, the specific functions of each algorithm, metrics that the algorithms will output, and inputs required by each algorithm. Specifications of algorithms for monitoring the performance of individual CHP components are developed first, followed by algorithms for monitoring specific CHP system configurations. That is followed by specification of the algorithms for commissioning verification, which use the outputs of performance monitoring as inputs to verify that performance meets expectations. This information forms the basis for development of the algorithms in the next phase of the project. The report then provides a scenario for deployment and use of the algorithms to help the reader better understand how the algorithms would be deployed in software and used to support CHP system operations. We conclude the report by briefly describing the focus of the next phase of the project, which will involve developing the algorithms for performance monitoring and commissioning verification.

\footnotetext{
${ }^{1}$ In the open literature, several different terms are used for combined heat and power systems, including building combined heat and power (BCHP), combined cooling, heating and power (CCHP), combined heat and power for buildings, and integrated energy systems. See Katipamula and Brambley (2006) for additional discussion of terminology and the overall scope of this project.
} 


\section{Scope}

In this section, we identify the specific capabilities to be developed under FY2006 funding and the systems for which they will be developed. Figure 1 shows the full scope of capabilities to be developed in this project, as originally proposed. Of these, performance monitoring and commissioning verification will be developed under funding provided in FY2006 (shown in black). ${ }^{2}$ This includes performance monitoring and commissioning verification. Algorithms for the other capabilities (e.g., automated fault detection and diagnostics and supervisory controls, shown as red dashed lines) will be developed under funding provided in years after FY2006. Although most of the automated fault detection and diagnostic (AFDD) capabilities will be developed under future funding, some of the AFDD algorithms that operate directly on performance monitoring data will be developed under FY2006 funding to the extent that resources permit (e.g. automated detection of degradation of performance metrics).

Rather than try to cover all possible CHP system configurations, we have selected a manageable subset for which to develop the algorithms. This subset of configurations represents those commonly used for CHP systems of less than $1 \mathrm{MWe}^{3}$ capacity and suitable for applications in commercial buildings (although some are suitable for agricultural, industrial and other applications as well). As stated in the overall scope specification document (Katipamula and Brambley 2006), this project will focus on CHP systems that use the following components: small gas turbines ${ }^{4}$ and reciprocating engines for primer movers, heat recovery heat exchangers, absorption chillers, cooling towers, desiccant systems, pumps and fans. System configurations based on these components are shown in Figure 2 through Figure 8.

Figure 2 shows a simple CHP system using a small turbine to power an electric generator. Exhaust gases pass through a heat recovery heat exchanger, where heat is transferred to air or water, producing hot water, steam or hot air for space heating or other thermal applications. An electrically driven pump or fan imparts flow to the water or air, which is heated in the heat recovery unit. The heat recovery unit may also have a fuel-fired auxiliary heater (duct-burner) to meet the demand for steam, hot air or water at times when the heat in the exhaust gases cannot meet the entire load. Turbine exhaust generally contains $16 \%$ or greater oxygen, which enables co-firing (unlike exhaust from reciprocating engines, which contains $1 \%$ to $6 \%$ oxygen and does not). When hot water is produced, supplemental heating of the hot water directly, rather than by use of a duct heater, leads to higher efficiencies. Useful outputs of the system include the electricity produced and hot water or air for thermal applications such as space heating.

A system similar to the one shown in Figure 2, except with a reciprocating engine used as the prime mover for the electric generator, is shown in Figure 3. In addition to recovering heat from

\footnotetext{
${ }^{2}$ Although the funding for these activities was provided in FY2006, because funding was not authorized until midFY2006, some of the corresponding work will be completed in the first half of FY2007.

${ }^{3}$ MWe is used to designate $1 \mathrm{MW}$ of electric generation capacity.

${ }^{4}$ The terms "small turbines" and "turbines" are used interchangeably in this report to represent all micro-turbines, mini-turbines, and small gas turbines used in CHP systems with up to about $1 \mathrm{MW}_{\text {elec }}$ output.
} 


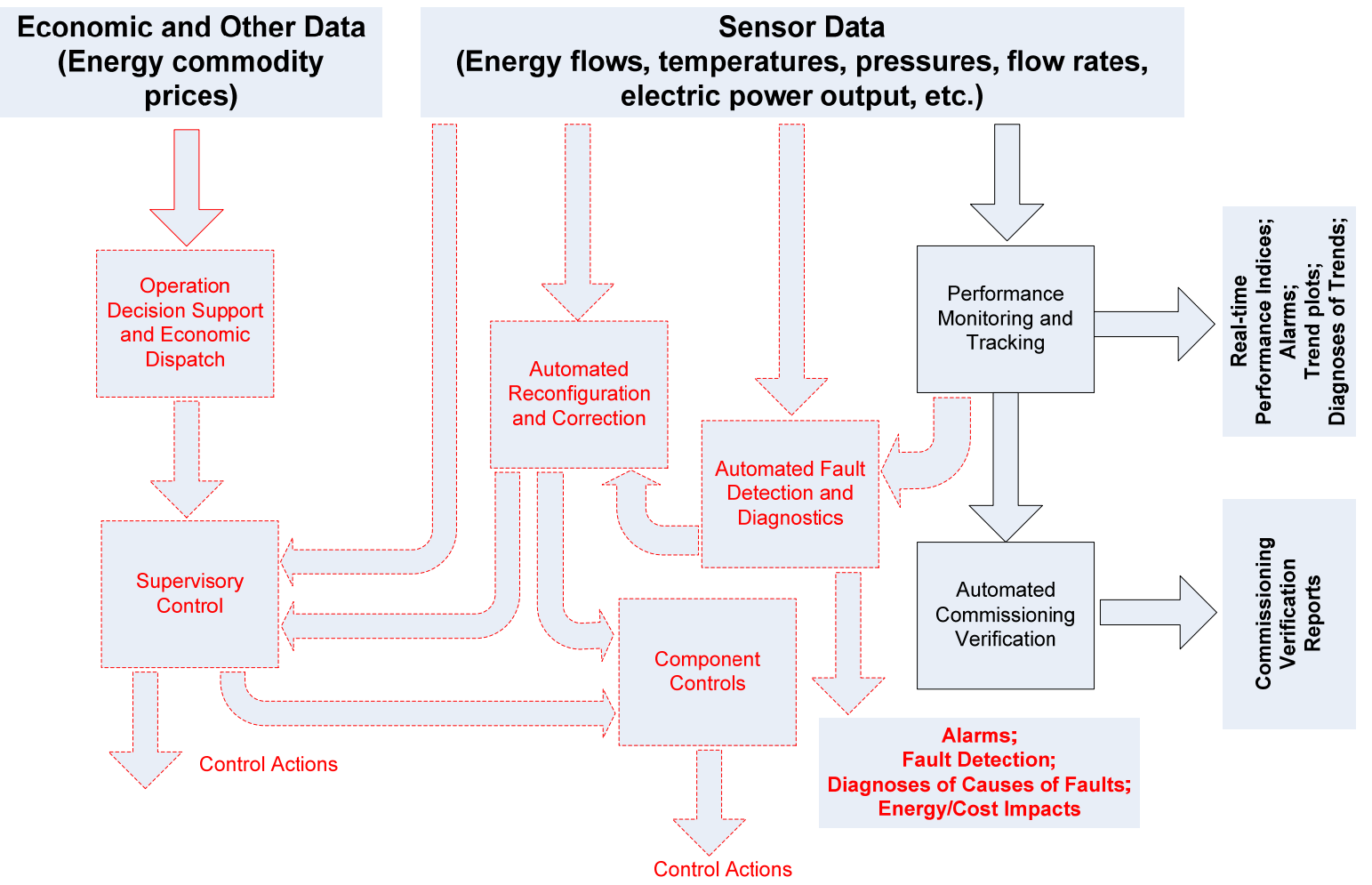

Figure 1 - Major categories of advanced CHP control capabilities with those for which algorithms will be developed by this project in FY2006 shown in solid black lines; algorithm categories for future work are shown in red dashed lines.

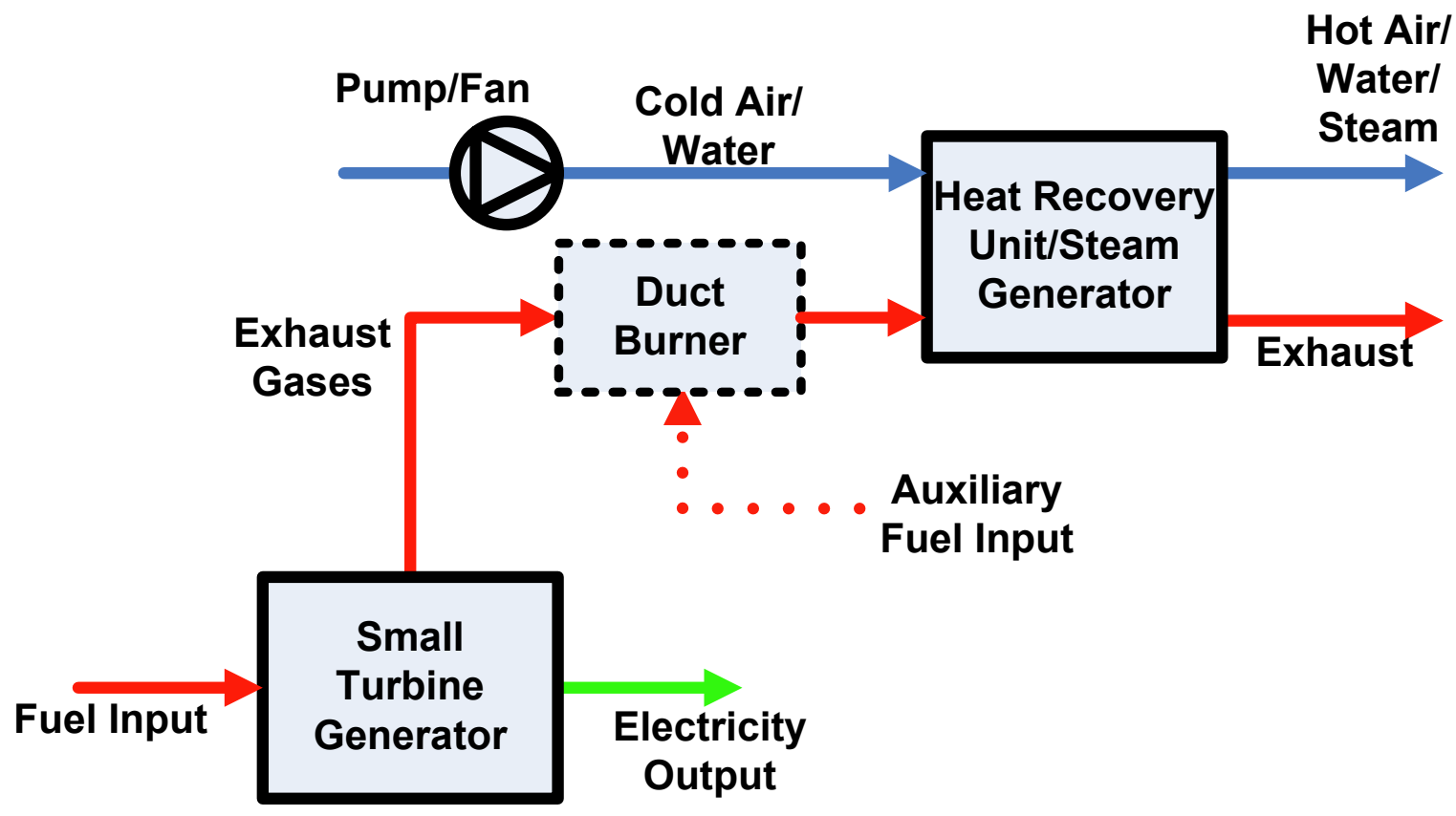

Figure 2 - A simple CHP system using a small turbine generator with exhaust gas heat recovery. 


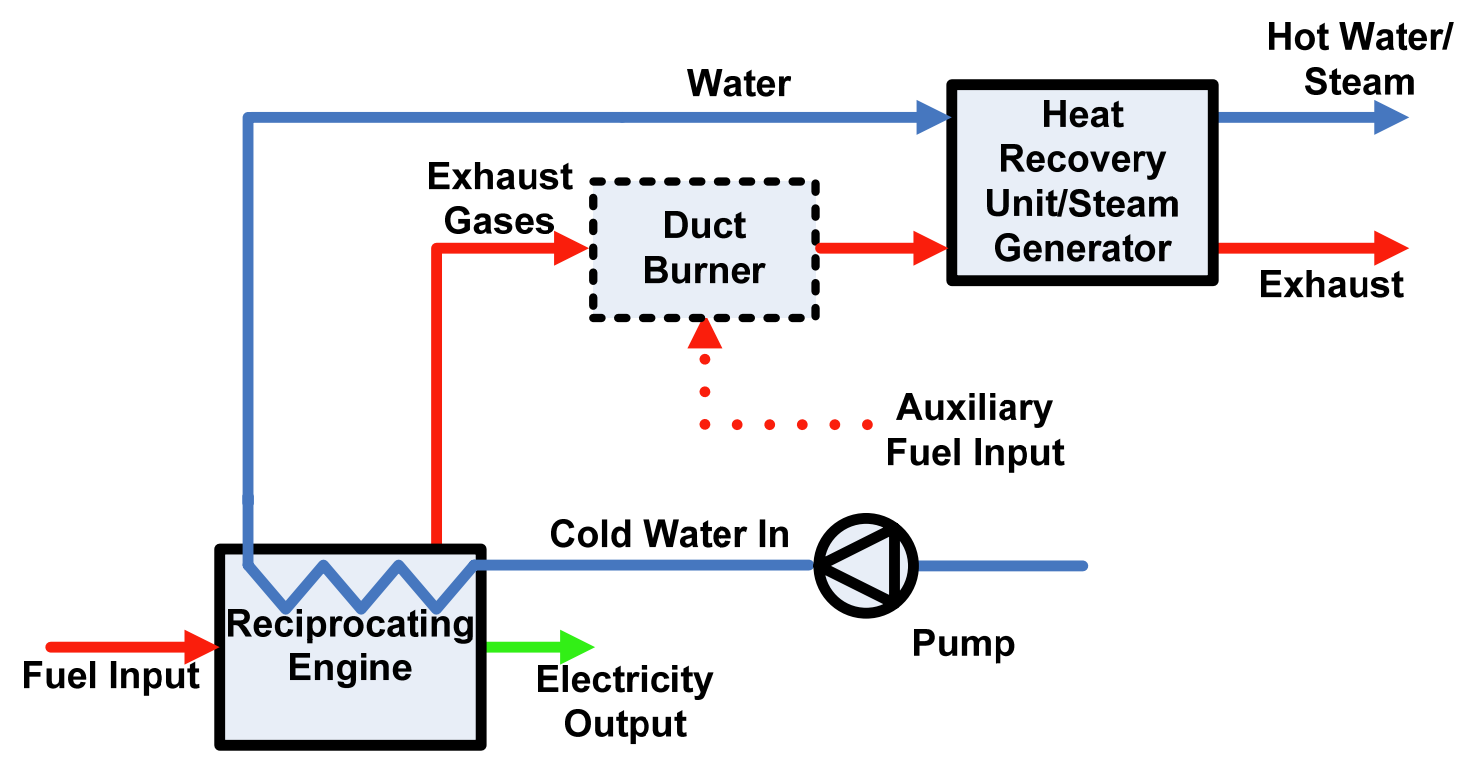

Figure 3 - CHP system using a reciprocating engine for electricity generation with engine jacket and exhaustgas heat recovery.

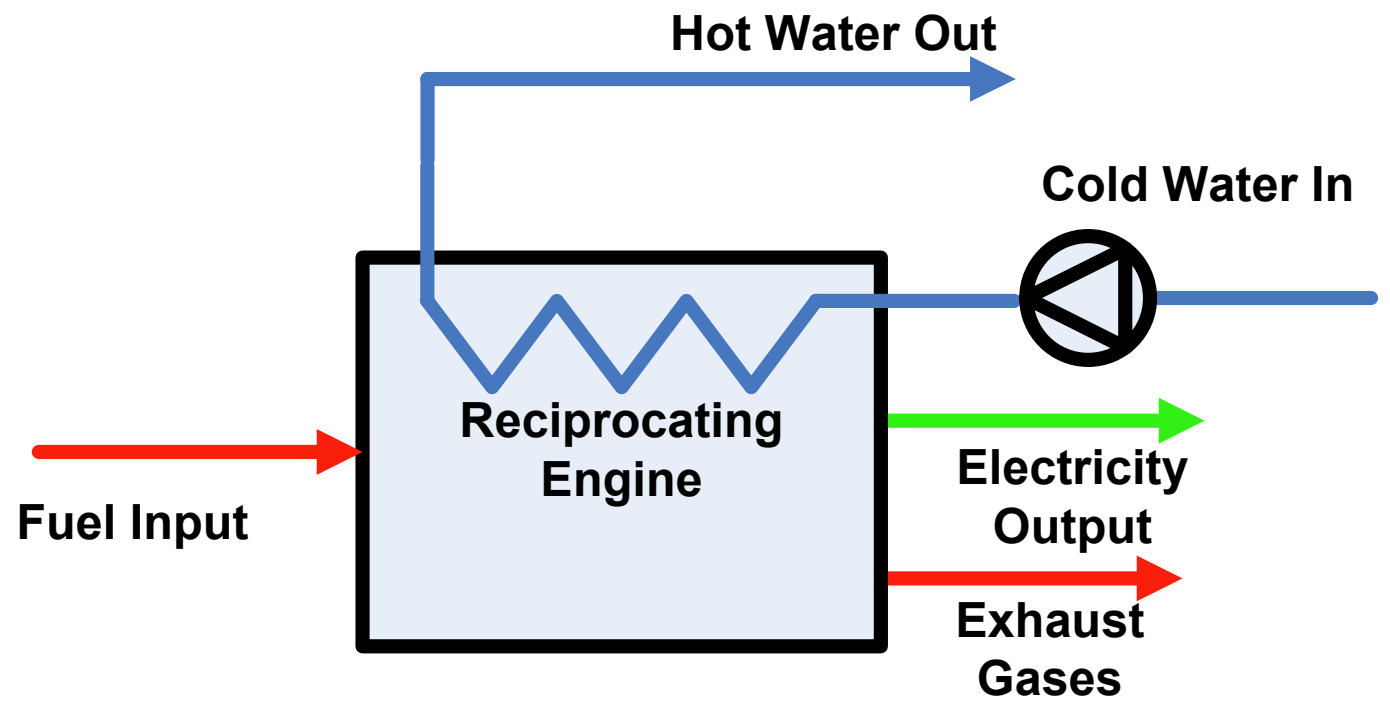

Figure 4 - CHP system using a reciprocating engine for electricity generation with heat recovery from the engine jacket's cooling water.

the engine exhaust gases, heat is also recovered from the engine by circulating cooling water through the engine jacket. The resulting preheated water is then passed through the heat recovery unit, where it is brought to the temperature required by applications. The output of the heat recovery process may be hot water or steam with auxiliary fuel-fired heating as necessary to meet thermal loads. 


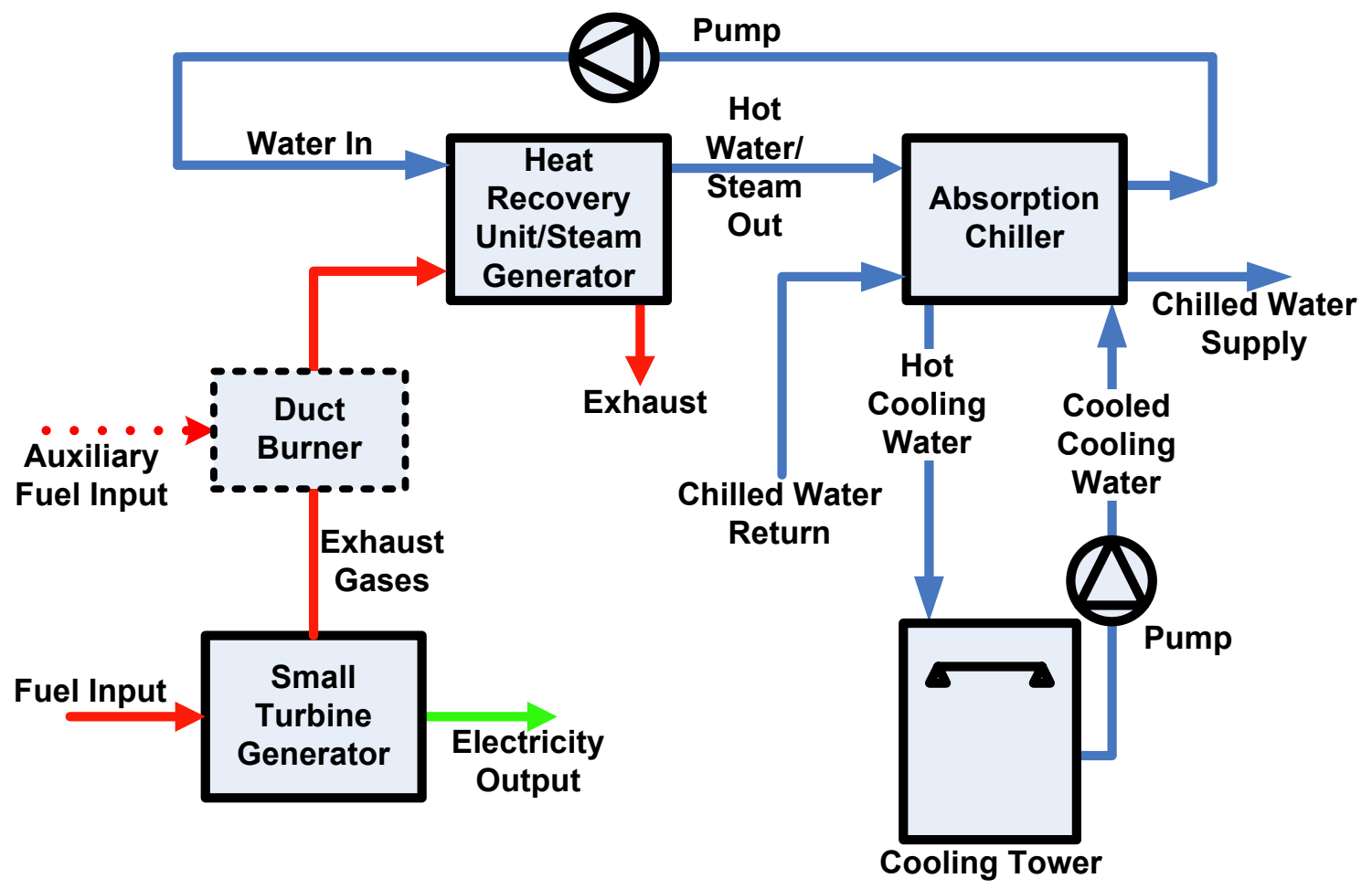

Figure 5 - CHP system using a small turbine generator with exhaust-gas heat recovery and an absorption chiller with a cooling tower.

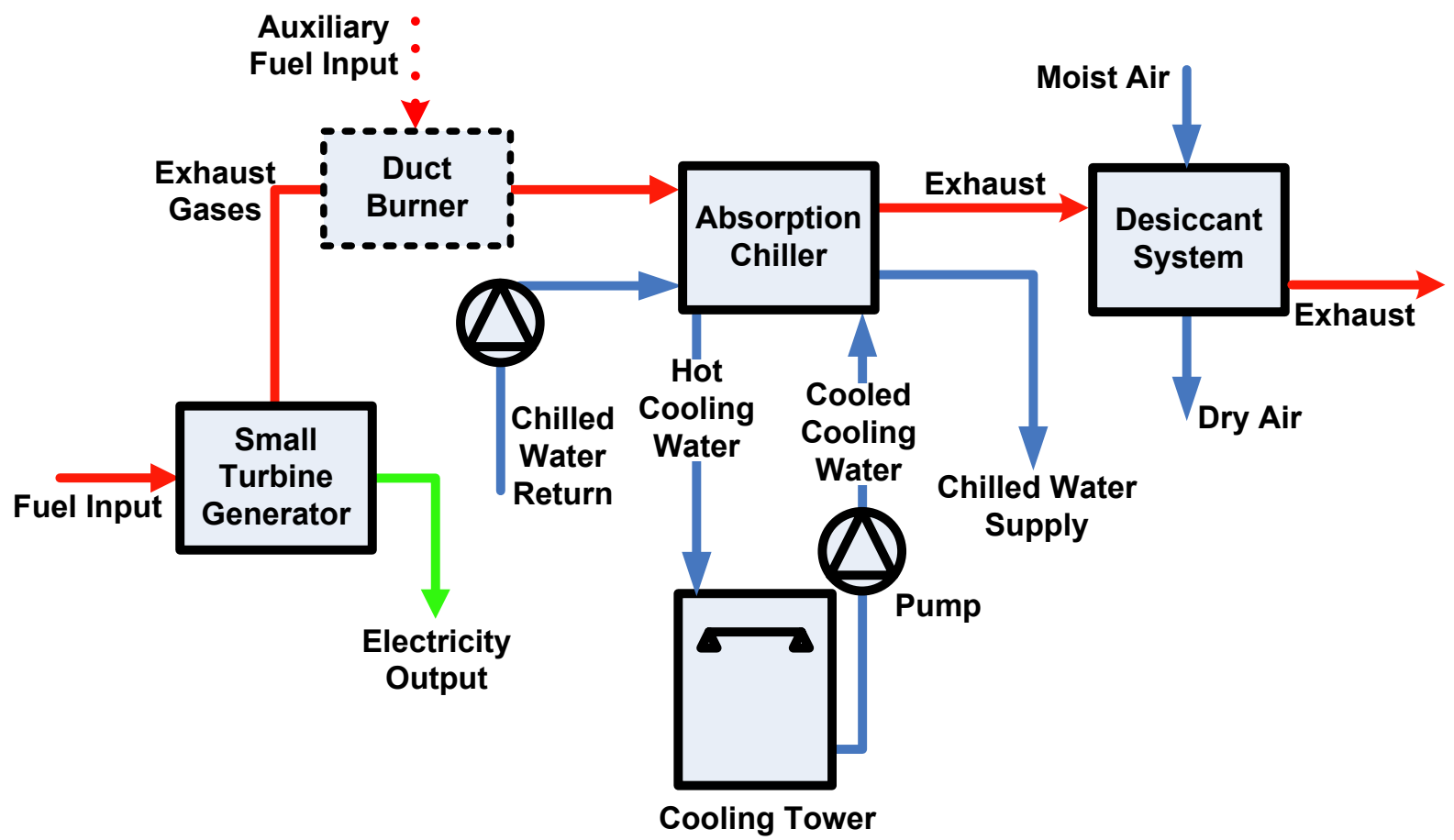

Figure 6 - CHP system using a small turbine generator with an absorption chiller direct-fired with hot turbine exhaust gases and a desiccant system. 


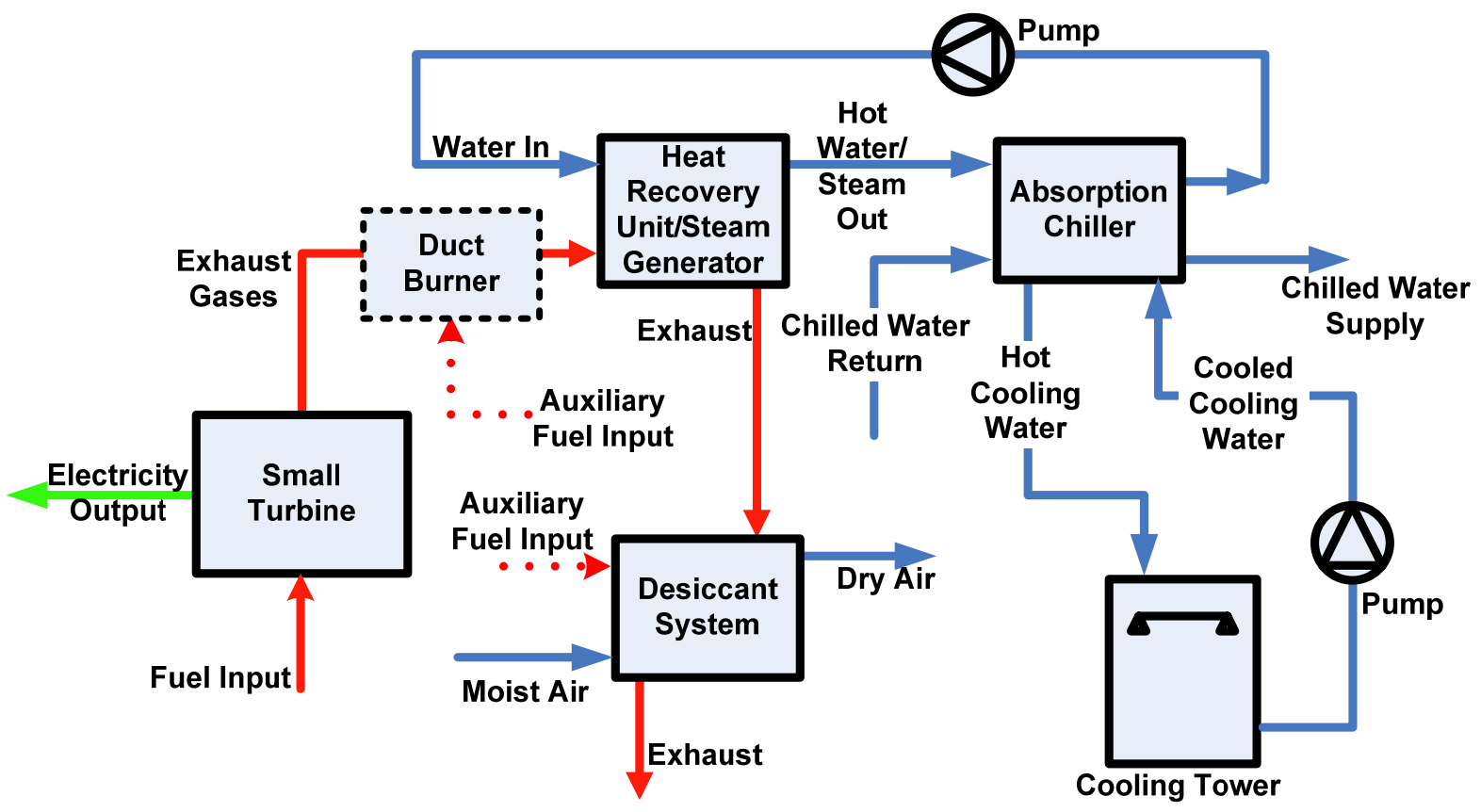

Figure 7 - CHP system using a small turbine generator with heat recovery heat exchanger, hot-water or steam-fired absorption chiller with a cooling tower and direct-fired desiccant system.

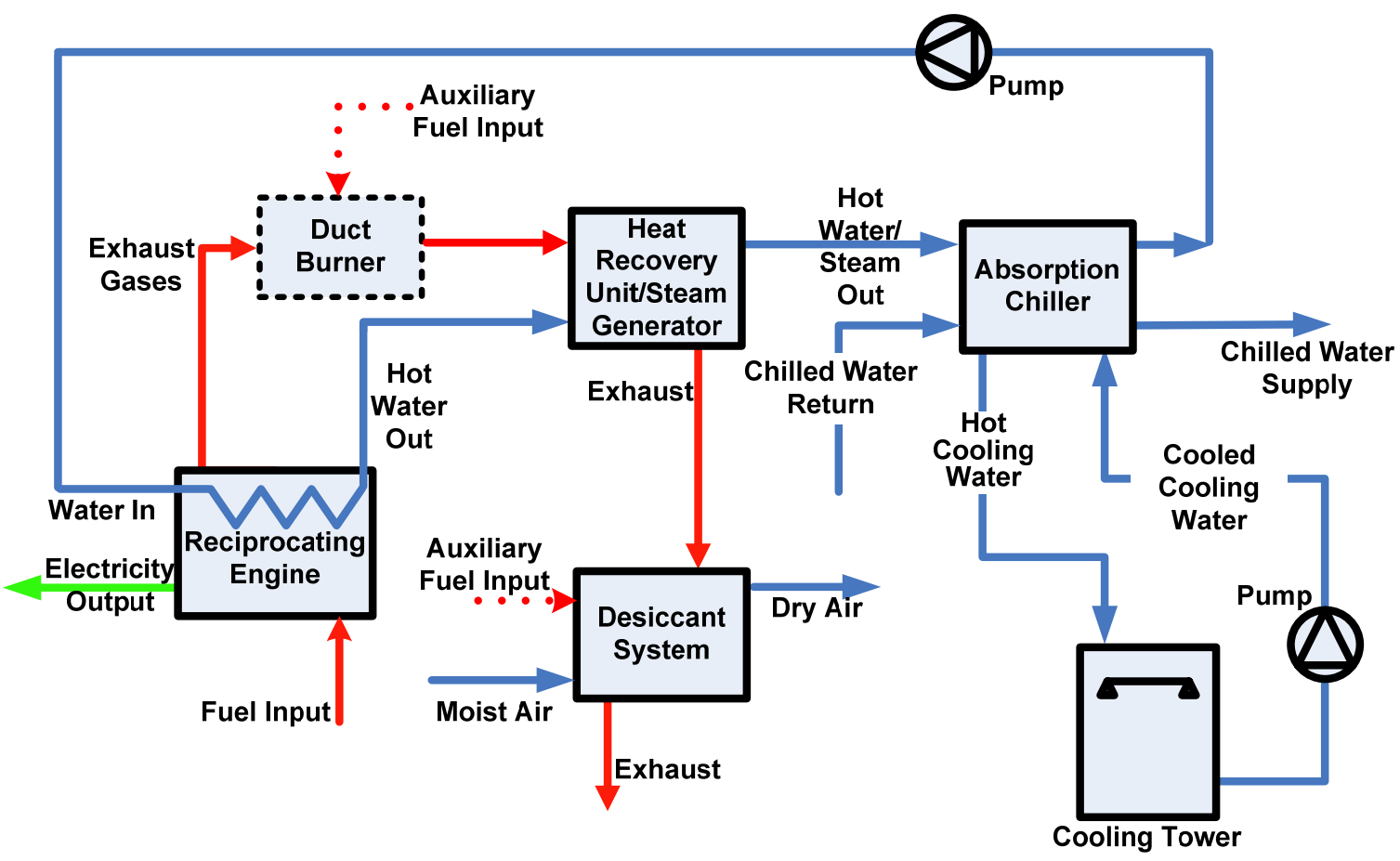

Figure 8 - CHP system that uses a reciprocating-engine generator with both jacket and exhaust-gas heat recovery, a hot-water or steam-fired absorption chiller with a cooling tower, and direct-fired desiccant system for air drying. 
Figure 4 shows a simple CHP system with heat recovery from the hot reciprocating engine cooling water only. Hot exhaust gases are dumped to the ambient environment with no heat recovery. The reciprocating engine serves as the prime mover for the electric generator. Useful energy flows from the system are the electricity generated and hot water at a temperature of $160^{\circ} \mathrm{F}$ to $180^{\circ} \mathrm{F}$.

The CHP configuration shown in Figure 5 uses a small turbine with exhaust-gas heat recovery and a hot-water or steam-fired absorption chiller ${ }^{5}$ and a cooling tower. In most cases, the absorption system is limited to single-effect lithium bromide and water. Additional fuel can be used in the heat recovery system to meet additional thermal demand. The output of the heat recovery may be hot water or steam. This configuration is most suited for commercial and institutional buildings and is commonly used in such buildings.

Figure 6 shows a CHP system with a small turbine used for electricity generation. Hot turbine exhaust gases are used to direct-fire ${ }^{6}$ an absorption chiller, which produces chilled water. Supplemental direct heat is provided to the chiller with auxiliary fuel (e.g., natural gas) when heat from turbine exhaust gases is insufficient to meet chiller demands. Exhaust gases exiting the absorption chiller are used to regenerate desiccant used to dry air. This configuration is commonly used in commercial buildings applications. Because hot exhaust gases are used directly in the absorption chiller, double- and triple-effect absorption systems (e.g., lithiumbromide/water) can be used.

Figure 7 shows a configuration with a small turbine, heat-recovery heat exchanger, hot-waterfired/steam-fired absorption chiller with cooling tower and a desiccant system that is direct-fired. The heat recovery unit can be designed to produce either hot water or steam. To increase the cooling or dehumidification capacity, auxiliary fuel can be used to supplement waste heat recovered from the prime mover to produce more hot water. This configuration is most suited for commercial buildings with significant latent loads - buildings such as restaurants, assembly facilities, and schools. A common variation on the configuration in Figure 7 splits the exhaust gas into two parallel flows before the heat recovery unit, with one flow going to the heat recovery unit (HRU) and the other directly to the desiccant system.

The system configuration shown in Figure 8 is very similar to the one shown in Figure 7 except for the use of a reciprocating engine as the prime mover for electricity generation. Moreover, heat from the engine jacket is used to preheat water before it enters the heat recovery unit, where it is further heated to produce hot water or steam for use by the absorption chiller. Heat remaining in the exhaust gases after leaving the heat recovery unit regenerates desiccant used for drying air. This configuration is most suited for commercial buildings with significant latent loads. As with the system in Figure 7, a variation of it splits the exhaust gas into two parallel flows before the heat recovery unit, with one flow going to the HRU and the other going directly to the desiccant system.

\footnotetext{
${ }^{5}$ Absorption systems could be used as heat pumps or chiller/heaters for both heating and cooling, but only absorption chillers are considered in this study.

${ }^{6}$ Direct-fired refers to the waste heat in exhaust gases being directly used to regenerate working fluid from solution in the absorption chiller.
} 


\section{Definitions and Approach}

In this section, we explain the purpose of and general approach to performance monitoring and commissioning verification to establish the context for the specifications provided in the sections that follow.

\section{Performance Monitoring}

The performance of CHP systems can be categorized according to the outcome of primary interest. CHP systems have the objective of providing both electric power and useful heat at the lowest cost possible, while meeting other requirements such as constraints on environmental emissions. Once the physical system is designed and built, operating costs can be controlled by maintaining efficient operation. This involves both operating the system well (ideally optimally) and maintaining the system so that it can perform efficiently. Efficiency should be maximized to minimize fuel use (and fuel cost) subject to external constraints on meeting (but not exceeding) loads and prices, which determine the value of the electricity and the heat produced. Of course, this must be balanced against the cost of each additional maintenance activity.

The algorithms to be developed in FY2006 focus on providing information to CHP system operators so they can initially ensure that the performance of their CHP systems and their individual components meet performance expectations established by the designer or manufacturer(s) (through commissioning verification) and then monitor performance to quickly spot degradations in efficiency sufficient to warrant changes in operation or maintenance action. Performance monitoring will then serve as the basis for corrections to operation and initiation of maintenance (or condition-based operation and maintenance). A later phase of the project (in FY2007 and possibly beyond) will provide supervisory control, which will enable system operators to balance the costs of various control strategies and maintenance actions to minimize the total cost of operating and owning the CHP facility, as described in the preceding paragraph.

To enable operators to track CHP system performance and detect problems with it, we propose to develop algorithms for monitoring the performance of the overall efficiency of the CHP system and the efficiency of each of the individual components. The overall efficiency is an indicator of how well the system is converting fuel into electricity and useful heat. Significant degradations in system efficiency would indicate both a loss in the capacity to generate these useful forms of energy and an increase in fuel use per unit of useful output energy. The latter would lead to increased fuel costs.

Emissions of gaseous pollutants to the atmosphere are controlled by regulation. Exceeding emissions limits can result in fines and the need to shut down the system (decrease emissions to zero by not operating) for a time period necessary to bring the system back into compliance with regulations. While not operating, the capital invested in the CHP system sits idle, providing no return on that investment. This gravely affects the economics of a CHP system. To help operators ensure compliance with emission regulations, algorithms should be developed for tracking environmentally important CHP system emissions as an aid to identify when emission rates increase above normal operation, possibly requiring operation changes or maintenance action, but this is beyond the scope of this project. 
We propose to use the fuel utilization efficiency $\left(\eta_{F}\right)$, defined as (Katipamula and Brambley 2006)

$$
\eta_{F}=\frac{\left(W_{\text {Elec }}+\sum_{j} Q_{t h, j}\right)}{Q_{\text {Fuel }}} .
$$

as the metric for overall CHP system performance. Here, $W_{\text {Elec }}$ is the net electrical power output, $Q_{t h, j}$ represents the net rate of useful thermal energy output from thermal recovery process $j$ with the sum being over all thermal recovery processes in the system, and $Q_{F u e l}$ is the total rate of input of fuel energy to the CHP system. This is the most commonly used indicator of CHP system efficiency, although as we noted in the previous report (Katipamula and Brambley), it fails to account for the quality (exergy) of the different energy streams. Equation (1) is specialized to a specific generic CHP system configuration later in this report. To account for the quality of the various energy streams, we will also use the value-weighted energy utilization factor $\left(\mathrm{EUF}_{\mathrm{VW}}\right)$, which is discussed in more detail later in this report and in Katipamula and Brambley (2006).

The generic components of the CHP systems selected for development in this project are: turbines or reciprocating engines as prime movers, heat recovery units (which are heat exchangers), absorption chillers (which covert waste heat from the prime mover to useful chilled water for cooling), supplemental vapor compression chillers to help meet cooling loads during times when the vapor compression chiller cannot or does not meet the entire load, ${ }^{7}$ cooling towers, desiccant systems for dehumidifying air, and pumps for moving liquid and fans for moving air. Equations for the efficiency of these components (except pumps and fans) are provided in Katipamula and Brambley (2006) and summarized in Table 1. These equations will be specialized and expanded for each of the selected CHP configurations later in this report.

\section{Commissioning Verification}

Commissioning verification $(\mathrm{CxV})$ is a process by which the actual performance of the individual components in a CHP system and the performance of the CHP system as a whole are verified to comply with the designers' and manufacturers' recommended performance. Furthermore, for new systems, commissioning should include a systematic series of activities, starting in the planning phase and continuing through design, installation, and start-up, aimed at ensuring correct operation of the CHP system. Before start-up, the process should include inspection and testing of all components in the CHP system to ensure proper components are installed, they are installed correctly, and they perform properly.

\footnotetext{
${ }^{7}$ Vapor compression chillers used for this purpose often are not considered part of the CHP system, but because use of absorption chilling must be optimized as part of a larger system that includes vapor compression chilling, they must be included in decisions made by the supervisory controller regarding how much absorption chilling and how much vapor compression chilling to use to meet the total cooling load.
} 
Table 1. Summary of expressions for CHP component efficiencies.

\begin{tabular}{|c|c|c|c|}
\hline Component & Purpose & $\begin{array}{c}\text { Efficiencyl } \\
\text { Effectiveness } \\
\text { Relation }\end{array}$ & Variables \\
\hline $\begin{array}{l}\text { Small turbine } \\
\text { generators }\end{array}$ & $\begin{array}{l}\text { Prime mover to } \\
\text { generate } \\
\text { electricity }\end{array}$ & $\eta_{E E}=\frac{W_{\text {Elec }}}{Q_{\text {Fuel, engine }}}$ & $\begin{aligned} \eta_{E E}= & \text { electric generation } \\
& \text { efficiency } \\
W_{E l e c}= & \text { net electrical power } \\
& \text { output } \\
Q_{\text {Fuel.engine }}= & \text { total rate of input of } \\
& \text { fuel energy to the } \\
& \text { prime mover }\end{aligned}$ \\
\hline $\begin{array}{l}\text { Reciprocating } \\
\text { Engines }\end{array}$ & $\begin{array}{l}\text { Prime mover to } \\
\text { generate } \\
\text { electricity }\end{array}$ & $\eta_{E E}=\frac{W_{\text {Elec }}}{Q_{\text {Fuel, engine }}}$ & $\begin{aligned} \eta_{E E}= & \text { electric generation } \\
& \text { efficiency } \\
W_{E l e c}= & \text { net electrical power } \\
& \text { output } \\
Q_{\text {Fuel.engine }}= & \text { total rate of input of } \\
& \text { fuel energy to the } \\
& \text { prime mover }\end{aligned}$ \\
\hline $\begin{array}{l}\text { Heat Recovery } \\
\text { Units (HRU) }\end{array}$ & $\begin{array}{l}\text { Heat exchange } \\
\text { from hot exhaust } \\
\text { gases from the } \\
\text { prime mover to } \\
\text { the heat recovery } \\
\text { fluid }\end{array}$ & $\varepsilon_{H R U}=\frac{Q_{H R U, \text { actual }}}{Q_{H R U, \max }}$ & $\begin{aligned} \varepsilon_{H R U}= & \text { heat recover unit } \\
& \text { effectiveness } \\
Q_{H R U, \text { actual }}= & \text { rate of heat gain by } \\
& \text { the heat recovery } \\
& \text { fluid } \\
Q_{H R U, m a x}= & \text { maximum possible } \\
& \text { rate of heat loss } \\
& \text { from the waste } \\
& \text { heat stream from } \\
& \text { the prime mover in } \\
& \text { the HRU }\end{aligned}$ \\
\hline $\begin{array}{l}\text { Absorption } \\
\text { Chillers }\end{array}$ & $\begin{array}{l}\text { Generate chilled } \\
\text { water using heat } \\
\text { to drive } \\
\text { refrigerant from } \\
\text { solution in an } \\
\text { absorption } \\
\text { refrigeration } \\
\text { cycle }\end{array}$ & $C O P_{\text {AbChiller }}=\frac{Q_{\text {evap }}}{Q_{\text {gen }}}$ & 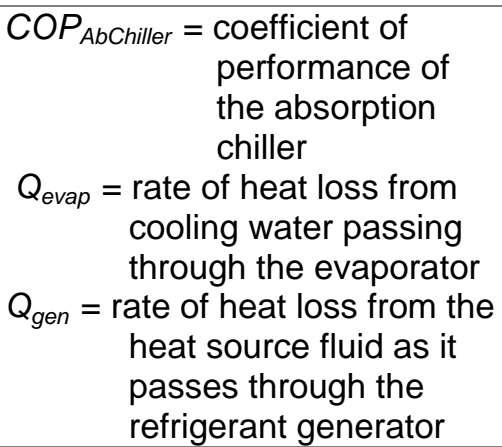 \\
\hline $\begin{array}{l}\text { Vapor- } \\
\text { Compression } \\
\text { Chillers }\end{array}$ & $\begin{array}{l}\text { Generate chilled } \\
\text { water using } \\
\text { electric power to } \\
\text { drive } \\
\text { compressors in a } \\
\text { vapor- } \\
\text { compression } \\
\text { refrigeration } \\
\text { cycle } \\
\end{array}$ & $C O P_{\text {Chiller }}=\frac{Q_{\text {evap }}}{W_{\text {ChillerElec }}}$ & $\begin{aligned} C O P_{\text {Chiller }}= & \text { coefficient of } \\
& \text { performance of the } \\
& \text { chiller } \\
Q_{\text {evap }}= & \text { rate of heat loss } \\
& \text { from chilled water } \\
& \text { passing through the } \\
& \text { evaporator } \\
W_{\text {ChillerElec }}= & \text { electric power input } \\
& \text { to the chiller }\end{aligned}$ \\
\hline
\end{tabular}




\begin{tabular}{|c|c|c|c|}
\hline $\begin{array}{l}\text { Cooling } \\
\text { Towers }\end{array}$ & $\begin{array}{l}\text { Cool chiller } \\
\text { condenser water } \\
\text { via evaporation } \\
\text { and sensible heat } \\
\text { transfer to } \\
\text { ambient air }\end{array}$ & $\begin{array}{c}\eta_{C T}=\frac{\left(T_{C T, w, i}-T_{C T, w, o}\right)}{\left(T_{C T, w, i}-T_{w b}\right)} \\
\eta_{C T, \text { Elec }}=\frac{Q_{C T, t h}}{W_{C T, \text { elec }}}\end{array}$ & $\begin{aligned} \eta_{C T}= & \text { cooling tower } \\
& \text { efficiency } \\
& \text { (effectiveness) } \\
\eta_{C T, \text { Elec }}= & \text { cooling tower electric } \\
& \text { utilization efficiency } \\
T_{C T, w, i}= & \text { inlet temperature of } \\
& \text { condenser water to } \\
& \text { the tower } \\
T_{C T, w, o}= & \text { outlet temperature of } \\
& \text { condenser water from } \\
& \text { the tower } \\
T_{w b}= & \text { wet bulb temperature } \\
& \text { of the ambient air } \\
Q_{C T, t h}= & \text { rate of heat loss by } \\
& \text { the cooling water as it } \\
& \text { passes through the } \\
& \text { cooling tower } \\
W_{C T, \text { elec }}= & \text { electric power use by } \\
& \text { the cooling tower fans } \\
& \text { and pumps }\end{aligned}$ \\
\hline $\begin{array}{l}\text { Desiccant } \\
\text { Systems }\end{array}$ & $\begin{array}{l}\text { Remove moisture } \\
\text { from air with the } \\
\text { desiccant } \\
\text { regenerated } \\
\text { using waste heat }\end{array}$ & $\eta_{D}=\frac{Q_{d}}{Q_{d, \text { input }}}$ & $\begin{aligned} \eta_{D}= & \text { desiccant system } \\
& \text { efficiency } \\
Q_{d}= & \text { rate of moisture } \\
& \text { removal from the air } \\
& \text { stream } \\
& \text { (dehumidification load) } \\
Q_{\text {d.input }}= & \text { rate of heat input for } \\
& \text { desiccant generation }\end{aligned}$ \\
\hline Pumps & $\begin{array}{l}\text { Create a } \\
\text { pressure } \\
\text { difference in } \\
\text { liquid to instigate } \\
\text { flow using an } \\
\text { electric motor as } \\
\text { a source of } \\
\text { mechanical } \\
\text { rotational energy }\end{array}$ & $\eta_{\text {Pump }}=\frac{W_{\text {Pump }}}{W_{\text {Pump }, \text { elec }}}$ & $\begin{aligned} \eta_{\text {Pump }}= & \text { pump efficiency } \\
W_{\text {Pump }}= & \text { mechanical power } \\
& \text { output from the } \\
& \text { pump to the liquid } \\
W_{\text {Pump,elec }}= & \text { electric power input } \\
& \text { to the pump motor }\end{aligned}$ \\
\hline Fans & $\begin{array}{l}\text { Create a } \\
\text { pressure } \\
\text { difference in air } \\
\text { to support flow, } \\
\text { using an electric } \\
\text { motor as the } \\
\text { source of } \\
\text { mechanical } \\
\text { rotational energy }\end{array}$ & $\eta_{\text {Fan }}=\frac{W_{\text {Fan }}}{W_{\text {Fan }, \text { elec }}}$ & $\begin{aligned} \eta_{\text {Fan }}= & \text { overall efficiency of } \\
& \text { the fan } \\
W_{\text {Fan }}= & \text { useful power output } \\
& \text { from the fan } \\
W_{\text {Fan,elec }}= & \text { electric power input } \\
& \text { to the fan motor }\end{aligned}$ \\
\hline
\end{tabular}

A goal of this project is to automate parts of the process for verifying that commissioning has been done correctly and resulted in a CHP system that meets design and operation expectations. Although $\mathrm{CxV}$ can include active testing of components and sub-systems, in this project the intent is to focus on verifying performance to ensure that the system has been adequately 
commissioned and to provide indicators of commissioning still needed when deficiencies are found.

This process will rely on the monitoring algorithms described in the preceding subsection on performance monitoring for inputs to $\mathrm{CxV}$. The $\mathrm{CxV}$ algorithms will provide the logic by which measurements on performance are interpreted relative to performance expectations to identify deficiencies in performance during initial operation of the CHP system and the major individual components. By verifying the performance of the individual components, deficiencies in overall system performance can be isolated so that follow up efforts can be targeted at the offending components. Some deficiencies may span multiple components of the system. In these cases, controls or other integration issues will be identified as needing rechecking and further commissioning. The outputs of the $\mathrm{CxV}$ algorithms will be alarms, quantitative indicators of deficiencies, and supporting information to help guide corrective actions.

Detailed specifications are provided in the Commissioning Verification section later in this report. 


\section{Component Monitoring}

This section specifies the equations as well as an input/output diagram for the algorithm module for performance monitoring of each component of the generic CHP systems identified in Figure 2 through Figure 8. These components can be combined in the various ways shown in these figures to create CHP systems and, therefore, these algorithms can be used to monitor the components in any of these systems.

\section{Prime Movers}

The prime mover converts chemical energy in the fuel to rotational mechanical energy, which then turns an electric generator (see Figure 9). Small turbines and reciprocating engines represent the most commonly used prime movers for CHP systems, especially those with electrical outputs of less than $1 \mathrm{MW}$. Both of these prime movers release waste heat in exhaust gases and through their jackets. Jacket losses are not sufficiently large for most small turbines to warrant heat recovery, but for reciprocating engines, water at approximately $180^{\circ} \mathrm{F}$ can be recovered by circulation of cooling water through the engine jacket (Figure 3, Figure 4 and Figure 8). For purposes of analysis, the prime mover and electric generator will be considered as a single component. So the useful energy output is the electric power $\left(W_{E l e c}\right)$, the rate of energy input is the energy content (based on lower heating value, LHV) of fuel flowing into the prime mover $\left(Q_{\text {Fuel,engine }}\right)$, and the unused power released from this component is the sum of the heat losses in the exhaust gases and through the jacket.

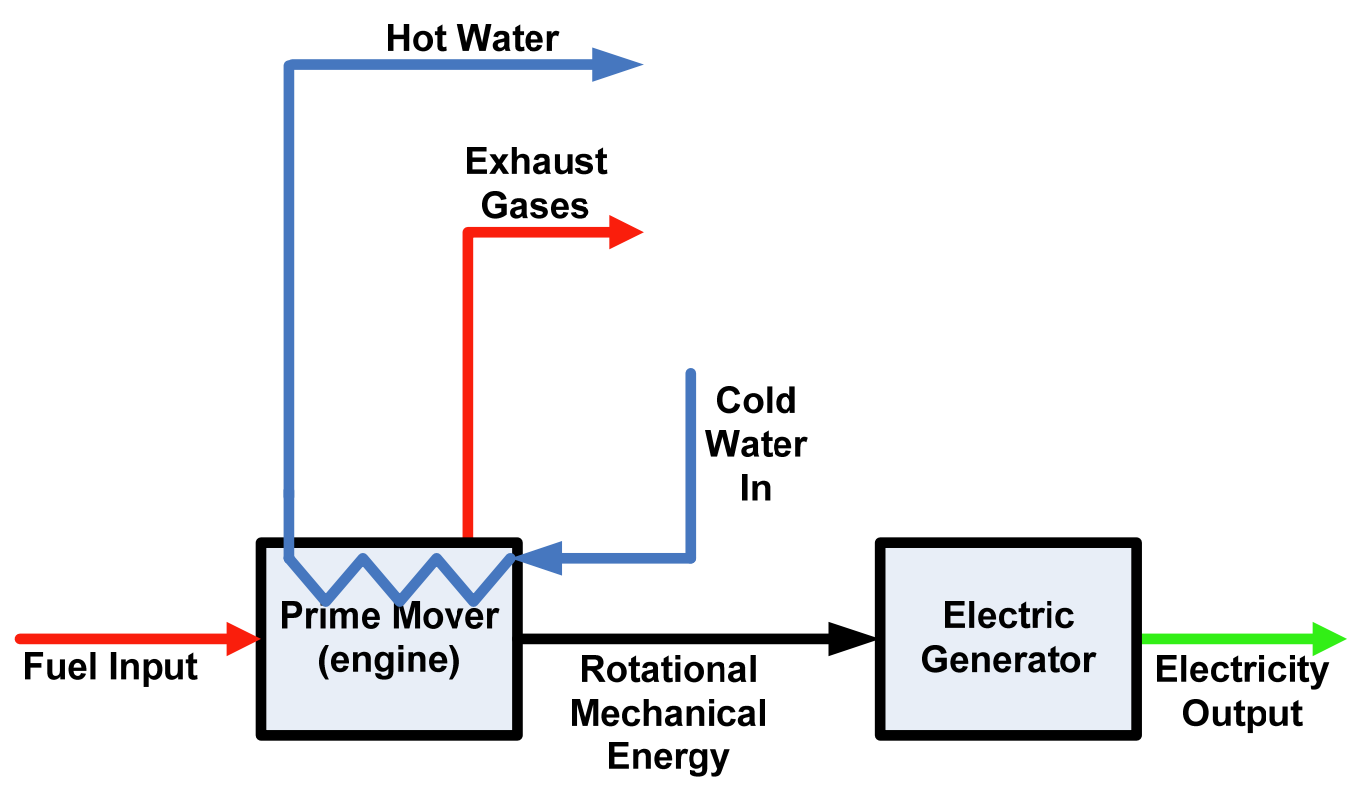

Figure 9 - Schematic diagram of prime mover and electric generator.

\section{Efficiency of Prime Movers}

The electrical generation efficiency $\left(\eta_{E E}\right)$ for the prime mover/electric generator combination is 


$$
\eta_{E E}=\frac{W_{\text {Elec }}}{Q_{\text {Fuel, engine }}} .
$$

This is also the electric generation efficiency of entire CHP systems for which there is no additional electricity production (e.g., by a steam turbine) using heat recovered from the exhaust gases of the prime mover and no additional fuel input to other components for supplemental heating. The rate of energy input to the engine can be expressed as

$$
\begin{aligned}
Q_{\text {Fuel, engine }} & =\dot{m}_{\text {Fuel }} L H V_{\text {Fuel }} \\
& =\rho_{\text {Fuel }} \dot{F}_{\text {Fuel }} L H V_{\text {Fuel }},
\end{aligned}
$$

where $\dot{m}_{\text {Fuel }}$ is the mass flow rate of fuel into the prime mover, $\dot{v}_{\text {Fuel }}$ is the volumetric flow rate of the fuel, and $L H V_{F u e l}$ and $\rho_{\text {Fuel }}$ are the lower heating value and density of the fuel, respectively, evaluated at the input conditions.

Combining Eq. (2) and Eq. (3), the electric generation efficiency can be expressed in terms of measurable variables as

$$
\eta_{E E}=\frac{W_{E l e c}}{\dot{m}_{\text {Fuel }} L H V_{\text {Fuel }}}
$$

or

$$
\eta_{E E}=\frac{W_{\text {Elec }}}{\rho_{\text {Fuel }} \dot{V}_{\text {Fuel }} L H V_{\text {Fuel }}},
$$

where Eq. (4) can be used when fuel consumption is measured as a mass flow rate, and Eq. (5) can be used when fuel consumption is measured as a volumetric flow rate.

The prime mover efficiency ( $\eta_{\text {engine }}$ ) is given by the relation

$$
\eta_{\text {engine }}=\frac{W_{\text {engine }}}{Q_{\text {Fuel, }, \text { engine }}},
$$

where $W_{\text {engine }}$ is the rotational mechanical power output of the engine (small turbine or reciprocating engine).

There are also losses from the electric generator, which ultimately dissipate as heat losses through the generator casing and can be accounted for with the electric generator efficiency,

$$
\eta_{\text {generator }}=\frac{W_{\text {Elec }}}{W_{\text {engine }}}
$$


where $W_{\text {engine }}$ represents the mechanical shaft power output of the prime mover, which equals the mechanical power input to the electric generator. When a gear box is used between the prime mover and the electric generator, the electric generator efficiency can be expressed as

$$
\eta_{\text {generator }}=\frac{W_{\text {Elec }}}{W_{\text {gearbox }}},
$$

where $W_{\text {gearbox }}$ is the mechanical shaft power output from the gearbox to the generator. In this case, the gearbox efficiency $\left(\eta_{\text {gearbox }}\right)$ is the ratio of the mechanical shaft output of the gearbox to the mechanical shaft output of the prime mover, i.e.,

$$
\eta_{\text {gearbox }}=\frac{W_{\text {gearbox }}}{W_{\text {engine }}}
$$

The electrical generation efficiency can be expressed as the product of these three component efficiencies, i.e.,

$$
\eta_{E E}=\eta_{\text {engine }} \eta_{\text {gearbox }} \eta_{\text {generator }} \text {. }
$$

Eq. (10) shows, together with Eq. (6) through Eq. (7), that more detailed measurements could be used to isolate degradation of electrical generation efficiency to either the engine (prime mover) or the electric generator. If no gearbox is used in the system (e.g., in the case of micro-turbine used as the prime mover), $\eta_{\text {gearbox }}$ is set to 1.0 in Eq. (10).

\section{Prime Mover Input/Output Diagram}

The input/output diagram for monitoring of prime mover-electric generator performance is shown in Figure 10. Arrows at the top of the diagram represent measured inputs, arrows on the left side of the diagram represent fixed inputs, and arrows at the bottom of the diagram represent outputs. The algorithms (represented by the box) are based on Eq. (4) and Eq. (5).

\section{Heat Recovery Unit}

Heat recovery units (HRU) are an essential part of a CHP system because they provide a means to recover heat from the exhaust gas of the prime mover (turbine or reciprocating engine). Although there are several types of HRUs used with CHP systems, we will limit our development effort to those that use indirect heating methods: 1) indirect heating to provide hot water, 2) indirect heating to provide hot dry air, and 3) indirect heating to provide process steam (described in the next section). Some CHP applications use auxiliary firing (also called co-firing or supplemental firing in the literature) to augment heat from the exhaust gases. Therefore, we will develop HRU effectiveness equations assuming that there is auxiliary firing. A schematic of an HRU is shown in Figure 11, where a duct-burner is used for supplementing the heat from the exhaust gases. Although the figure shows cold water entering the HRU and hot water existing it, this configuration can also be used with cold air entering and hot air exiting the HRU.

Furthermore, this configuration can also be used to generate steam from water (which is covered in the next section on heat recovery steam generators). 


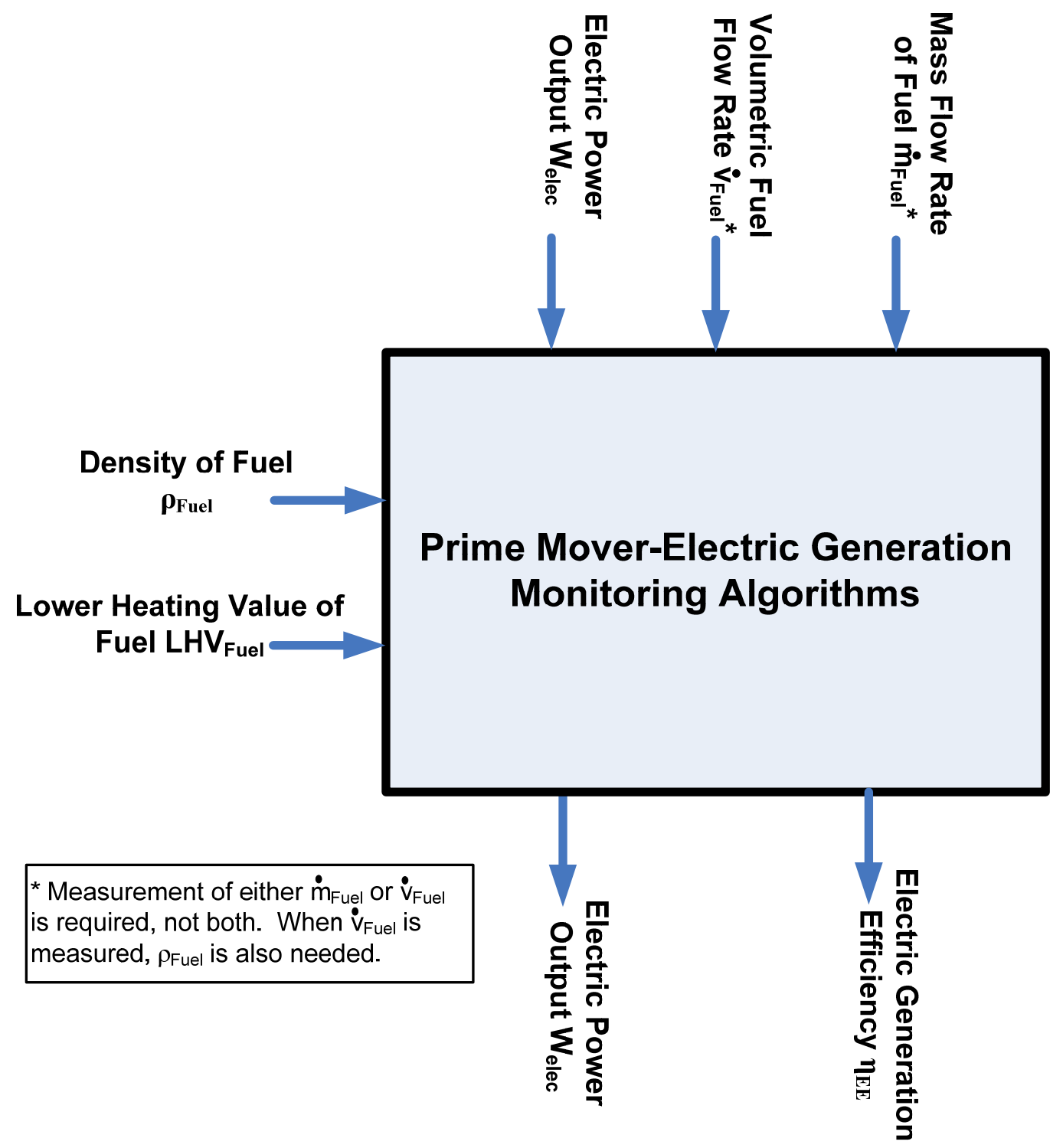

Figure 10 - Input/output diagram for prime mover-electric generator monitoring algorithms.

\section{Effectiveness of Heat Recovery System}

The effectiveness of the HRU is defined as the ratio of the actual heat transfer rate to the maximum possible heat transfer rate, i.e.,

$$
\varepsilon_{H R U}=\frac{Q_{H R U, \text { actual }}}{Q_{H R U, \text { max }}}
$$




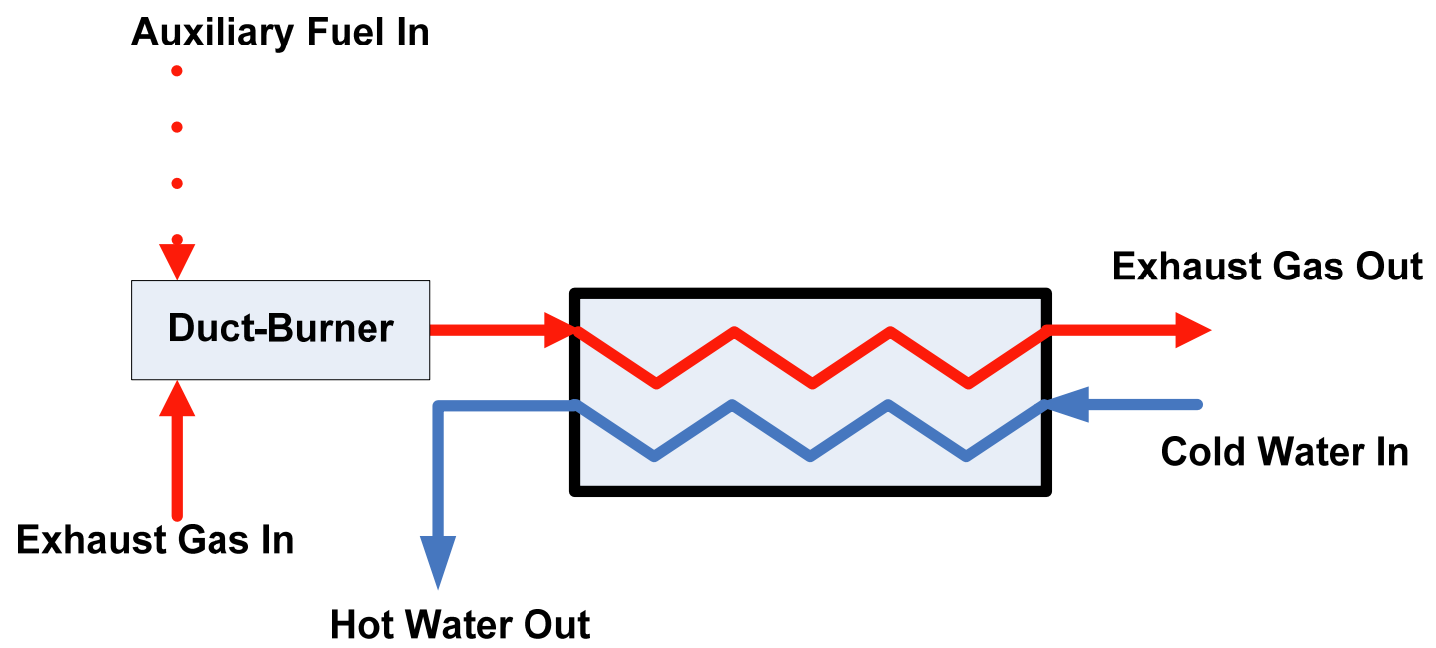

Figure 11 - Schematic of heat recovery unit used to generate hot water. A similar arrangement can be used to generate hot air.

where $Q_{H R U, \text { actual }}$ is the rate of thermal energy gain across the HRU by the heat recovery fluid (e.g., heated water, heated air or water converted to steam) and $Q_{H R U, \max }$ is the maximum possible rate of heat loss by the waste heat stream from the prime mover as it passes through the HRU. If the cold-side material does not change phase in the HRU, $Q_{H R U, \text { actual }}$ can be written as:

$$
Q_{H R U, a c t u a l}=\left(\rho \dot{v} c_{p}\right)_{H R U, w}\left(T_{H R U, w, o}-T_{H R U, w, i}\right) .
$$

Similarly, $Q_{H R U, \max }$ can be written (for the non-phase-change case) as:

$$
Q_{H R U, \max }=\left(\rho \dot{v} c_{p}\right)_{H R U, \min }\left(T_{H R U, e x, i}-T_{H R U, w, i}\right),
$$

where, $\left(\rho \dot{v} c_{p}\right)_{H R U, \min }$ is the minimum of the two quantities

$$
\left(\rho \dot{v} c_{p}\right)_{H R U, e x} \quad \text { (for the exhaust gas flow) }
$$

and

$$
\left(\rho \dot{v} c_{p}\right)_{H R U, w} \quad \text { (for the heat recovery stream). }
$$

Although the temperature of the exhaust gas may change significantly across the HRU, Eq. (13) remains valid even when $\left(\rho \dot{v} c_{p}\right)_{H R U, \text { min }}=\left(\rho \dot{v} c_{p}\right)_{H R U, e x}$ because the mass flow rate of exhaust gas $(\rho \dot{v})_{H R U, e x}$ at the HRU inlet equals its value at the outlet under steady-state conditions.

Furthermore, the heat capacity of the exhaust gas varies by less than $10 \%$ between representative HRU inlet and outlet conditions ${ }^{8}$, further supporting the assumptions implicit in using Eq. (13).

\footnotetext{
${ }^{8}$ See, for example, Kovacik 1982.
} 
To reduce errors associated with using a constant value for the heat capacity, $\mathrm{c}_{p, e x}$ can be evaluated at the average of the HRU inlet and outlet temperatures.

Using Eq. (12) and Eq. (13), Eq. (11) can be re-written as:

$$
\varepsilon_{H R U}=\frac{\left(\rho \dot{v} c_{p}\right)_{H R U, w}\left(T_{H R U, w, o}-T_{H R U, w, i}\right)}{\left(\rho \dot{v} c_{p}\right)_{H R U, \text { min }}\left(T_{H R U, e x, i}-T_{H R U, w, i}\right)} .
$$

Similarly, if hot air is generated instead of hot water, Eq. (14) can be re-written as follows:

$$
\varepsilon_{H R U}=\frac{\left(\rho \dot{v} c_{p}\right)_{H R U, a}\left(T_{H R U, a, o}-T_{H R U, a, i}\right)}{\left(\rho \dot{v} c_{p}\right)_{H R U, \min }\left(T_{H R U, e x, i}-T_{H R U, a, i}\right)} .
$$

One of the flow rates appearing in Eq. (14) can be eliminated using a heat balance on the HRU, i.e., the heat loss by the exhaust gas as it passes through the HRU ( $\mathrm{Q}_{\mathrm{HRU}}$, ex $)$ is equal to the sum of the heat gain by the water as it passes through the HRU ( $\left.\mathrm{Q}_{\mathrm{HRU}, \mathrm{w}}\right)$ and heat losses through the walls of the HRU ( $\left.\mathrm{L}_{\mathrm{HRU}}\right)$ :

$$
Q_{H R U, e x}=Q_{H R U, w}+L_{H R U}
$$

Here,

$$
Q_{H R U, e x}=\left(\rho \dot{v} c_{p}\right)_{H R U, e x}\left(T_{H R U, e x, i}-T_{H R U, e x, o}\right)
$$

and

$$
Q_{H R U, w}=\left(\rho \dot{v} c_{p}\right)_{H R U, w}\left(T_{H R U, w, o}-T_{H R U, w, i}\right) .
$$

The rate of heat loss through the walls will generally be very small compared to both $Q_{H R U \text {, ex }}$ and $Q_{H R U, w}$ (approximately $1.5 \%$ of $Q_{H R U, \text { ex }}$ for an HRSG according to Kovacik (1982), p. 213). Therefore, $L_{H R U}$ can be neglected without introducing significant errors, and $\dot{v}_{H R U, e x}$ can be obtained as a function of $\dot{v}_{H R U, w}$ from Eq. (16) as

$$
\dot{v}_{H R U, e x}=\frac{\left(\rho c_{p}\right)_{H R U, w}\left(T_{H R U, w, o}-T_{H R U, w, i}\right)}{\left(\rho c_{p}\right)_{H R U, e x}\left(T_{H R U, e x, i}-T_{H R U, e x, o}\right)} v_{H R U, w} .
$$

Substituting this expression for $\dot{v}_{H R U, e x}$ into Eq. (14), we obtain

$$
\varepsilon_{H R U}=\frac{\left(T_{H R U, e x, i}-T_{H R U, e x, o}\right)}{\left(T_{H R U, e x, i}-T_{H R U, w, i}\right)},
$$


for an HRU that uses exhaust gases from a prime mover to produce hot water, when $\left(\rho \dot{v} c_{p}\right)_{H R U, \min }=\left(\rho \dot{v} c_{p},\right)_{H R U, e x}$, which will ordinarily be true.

Following similar logic for an HRU that uses exhaust from a prime mover to heat air, from Eq. $(15)$,

$$
\varepsilon_{H R U}=\frac{\left(T_{H R U, e x, i}-T_{H R U, e x, o}\right)}{\left(T_{H R U, e x, i}-T_{H R U, a, i}\right)},
$$

when $\left(\rho \dot{v} c_{p}\right)_{H R U, \min }=\left(\rho \dot{v} c_{p}\right)_{H R U, e x}$.

Also from Eq. (15),

$$
\varepsilon_{H R U}=\frac{\left(T_{H R U, a, o}-T_{H R U, a, i}\right)}{\left(T_{H R U, e x, i}-T_{H R U, a, i}\right)},
$$

when $\left(\rho \dot{v} c_{p}\right)_{H R U, \min }=\left(\rho \dot{v} c_{p}\right)_{H R U, a}$.

Determination of which fluid provides $\left(\rho \dot{v} c_{p}\right)_{H R U, \min }$ and, therefore, whether to use Eq. (26) or Eq. (27), for an HRU heating air, can be accomplished using the following relations obtained by rearranging Eq. (19):

$$
\left(\rho \dot{v} c_{p}\right)_{H R U, \min }=\left(\rho \dot{v} c_{p}\right)_{H R U, e x} \text { for }\left(T_{H R U, e x, i}-T_{H R U, e x, o}\right)>\left(T_{H R U, a, o}-T_{H R U, a, i}\right)
$$

and

$$
\left(\rho \dot{v} c_{p}\right)_{H R U, \min }=\left(\rho v c_{p}\right)_{H R U, a} \text { for }\left(T_{H R U, a, o}-T_{H R U, a, i}\right)>\left(T_{H R U, e x, i}-T_{H R U, e x, o}\right) .
$$

By using Eq. (25) through Eq. (24), the effectiveness of an HRU using exhaust gases to produce hot air or hot water can be determined from temperature measurements alone, without the need for any flow rate measurement. Of course, to determine the useful heat output of the HRU, one flow rate must be measured.

\section{Heat Recovery Unit Input/Output Diagram}

The input and output diagram for the HRU is shown in Figure 12 for water as the heat recovery fluid. To estimate the HRU effectiveness (one of the outputs shown), three temperature measurements are needed [see Eq. (20)]. Furthermore, to determine the rate of useful heat output $\left(Q_{H R U, a c t u a l}\right)$ from the HRU the flow rate of the water and one additional temperature $\left(T_{H R U, w, o}\right)$ must be measured [see Eq. (12)]. The measurement of auxiliary input flow is optional and is not needed to estimate the effectiveness or the rate of useful heat output. In addition to the five measured inputs, the specific heat and the density of water are also needed. 


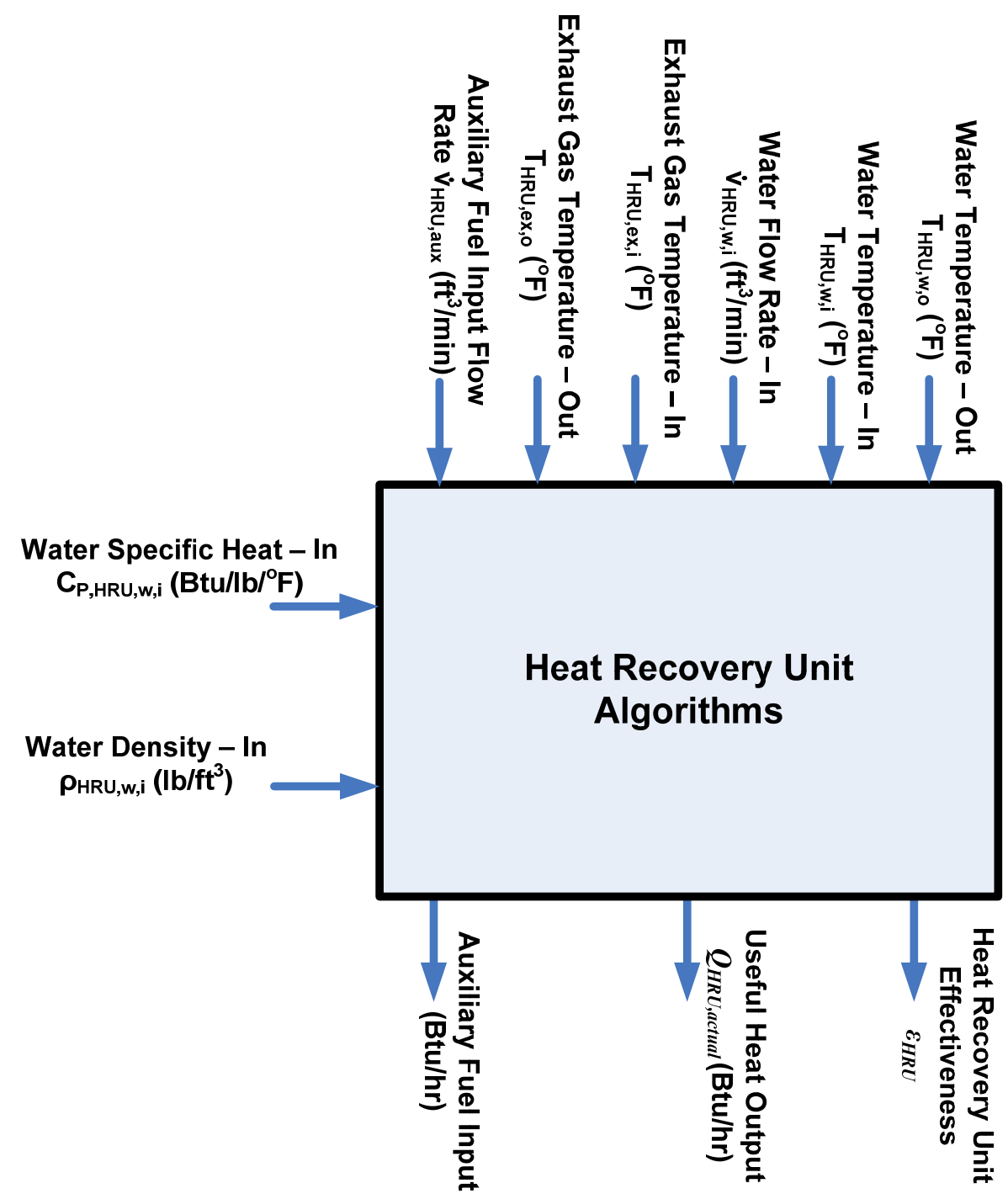

Figure 12 - Input/output diagram for a heat recovery unit (HRU) with water as a cold-side fluid.

The input/output diagram for monitoring of an HRU producing hot air from exhaust gases is shown in Figure 13. Four temperature measurements are required to determine which fluid establishes $\left(\rho \dot{v} c_{p}\right)_{H R U, \min }$ using Eq. (23) and Eq. (24), and then three of those measurements are used to calculate the HRU effectiveness from Eq. (21) or Eq. (22). No flow rate measurements are required to determine the HRU effectiveness; however, as with the HRU that produces hot water, determination of the rate of useful heat output requires measurement of one flow rate, preferably the flow rate of air, and values for the specific heat and density of the air (only the specific heat if the mass flow rate is measured directly). The accuracy of results can be increased by evaluating the specific heat of gases at the average of inlet and outlet conditions. 


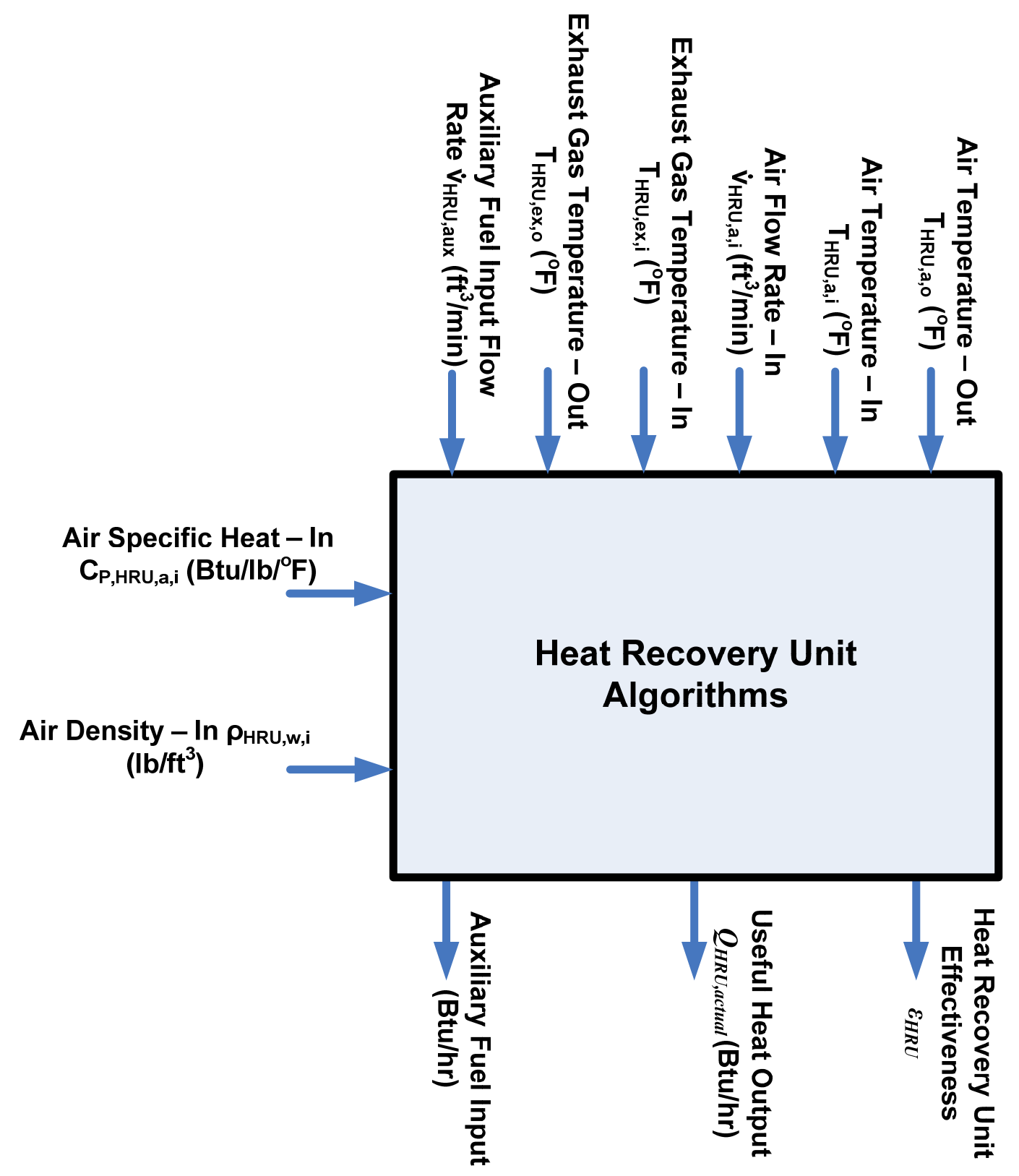

Figure 13. Input/output diagram for a heat recovery unit producing hot air.

\section{Heat Recovery Steam Generator}

A heat recovery steam generator (HRSG) is a heat exchanger that recovers heat from a hot gas stream and produces steam that can be used in a process or used to drive a steam turbine. A common application for a HRSG is in a combined cycle power plant, where hot exhaust from a gas turbine is fed to a HRSG to generate steam, which in turn drives a steam turbine. In CHP applications, the HRSG is generally used to generate steam to fire an absorption chiller. HRSG is similar to a HRU. The main difference between the HRU and HRSG is that the HRSG generates steam instead of hot water or hot air. 


\section{Effectiveness of Heat Recovery Steam Generator}

The effectiveness of a heat recovery steam generator $\left(\varepsilon_{H R S G}\right)$ also can be determined from the general equation for $\varepsilon_{H R U}$, Eq. (11). In this case, the actual heat transfer includes the heat of vaporization of the water as well as the sensible heat used to increase its temperature. Therefore, when expressed in terms of the change in the water side, the rate of heat transfer is equal to the difference in enthalpy between the water entering the HRSG and the steam leaving the HRSG, both of the enthalpies being functions of the fluid temperatures and pressures, i.e.,

$$
Q_{H R S G, a c t u a l}=(\dot{v} \rho)_{H R S G, w, i}\left[h\left(T_{o}, P_{o}\right)_{H R S G, s t e a m, o}-h\left(T_{i}, P_{i}\right)_{H R S G, \mathrm{w}, i}\right]
$$

under the assumption that the mass flow rate of water input to the HRSG is equal to the mass flow rate of steam output. Here, $h_{H R S G \text {,steam,o }}$ is the specific enthalpy of steam leaving the HRSG at temperature $T_{o}$ and pressure $P_{o}$, and $h_{H R S G, w, i}$ is the specific enthalpy of the water entering the HRSG at temperature $T_{i}$ and pressure $P_{i}$. The volumetric flow rate $\left(\dot{v}_{H R S G, w, i}\right)$ and density $\left(\rho_{H R S G, w, i}\right)$ are for water at the inlet to the HRSG.

Alternatively, the rate of heat transfer could be determined for the rate of heat loss from the hot exhaust gas as it passes through the HRSG (assuming that jacket heat losses are negligible). In this case, the rate of heat transfer is given by the relation

$$
Q_{H R S G, \text { actual }}=\left(\dot{v} \rho c_{p}\right)_{H R S G, e x, i}\left(T_{H R S G, e x, i}-T_{H R S G, e x, 0}\right) \text {, }
$$

where $\dot{v}_{H R S G, e x, i}$ and $\rho_{H R S G, e x, i}$ are, respectively the volumetric flow rate and density of exhaust gas coming into the HRSG; $c_{p, e x}$ is the specific heat of the exhaust gas mixture; and $T_{H R S G, e x, i}$ and $T_{H R S G, e x, o}$ are the temperatures of the exhaust gas streams coming into and leaving the HRSG, respectively.

The maximum possible rate of heat transfer between the two fluids $\left(Q_{H R S G, \max }\right)$ is given by

$$
Q_{H R S G, \max }=\left(\dot{v} \rho c_{p}\right)_{H R S G, e x, i}\left(T_{H R S G, e x, i}-T_{H R S G, w, i}\right),
$$

where $T_{H R S G, w, i}$ is the temperature of the saturated liquid water coming into the HRSG.

Therefore, for an HRSG, the effectiveness can be expressed as ${ }^{9}$

$$
\varepsilon_{H R S G}=\frac{(\dot{v} \rho)_{H R S G, w, i}\left[h\left(T_{o}, P_{o}\right)_{H R S G, \text { steam }, o}-h\left(T_{i}, P_{i}\right)_{H R S G, \mathrm{w}, i}\right]}{\left(\dot{v} \rho c_{p}\right)_{H R S G, e x, i}\left(T_{H R S G, e x, i}-T_{H R S G, w, i}\right)},
$$

or

\footnotetext{
${ }^{9}$ Assuming that $\left(\dot{v} \rho c_{p}\right)$ ex,i $<\left(\dot{v} \rho c_{p}\right)_{\mathrm{w}, \mathrm{i}}$.
} 


$$
\varepsilon_{H R S G}=\frac{T_{H R S G, e x, i}-T_{H R S G, e x, o}}{T_{H R S G, e x, i}-T_{H R S G, w, i}} .
$$

HRSGs often have stages, which produce steam at different pressures (e.g., high-pressure steam, medium pressure steam, and low pressure steam). In these cases, the enthalpy difference of each output stream must be considered separately, so that

$$
Q_{\text {HRSG ,actual }}=\sum_{j}\left[\dot{v}_{\text {HRSG }, s, o} \rho_{H R S G, s, o} h\left(T_{o}, P_{o}\right)_{H R S G, \text { stam }, o}\right]_{j}-\dot{v}_{H R S G, w, i} \rho_{H R S G, w, i} h\left(T_{i}, P_{i}\right)_{H R S G, w, i},
$$

and

$$
\varepsilon_{H R S G}=\frac{\sum_{j}\left[(\dot{v} \rho)_{H R S G, s, o} h\left(T_{o}, P_{o}\right)_{H R S G, s t e a m, o}\right]-(\dot{v} \rho)_{H R S G, w, i} h\left(T_{i}, P_{i}\right)_{H R S G, w, \mathrm{i}}}{\left(\dot{v} \rho c_{p}\right)_{H R S G, e x, i}\left(T_{H R S G, e x, i}-T_{H R S G, w, i}\right)} \cdot{ }^{10}
$$

Here, the summation in the numerator is over all HRSG stages of steam production with the flow rate, density and enthalpy for each stage corresponding to the conditions (e.g., temperature and pressure) of the steam flow exiting the $j$ th stage of the HRSG. If energy losses from the HRSG are negligible and essentially all of the energy transferred from the exhaust gas is used to produce steam, the effectiveness of the HRSG can still be determined from the relation

$$
\varepsilon_{H R S G}=\frac{T_{H R S G, e x, i}-T_{H R S G, e x, 0}}{T_{H R S G, e x, i}-T_{H R S G, w, i}} .
$$

\section{Heat Recovery Steam Generator Input/Output Diagram}

The input and output diagram for the HRSG is shown in Figure 14. To estimate the HRSG effectiveness $\left(\varepsilon_{H R S G}\right)$, three temperature measurements are needed [see Eq. (32)]. To determine the rate of useful heat output $\left[Q_{H R S G \text {,actual; }}\right.$ see Eq. (30)] from the HRSG, additional measurements are needed. These include the flow rate of the water input to the HRSG, the flow rate, temperature and pressure for each steam flow output from the HRSG, along with the corresponding water and steam densities. In addition, enthalpy tables are needed from which to determine the specific enthalpies of each steam flow and the water flow from their corresponding measured temperatures and pressures. The measurement of auxiliary input flow is optional and is not needed to estimate the effectiveness or the rate of useful heat output; however, its measurement will provide information useful to characterizing the fuel use and overall performance of the CHP system.

\section{Absorption Chiller}

Absorption chillers are cooling machines that operate just like the mechanically/electrically driven (vapor-compression cycle based) chillers, except for the compression process. Like

\footnotetext{
${ }^{10}$ Note that because water entering the HRSG is in the liquid state, $\mathrm{h}_{\mathrm{w}, \mathrm{i}}$ is essentially a function of temperature only, so that $\mathrm{P}_{\mathrm{HRSG}, \mathrm{i}}$ need not be measured.
} 


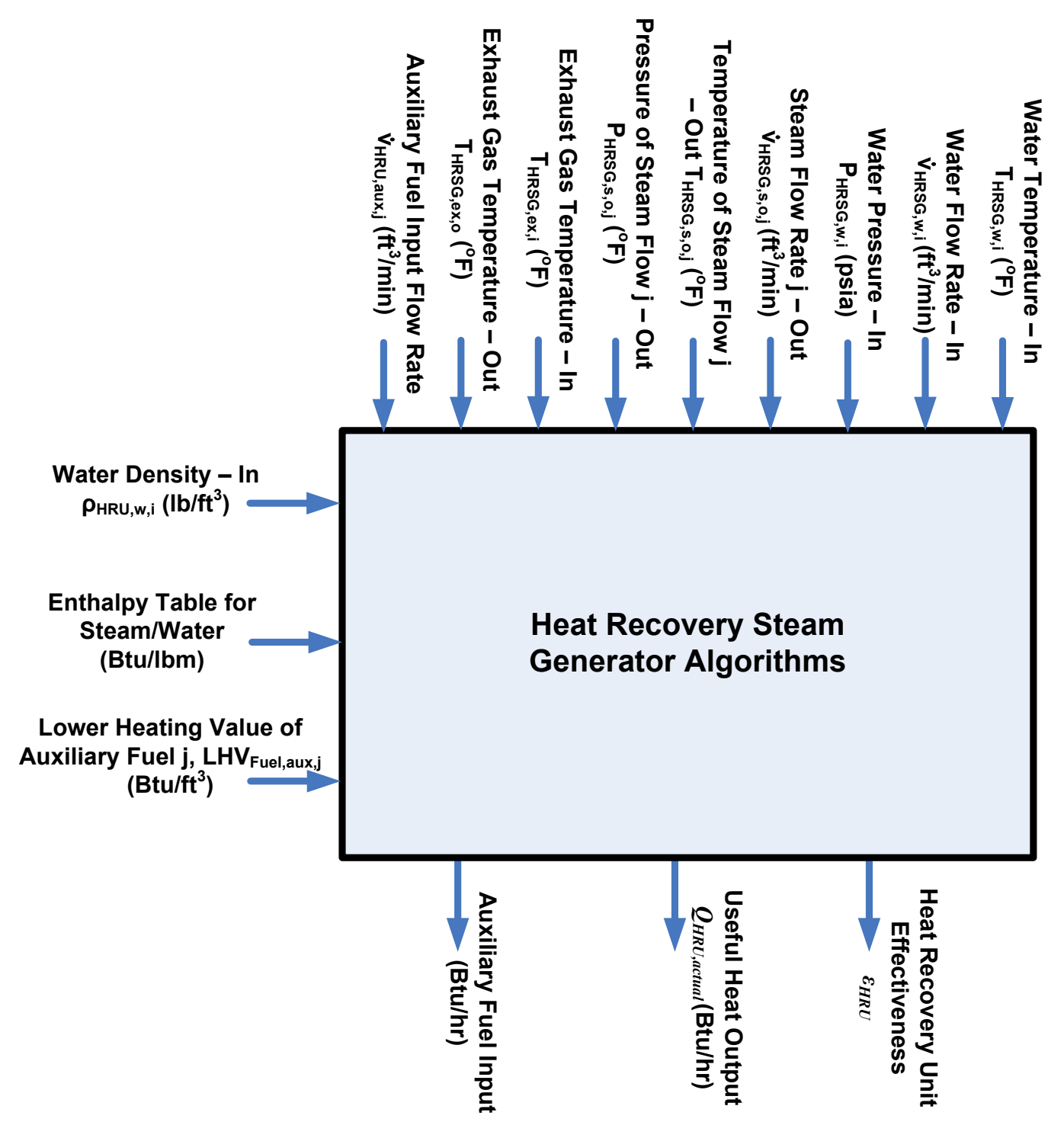

Figure 14. Input/output diagram for a heat recovery steam generator.

vapor-compression cycle based chillers, absorption chillers use a condenser, evaporator and expansion device. The main difference between the two types of chillers is how the low-pressure vapor exiting the evaporator is converted to high-pressure vapor that enters the condenser (see Figure 15). Instead of a mechanically-driven compressor, absorption chillers use heat to drive the refrigeration cycle. The heat needed to operate an absorption chiller can be delivered directly or indirectly. In a direct-fired absorption system, heat is provided directly by hot exhaust gases from the prime mover, while indirect-fired systems use either steam or hot-water to power the refrigeration cycle. If supplemental heat is needed, it can be provided by burning auxiliary fuel in a duct heater placed in the exhaust gas stream. 


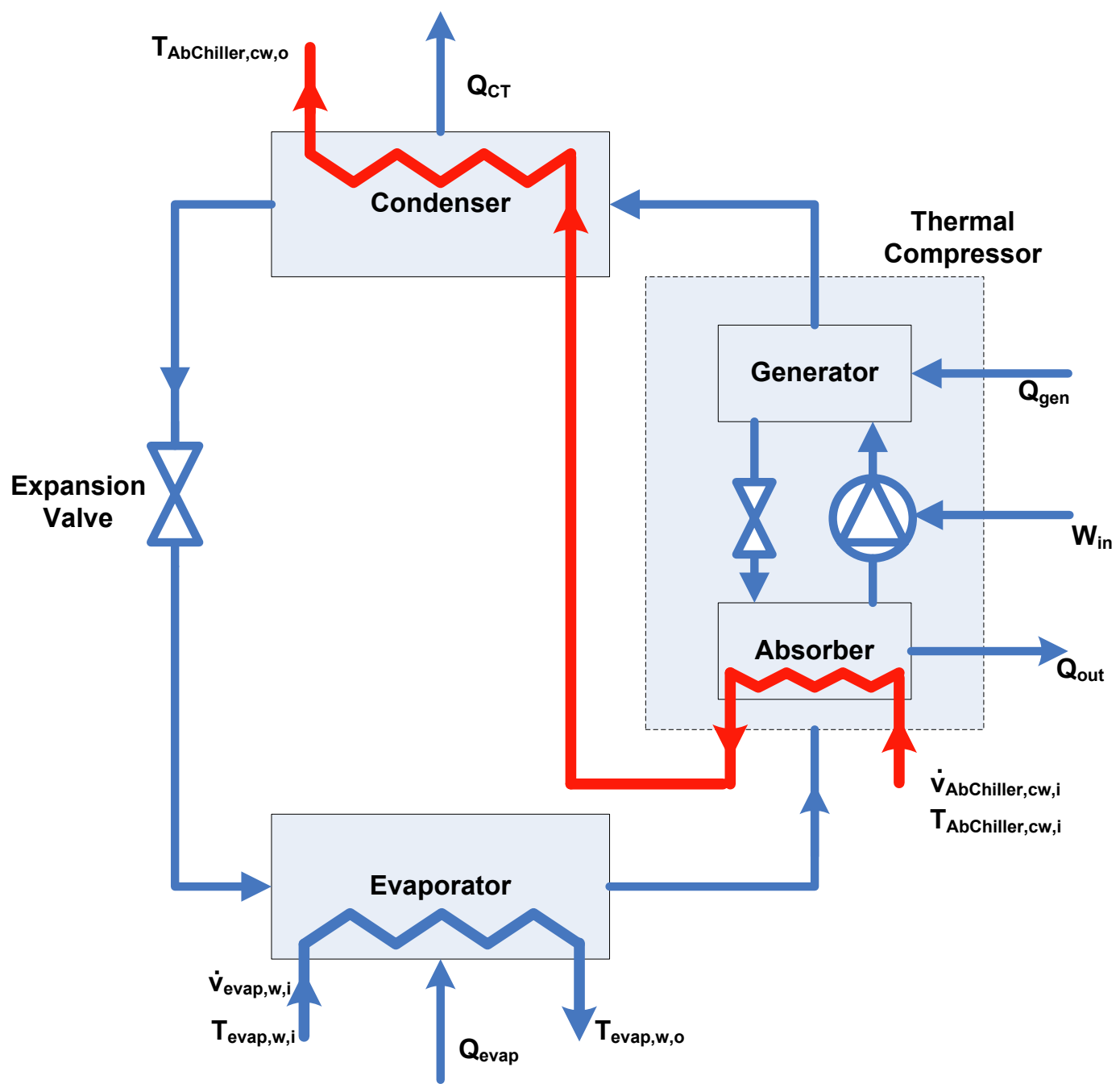

Figure 15 - Schematic Diagram of a single-effect absorption chiller

\section{Efficiency of Absorption Chiller}

The efficiency of absorption chillers is given by the coefficient of performance ( $\left.C O P_{A b C h i l l e r}\right)$ defined as

$$
C O P_{A b C h i l l e r}=\frac{Q_{\text {evap }}}{Q_{\text {gen }}}
$$

where $Q_{\text {evap }}$ is the rate at which water is cooled by the evaporator, $Q_{g e n}$ is the rate of heat loss from the exhaust gas, steam or hot water as it passes through the absorption unit's generator to desorb the refrigerant from solution, and the pump energy, $W_{i n}$, is small compared to $Q_{\text {evap }}$. 
Here,

$$
\begin{aligned}
Q_{\text {evap }} & =\dot{m}_{\text {evap }, w, i} c_{p, w}\left(T_{\text {evap }, w, i}-T_{\text {evap }, w, \mathrm{o}}\right) \\
& =\dot{v}_{\text {evap }, w, i} \rho_{\text {evap }, w, i} c_{p, w}\left(T_{\text {evap }, w, i}-T_{\text {evap }, w, \mathrm{o}}\right),
\end{aligned}
$$

where $\dot{m}_{\text {evap }, w, i}$ is the mass flow rate of chilled water into the evaporator, $\dot{v}_{\text {evap }, w, i}$ is the volumetric flow of chilled water entering the evaporator; $\rho_{\text {evap }, w, i}$ and $c_{p, w}$ are the density and specific heat of chilled water entering the evaporator, respectively; and $T_{\text {evap }, w, i}$ and $T_{\text {evap w,o }}$ are the evaporator entering and leaving chilled water temperatures. For direct-fired absorption chillers:

$$
Q_{g e n}=\dot{v}_{e x, i} \rho_{e x, i} c_{p, e x}\left(T_{e x, i}-T_{e x, 0}\right),
$$

where $\rho_{e x, i}$ is the density of the exhaust gases entering the absorption chiller, $\dot{v}_{e x, i}$ is the volumetric flow of exhaust gases entering the chiller, $c_{p, e x}$ is the specific heat of the exhaust gases (evaluated at the average exhaust gas temperature in the chiller), ${ }^{11}$ and $T_{e x, i}$ and $T_{e x, o}$ are the exhaust gas entering and leaving temperatures. For absorption chillers that use hot water from an HRU to generate the refrigerant:

$$
Q_{\text {gen }}=\dot{v}_{\text {hotwater }, i} \rho_{\text {hotwater }, i} c_{p, \text { hotwater }}\left(T_{\text {hotwater }, i}-T_{\text {hotwater }, \mathrm{o}}\right),
$$

where $\rho_{\text {hotwater, } i}$ and $c_{p, \text { hotwater }}$ are the density and specific heat of hot water entering the absorption chiller, $\dot{v}_{\text {hotwater }, i}$ is the volumetric flow of hot water entering the chiller, and $T_{\text {hotwater }, i}$ and $T_{\text {hotwater, } o}$ are the hot water entering and leaving temperatures. For absorption chillers that use steam to generate the refrigerant:

$$
Q_{\text {gen }}=\dot{v}_{\text {steam }, i} \rho_{\text {steam }, i}\left(h\left(T_{i}, P_{i}\right)_{\text {steam }, i}-h\left(T_{o}, P_{o}\right)_{\text {steam }, \mathrm{o}}\right),
$$

where $\rho_{\text {steam }, i}$ is the density of steam entering the absorption chiller, $\dot{v}_{\text {steam }, i}$ is the volumetric flow of steam entering the chiller, $h\left(T_{i}, P_{i}\right)$ is the enthalpy of steam entering the chiller at temperature $T_{i}$ and pressure $P_{i}$, and $h\left(T_{o}, P_{o}\right)$ is the enthalpy of steam leaving the chiller at temperature $T_{o}$ and pressure $P_{o}$.

\section{Absorption Chiller Input/Output Diagram}

Input/output diagrams for monitoring of absorption chiller performance are shown in Figure 16 for hot-water-fired chillers, Figure 17 for steam-fired chillers and Figure 18 for direct-fired chillers. Arrows at the top of the diagram represent measured inputs, arrows on the left side of

\footnotetext{
${ }^{11}$ The product of volumetric flow rate of the exhaust gas and its density, which is the mass flow rate, is constant through the chiller during steady operation; therefore, $\dot{v}_{e x, i} \rho_{e x, i}=\dot{v}_{e x, o} \rho_{e x, o}$, and this quantity can be evaluated at either the inlet or exit conditions. We recommend evaluating $c_{p, e x}$ at the average of the inlet and outlet temperatures of the exhaust gas; however, the difference in the value of $c_{p, e x}$ evaluated at the inlet conditions and the outlet conditions will be less than about $8 \%$ for the exhaust gases in most practical situations.
} 


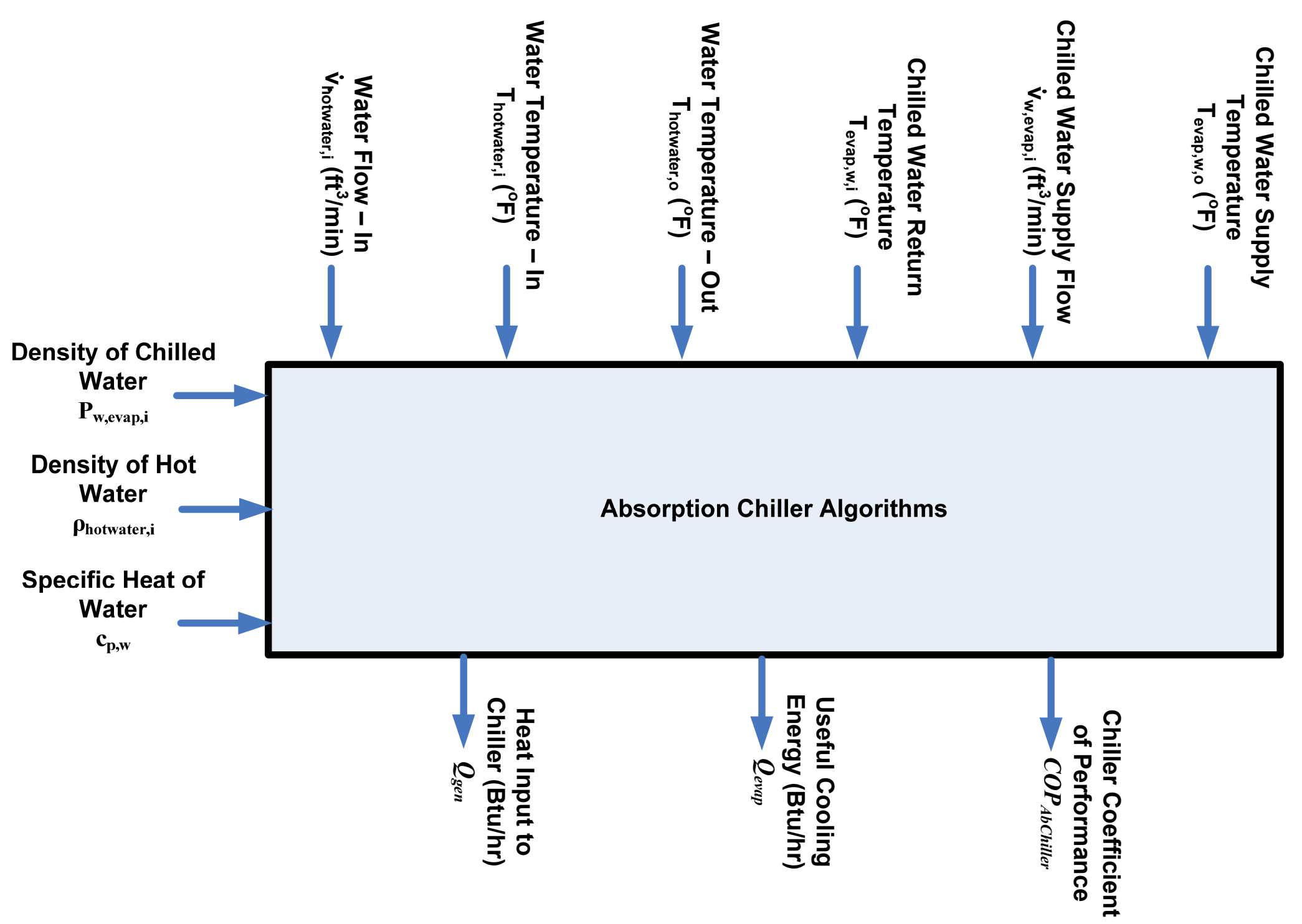

Figure 16 - Input/output diagram for monitoring algorithms for an absorption chiller with hot water as the source of heat for generating refrigerant from solution. 


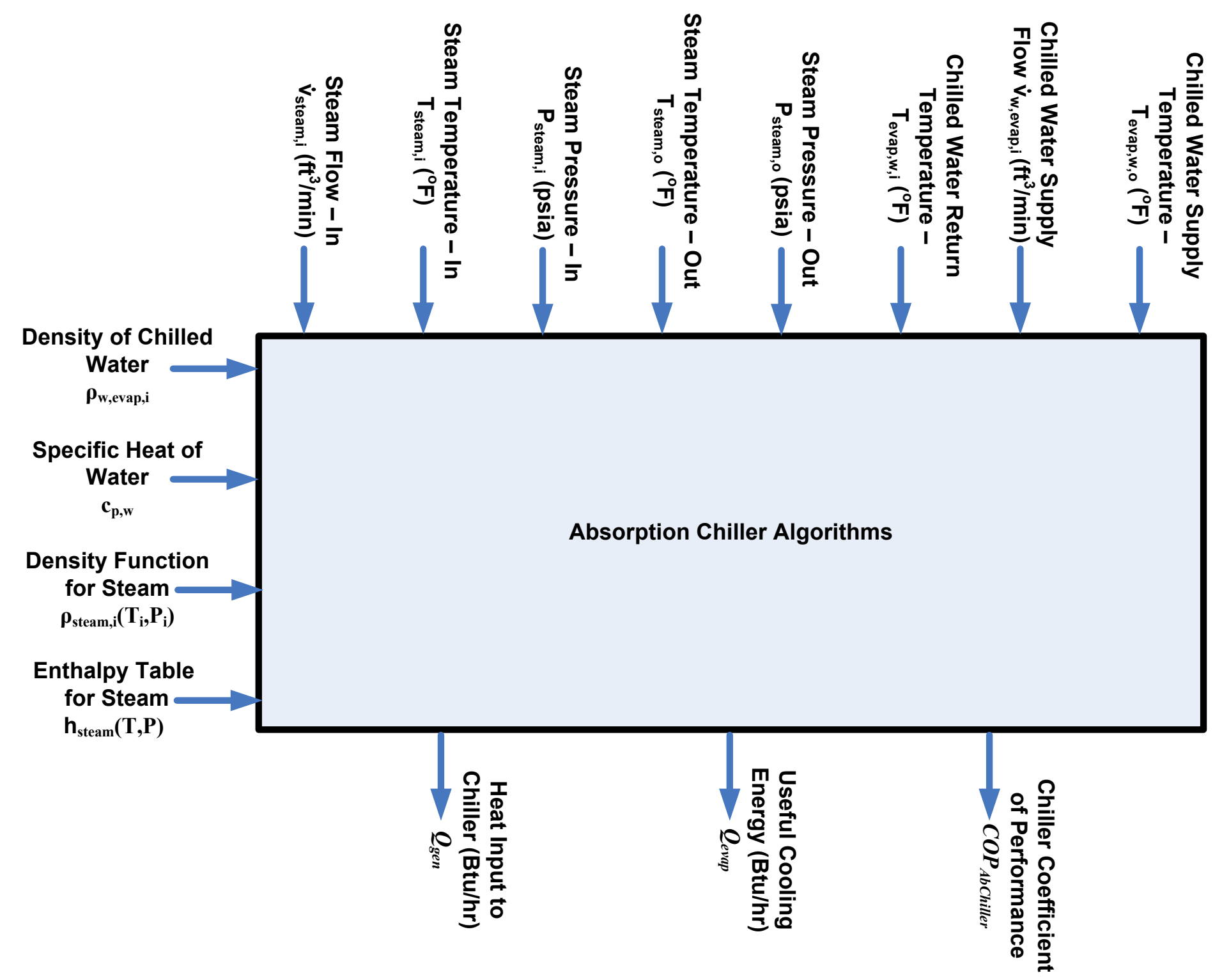

Figure 17 - Input/output diagram for monitoring algorithms for an absorption chiller with steam as the source of heat for refrigerant generation. 


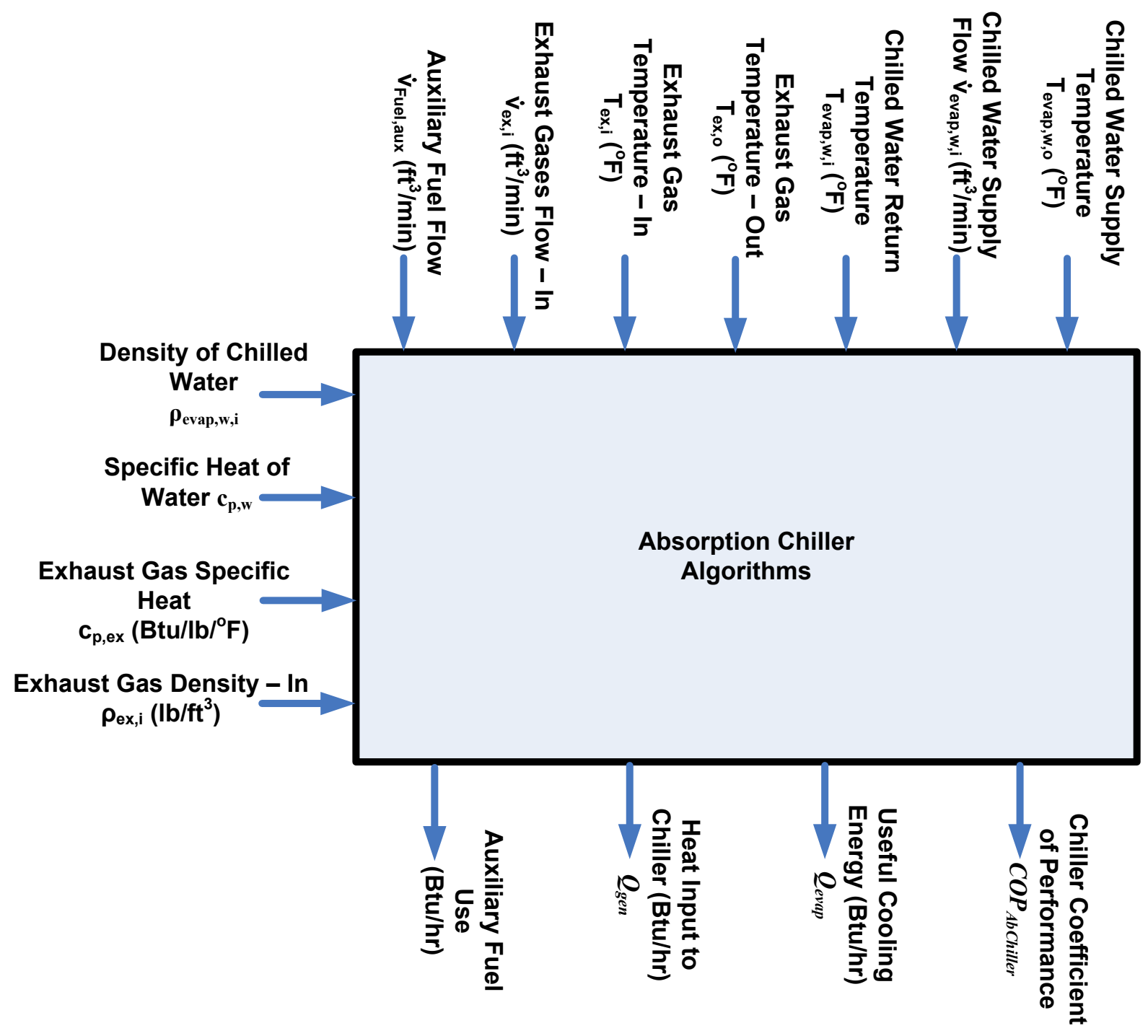

Figure 18 - Input/output diagram for direct-fired absorption chiller monitoring algorithms.

the diagram represent fixed inputs, and arrows at the bottom of the diagram represent outputs. For Figure 16 and Figure 17, the algorithms (represented by the box) are based on Eq. (33), Eq. (34), Eq. (36) and Eq. (37). For Figure 18, the algorithms (represented by the box) are based on Eq. (33), Eq. (34), and Eq. (35). In the diagrams, the density of liquid water or exhaust gases should be evaluated at the same conditions as the inlet flow rate is measured (the inlet as specified in the diagrams). The specific heat of water and exhaust gases is assumed constant across the chiller, which is a good assumption for liquid water for the typical range of temperatures across the chiller, but it should be evaluated at the average of the inlet and outlet temperatures for exhaust gas. Although, the auxiliary fuel flow rate is not included in the equations cited for direct-fired absorption chillers, it is input into the algorithms and converted to an output as the auxiliary rate of fuel use so that fuel used for supplemental firing can be tracked (it is not included as an output for hot-water- and steam-fired chillers because it is an output for the HRU in those cases). 


\section{Cooling Tower}

Cooling towers (CTs) provide the rejection of heat from the condenser and the absorber, which is required by the absorption refrigeration cycle. For a water-cooled condenser, heat is transferred from refrigerant to cool water, which is pumped to the cooling tower. The cooling tower uses evaporative cooling to reject heat from the hot water to the ambient environment. The fans push (forced draft) or pull (induced draft) ambient air through the cooling tower. A schematic diagram of a cooling tower is shown in Figure 19.

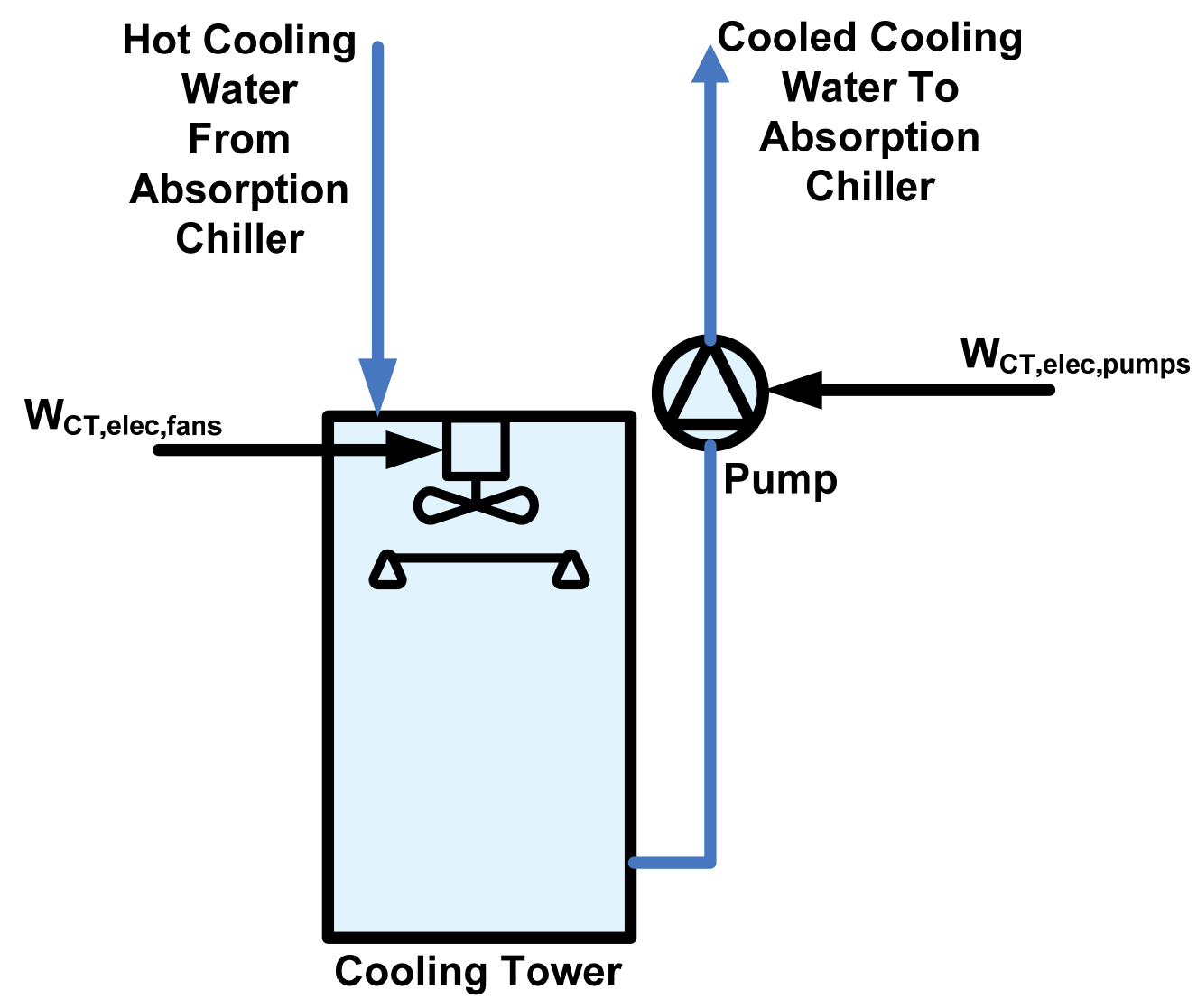

Figure 19 - Schematic diagram of cooling tower used to reject heat from the condenser to the ambient environment with the fan shown in a location to provide induced draft.

\section{Efficiency of Cooling Towers}

The cooling tower efficiency $\left(\eta_{C T}\right)$ is defined as:

$$
\eta_{C T}=\frac{\left(T_{C T, w . i}-T_{C T, w, o}\right)}{\left(T_{C T, w, i}-T_{w b}\right)},
$$


where, $T_{C T, w, i}$ is the inlet temperature of the hot water to the tower, $T_{C T, w, o}$ is the outlet temperature of cooled water from the tower, and $T_{w b}$ is the wet-bulb temperature of the ambient air to which heat is rejected by the cooling tower. ${ }^{12}$

The value of $\eta_{C T}$ only indicates how well the cooling tower cools the condenser water in terms of how close the water temperature approaches the limiting wet-bulb temperature of the ambient air. It does not indicate how the cooling was achieved or how much external electrical energy input was used to achieve this reduction in temperature. For example, if the cooling tower medium becomes fouled, increasing resistance to air flow and inhibiting heat transfer, the cooling tower fans might run longer or at a higher speed (for variable speed fans) to achieve the same temperature drop for the water that was accomplished with less fan energy when the medium was not fouled. In addition, electric power is used to pump the condenser water to and from the cooling tower. To provide a metric for how efficiently electricity is used in this process, we define a cooling-tower electric utilization efficiency $\left(\eta_{C T, e l e c}\right)$ as

$$
\eta_{C T, \text { Elec }}=\frac{Q_{C T, \text { th }}}{W_{C T, \text { elec }}}
$$

where $Q_{C T, t h}$ is the rate of heat loss by the condenser water in passing through the cooling tower and $W_{C T \text {,elec }}$ is the electric power use by the cooling tower fans and pumps. The electric power use is the sum of the electric power used by all the individual pumps and fans, i.e.,

$$
W_{C T, \text { elec }}=\sum_{j} W_{C T, e l e c, j}
$$

where $W_{C T, e l e c, j}$ is the electric power use by the $j$ th pump or fan and the summation is over all pumps and fans.

The rate of heat loss from the condenser water can be determined from measurements of the entering water temperature $\left(T_{C T, w, i}\right)$, the exiting water temperature $\left(T_{C T, w, o}\right)$, and the volumetric flow rate of water through the cooling tower $\left(\dot{v}_{C T, w}\right)$ using the relation

$$
Q_{C T, t h}=\rho_{w} \dot{v}_{C T, w} c_{p, w}\left(T_{C T, w, i}-T_{C T, w, o}\right)
$$

where $\rho_{w}$ and $c_{p, w}$ are the density and specific heat of liquid water, respectively.

Combining Eq. (39) through Eq. (41), the cooling-tower electric utilization efficiency can be expressed as

$$
\eta_{C T, \text { Elec }}=\frac{\rho_{w} \dot{v}_{C T, w} c_{p, w}\left(T_{C T, w, i}-T_{C T, w, o}\right)}{\sum_{j} W_{C T, e l e c, j}} .
$$

\footnotetext{
${ }^{12}$ If heat losses from piping between the absorption chiller and cooling tower are small, then $T_{C T, w, i} \approx T_{A b C h i l l e r, c w, o}$ and $T_{C T, w, o} \approx T_{A b C h i l l e r, c w, i}$.
} 


\section{Cooling Tower Input/Output Diagram}

The input/output diagram for monitoring of cooling tower performance is shown in Figure 20. Arrows at the top of the diagram represent measured inputs, arrows on the left side of the diagram represent fixed inputs, and arrows at the bottom of the diagram represent outputs. The algorithms (represented by the box) are based on Eq. (38) and Eq. (42). In this diagram, the density and specific heat of liquid water are assumed to be constant across the cooling tower. They can be evaluated at the average of the water inlet and outlet temperatures.

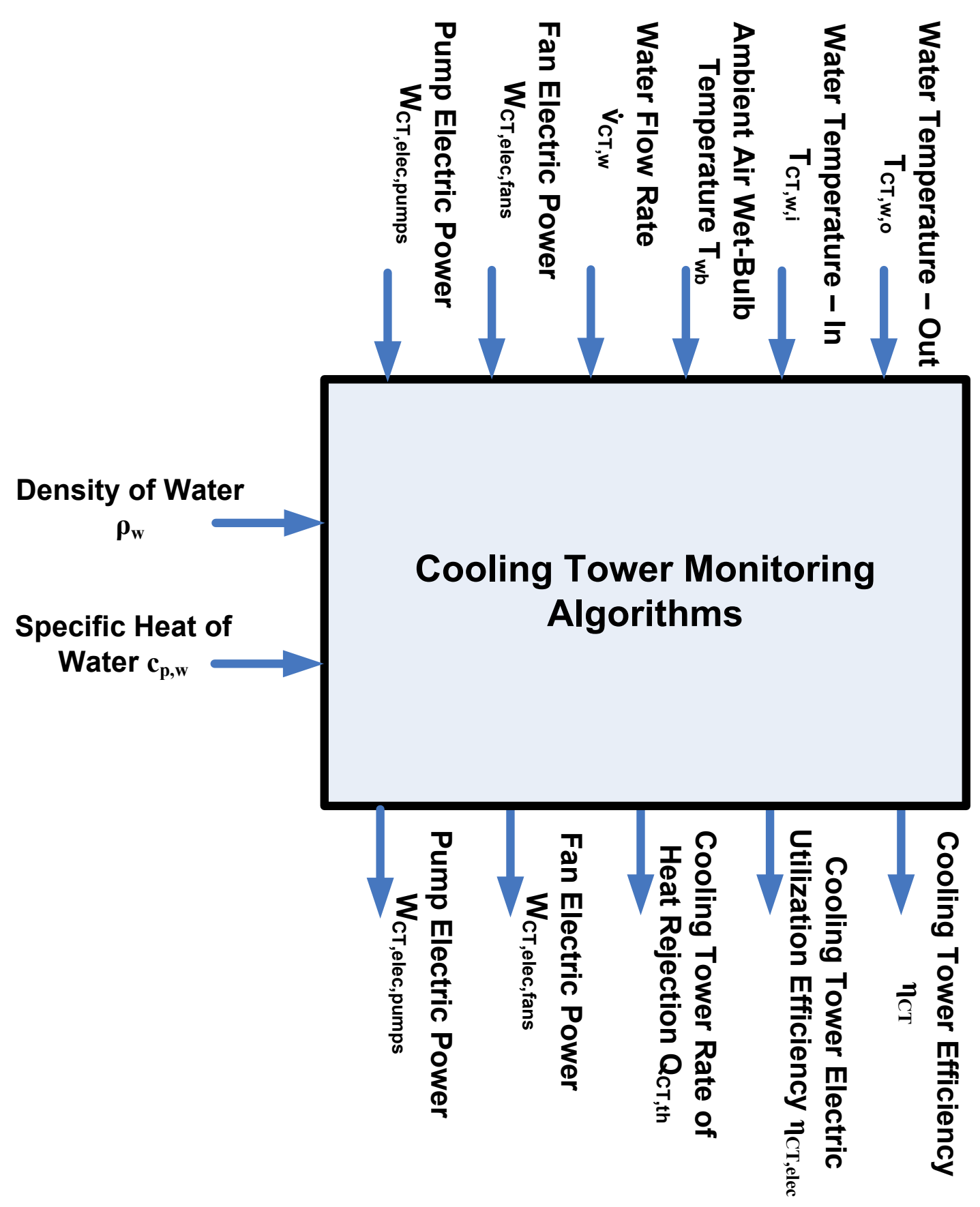

Figure 20 - Input/output diagram for cooling tower monitoring algorithms. 


\section{Pumps}

Pumps use rotational mechanical energy, usually provided by an electric motor, to create the pressure differences that drive the flow of liquids. A schematic diagram of a simple pump is shown with pertinent variables identified in Figure 21.

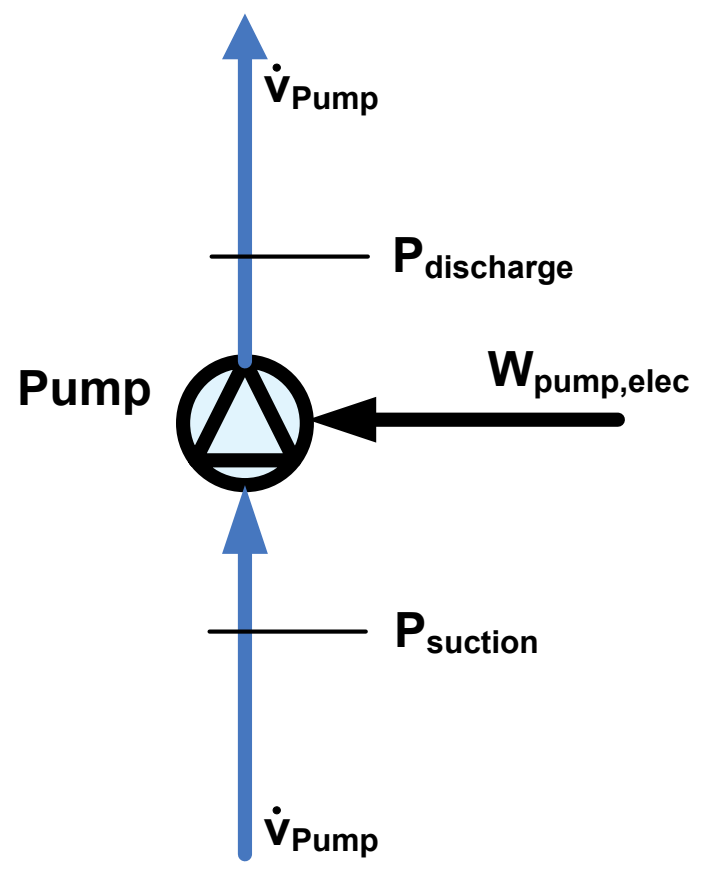

Figure 21 - Schematic diagram of a pump.

\section{Efficiency of Pumps}

The efficiency of a pump $\left(\eta_{\text {Pump }}\right)$ can be expressed as

$$
\eta_{\text {Pump }}=\frac{W_{\text {Pump }}}{W_{\text {Pump }, \text { elec }}},
$$

where $W_{\text {Pump }}$ is the mechanical power output imparted by the pump to the liquid, and $W_{\text {Pump,elec }}$ is the electric power input to the pump motor. The mechanical power imparted by the pump to the liquid is equal to the product of the volumetric flow rate through the pump and the pressure difference across the pump, i.e.,

$$
W_{\text {Pump }}=\dot{v}_{\text {Pump }, w}\left(P_{\text {disch arge }}-P_{\text {suction }}\right),
$$

where $\dot{v}_{\text {Pump }}$ is the volumetric flow rate through the pump, $P$ represents pressure, and the subscripts discharge and suction identify variables at the pump suction port (inlet) and discharge 
port (outlet). The difference between the discharge and suction pressures is sometimes called the static head of the pump.

Combining Eq. (43) and Eq. (44), yields the relation for pump efficiency

$$
\eta_{\text {Pump }}=\frac{\dot{v}_{\text {Pump }}\left(P_{\text {discharge }}-P_{\text {suction }}\right)}{W_{\text {Pump }, \text { elec }}}
$$

\section{Pump Input/Output Diagram}

The input/output diagram for monitoring of pump performance is shown in Figure 22. Arrows at the top of the diagram represent measured inputs, and arrows at the bottom of the diagram represent outputs. The pump monitoring algorithms (represented by the box) are based on Eq. (45).

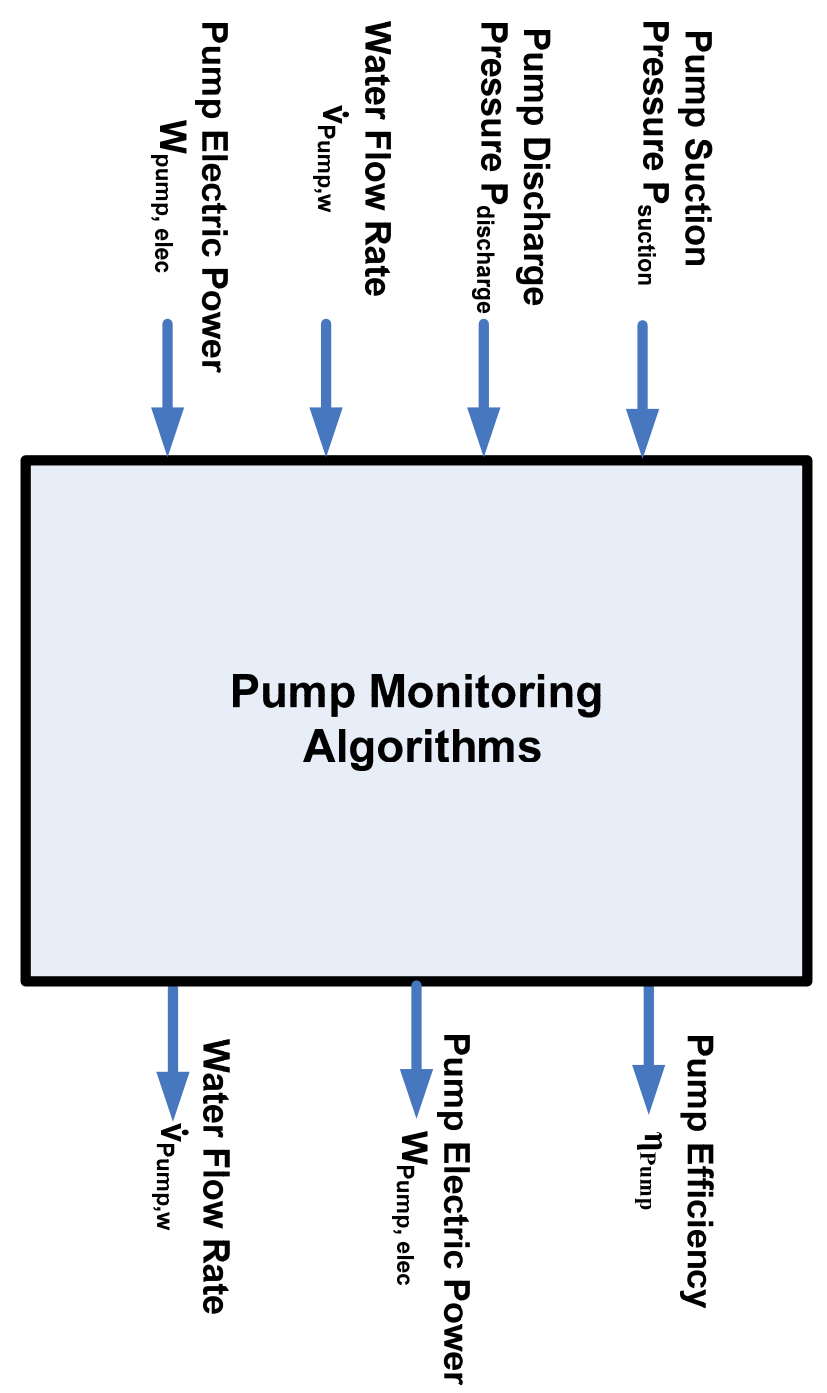

Figure 22 - Input/output diagram for pump monitoring algorithms. 


\section{Fans}

Fans use rotational mechanical energy, usually provided by an electric motor, to create the pressure differences that drive the flow of gases, often air. A schematic diagram of a simple fan is shown with pertinent variables identified in Figure 23.

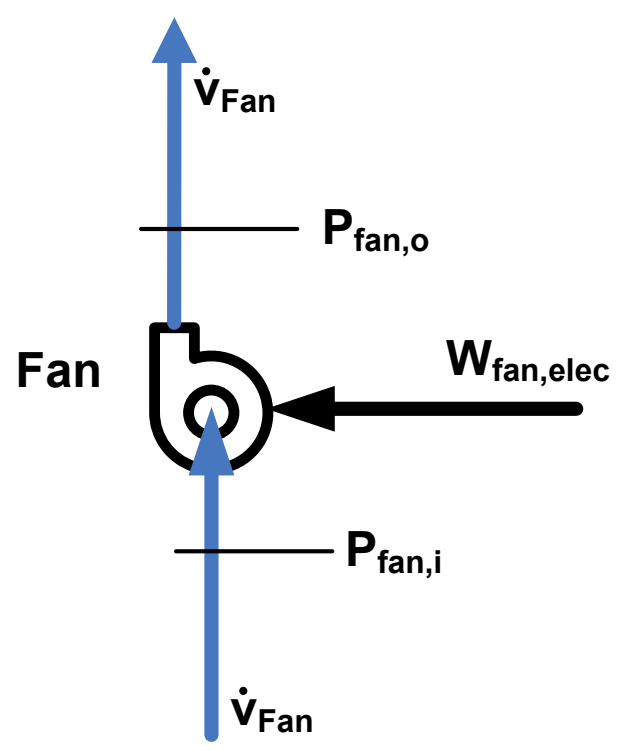

Figure 23 - Schematic diagram of a fan.

\section{Efficiency of Fans}

The efficiency of a fan $\left(\eta_{F a n}\right)$ can be expressed as

$$
\eta_{\text {Fan }}=\frac{W_{\text {Fan }}}{W_{\text {Fan,elec }}},
$$

where $W_{\text {Fan }}$ is the mechanical power output imparted by the fan to the gas, and $W_{\text {Fan,elec }}$ is the electric power input to the fan motor. The mechanical power imparted by the fan to the gas is equal to the product of the volumetric flow rate ${ }^{13}$ through the fan and the pressure difference across the fan, i.e.,

$$
W_{F a n}=\dot{v}_{F a n}\left(P_{F a n, o}-P_{F a n, i}\right)
$$

where $\dot{v}_{F a n}$ is the volumetric flow rate through the fan, and $P_{F a n, i}$ and $P_{F a n, o}$ represent the pressure immediately upstream and downstream of the fan.

\footnotetext{
${ }^{13}$ The work of compressing the air is assumed negligible, which is reasonable for fans operating at or below about 4 inches w.c. $(=0.145 \mathrm{psig}=996 \mathrm{~Pa})$.
} 
Combining Eq. (43) and Eq. (44), yields the relation for fan efficiency

$$
\eta_{F a n}=\frac{\dot{v}_{F a n}\left(P_{F a n, o}-P_{F a n, i}\right)}{W_{F a n, e l e c}} .
$$

Eq. (48) provides the efficiency of the fan-motor combination rather than the fan alone.

\section{Fan Input/Output Diagram}

The input/output diagram for monitoring of pump performance is shown in Figure 24. Arrows at the top of the diagram represent measured inputs, and arrows at the bottom of the diagram represent outputs. The fan monitoring algorithms (represented by the box) are based on Eq. (45).

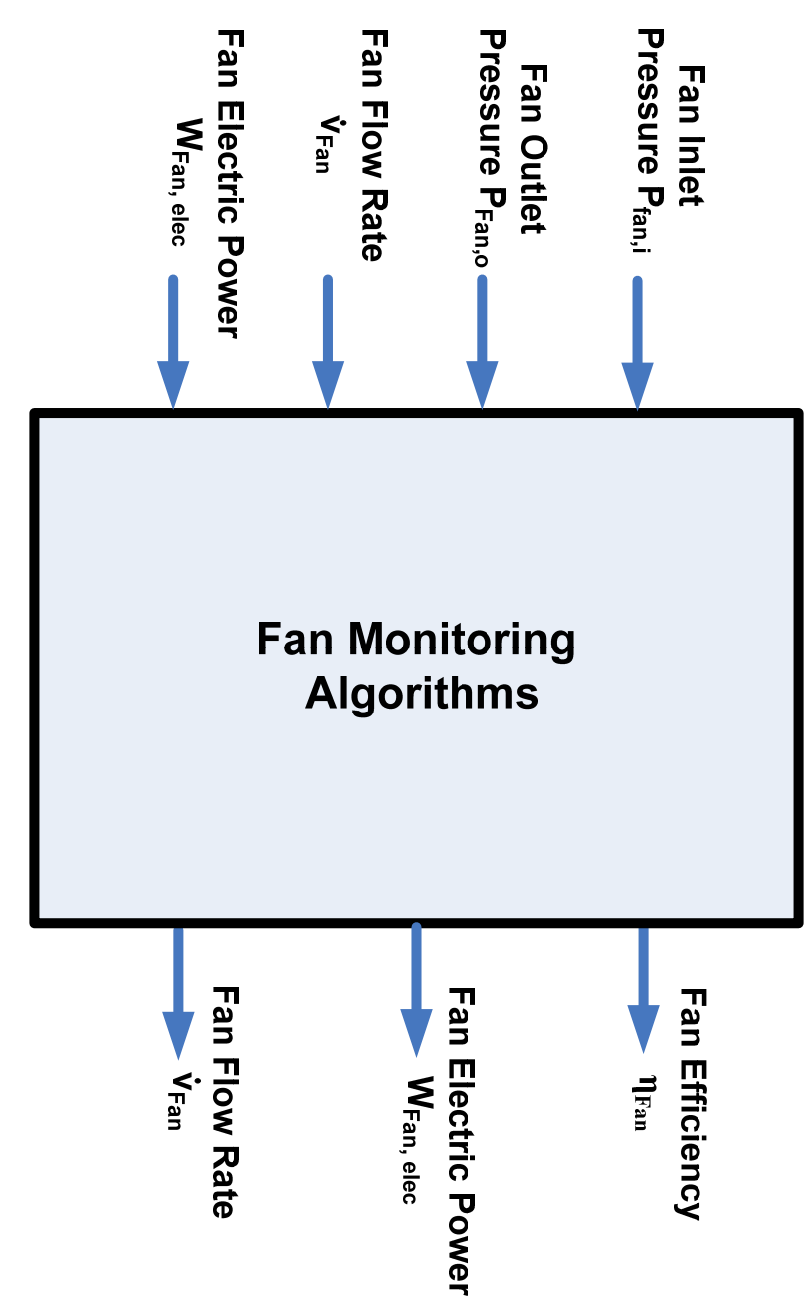

Figure 24 - Input/output diagram for fan monitoring algorithms. 


\section{Desiccant System}

A desiccant system is used in a CHP system for dehumidification because it is capable of using a low-grade thermal source to remove moisture from the air, which eliminates the overcooling and reheating step typically employed in a conventional cooling system for dehumidification. The dry air produced by the desiccant system can be used for industrial processes or space conditioning. A desiccant system consists of a desiccant wheel, a supply (process) fan, an exhaust fan, and a heat source for regenerating the desiccant. In a CHP system, exhaust gases, either directly from the prime mover or indirectly after passing through an HRU, are used for reactivation of the desiccant. In some cases, additional heating is provided by a duct-burner, which supplements the heat in the exhaust stream, as shown in Figure 25.

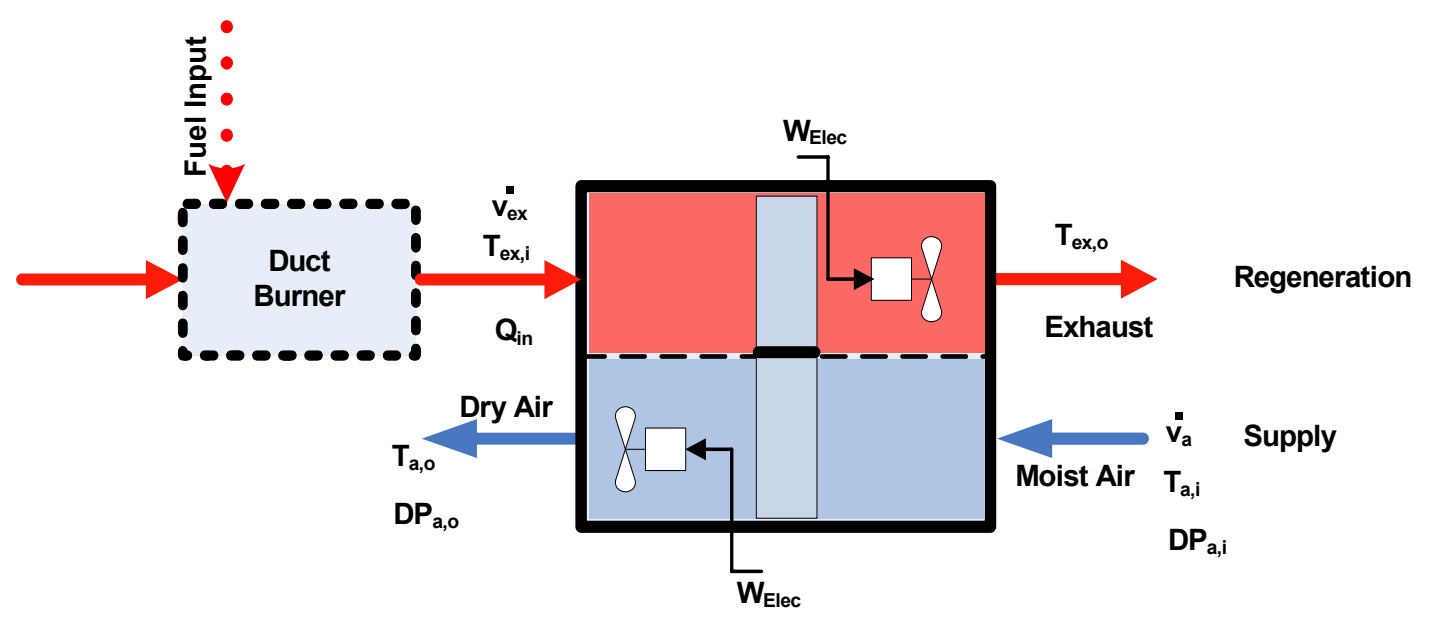

Figure 25 - Schematic of desiccant system used to dehumidify air.

\section{Efficiency of Desiccant System}

The efficiency of the desiccant system $\left(\eta_{D}\right)$ is defined as the ratio of dehumidification load (rate of moisture removal) to the total electric and thermal power input for regenerating the desiccant:

$$
\eta_{D}=\frac{Q_{d}}{Q_{d, \text { in }}+W_{d, \text { Elec }}}
$$

where, $Q_{d}$ is the rate of dehumidification, $Q_{d, i n}$ is the rate at which heat is used to regenerate the desiccant and $W_{d, E l e c}$ is the total fan power input (for both the process and the regeneration streams). $Q_{d}$ can be calculated using the following equation:

$$
Q_{d}=Q_{d, \text { total }}-Q_{d, \text { sensible }},
$$

where $Q_{d, \text { total }}$ is the rate of total heat transfer between the inlet and outlet on the supply (air) side, given by

$$
Q_{d, \text { total }}=(\dot{v} \rho)_{d, a}\left(h(T, D P)_{d, a, i}-h(T, D P)_{d, a, o}\right),
$$


$h(T, D P)_{d, a, i}$ and $h(T, D P)_{d, a, o}$ are the specific enthalpies of the entering and leaving air (process) streams at the corresponding dry-bulb and dew-point temperatures ( $T$ and $D P$, respectively). The mass flow measured either at the inlet or outlet of the process stream is represented by the term $(\dot{v} \rho)_{\mathrm{d}, \mathrm{a}}$.

$Q_{d, \text { sensible }}$ is the rate of sensible heat transfer to the process air stream between the inlet and outlet of the desiccant system and can be calculated from:

$$
Q_{d, \text { sensible }}=\left(\dot{v} \rho C_{p}\right)_{d . a}\left(T_{d . a, i}-T_{d, a, o}\right)
$$

where, $T_{d, a, i}$ and $T_{d, a, o}$ are dry-bulb temperatures at the inlet and outlet of the air side of the desiccant system. The term $Q_{d, \text { in }}$ represents the regeneration energy input:

$$
Q_{\text {d.in }}=\left(\dot{v} \rho C_{p}\right)_{\text {d.ex }}\left(T_{d . e x, i}-T_{d, e x, o}\right) \text {, }
$$

where $T_{d, e x, i}$ and $T_{d, e x, o}$ are dry-bulb temperatures at the inlet and outlet of the regeneration stream. The term $W_{d, \text { Elec }}$ represents the sum of the fan power consumption of the process (air) and regeneration (exhaust gas) fans.

\section{Desiccant System Input/Output Diagram}

An input/output diagram for monitoring of desiccant system performance is shown in Figure 26. Arrows at the top of the diagram represent measured inputs, arrows on the left side of the diagram represent fixed inputs, and arrows at the bottom of the diagram represent outputs. The outputs, with exception to the auxiliary fuel input, are all based on Eq. (49) through Eq. (53).

In the diagram, the density of supply air and exhaust gases should be evaluated at the same conditions as the inlet flow rate is measured (the inlet as specified in the diagrams). The specific heat of supply air and exhaust gases is assumed constant across the desiccant system, which is a good assumption for both air and exhaust gas because the variation across the inlet and outlet is small. 


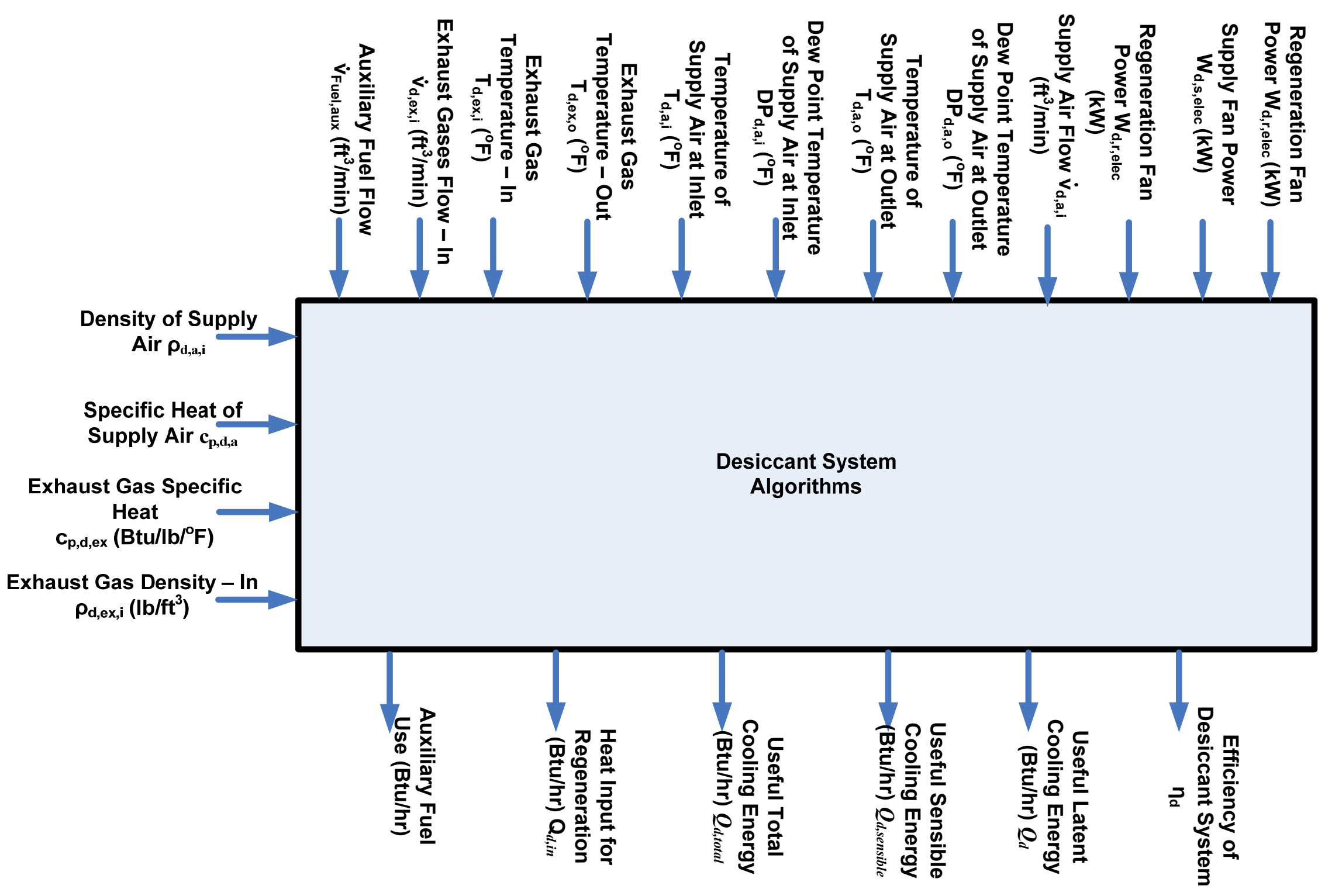

Figure 26 - Input/output diagram for monitoring algorithms for a desiccant system. 


\section{System Level Monitoring}

System level monitoring is provided to ensure that the overall CHP system is performing up to specifications and that significant degradation in performance has not occurred. If degradation is detected and quantified, monitored component-level information can be used to isolate the cause of degradation and correct it. This process is illustrated in the Application Scenario section later in this report.

The system shown in Figure 27 (created from Figure 8 by making the prime mover either a reciprocating engine or small gas turbine) represents the most complete of the generic systems identified for treatment in this project. All of the other CHP systems (Figure 2 through Figure 8) can be derived by specifying the prime mover and eliminating components from Figure 27 . As an example, consider the system shown in Figure 5. By specifying a turbine as the prime mover, eliminating jacket heat recovery so that water from the absorption cooler generator is pumped back to the heat recovery unit, and eliminating the desiccant system, the system in Figure 5 is obtained from the general diagram in Figure 27.

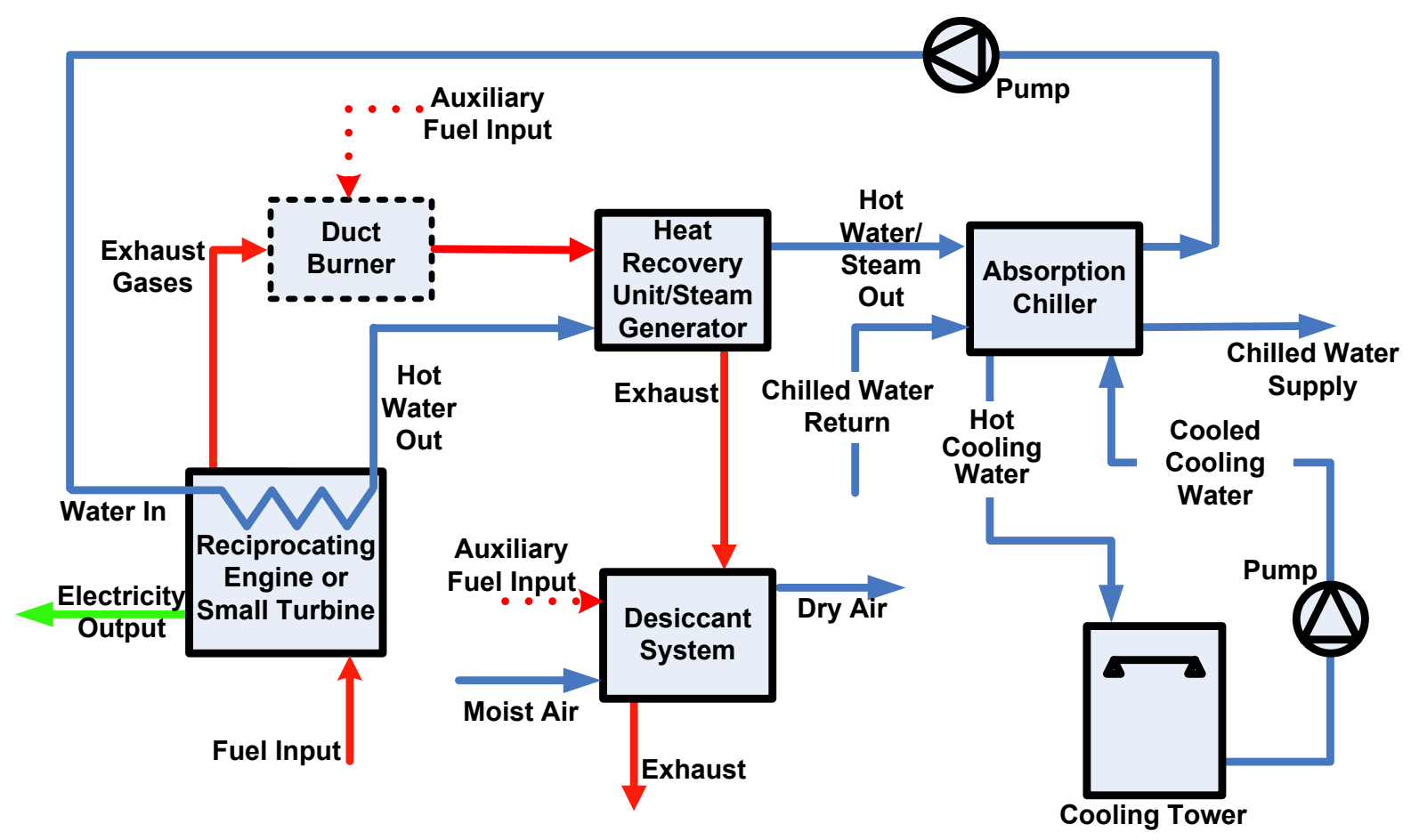

Figure 27 - Most complete of the CHP systems considered in this project.

\section{System-Level Performance}

To monitor the system-level performance of CHP systems, we propose to use two metrics for efficiency and several other metrics calculated from sensed conditions or measured directly. Based on the discussion in the Scope Specification (Katipamula and Brambley 2006), the two 
selected efficiency metrics are the overall fuel utilization efficiency $\left(\eta_{F}\right)$ and the valueweighted energy utilization factor $\left(E U F_{V W}\right)^{14}$, which are defined as

$$
\eta_{F}=\frac{\left(W_{\text {Elec }}+\sum_{j} Q_{t h, j}\right)}{Q_{\text {Fuel }}}
$$

and

$$
E U F_{V W}=\frac{W_{\text {Elec }} Y_{\text {Elec }}+\sum_{j} Q_{t h, j} Y_{t h, j}}{\sum_{j} Q_{\text {Fuel }, j} \text { Price }_{\text {Fuel }, j}} .
$$

Here, $W_{\text {Elec }}$ is the net electrical power output, $Q_{\mathrm{th}, \mathrm{j}}$ represents the net rate of useful thermal energy output from thermal recovery and/or conversion process $j$ (e.g., the cooling provided by an absorption chiller) with the sum being over all thermal recovery and conversion processes in the system delivering energy for end use (e.g., an absorption chiller or a desiccant unit), and $Q_{\text {Fuel }}$ is the total rate of input of fuel energy to the CHP system. For systems with fuel used for supplemental heating (e.g., for a heat recovery unit, steam generator, or desiccant regenerator), $Q_{\text {Fuel }}$ is the sum over all fuel inputs to the system, i.e.,

$$
Q_{\text {Fuel }}=\sum_{j} Q_{F u e l, j}
$$

where $Q_{f u e l, j}$ is the rate of fuel energy input at point $j$ in the system (e.g., to the prime mover or for supplemental heating of exhaust gases before entering the heat recovery unit) with the sum being over all fuel inputs to the CHP system. These fuel inputs may include the same fuel (e.g., natural gas) introduced at several different points in the system or may be different fuels (e.g., diesel fuel for a reciprocating engine prime mover and natural gas for supplemental heat elsewhere in the system). The fuel energy may be based on the lower heating value (LHV) or higher heating value (HHV) of the fuel. By convention, the gas turbine industry uses the lower heating value to characterize energy use and calculate efficiencies, while the natural gas distribution and electric power generation industries use the HHV for sales and to characterize natural-gas energy use (Energy Nexus Group 2002). Use of the LHV for determining energy use or the efficiency of small turbines and reciprocating engines in CHP systems seems reasonable because the products of combustion (exhaust) leave the turbine or engine at conditions at which the water is in vapor phase. For monitoring CHP system performance and detecting degradation over time, either the LHV or the HHV can be used as long as the use is consistent. For comparisons to benchmarks such as data from manufacturers, care must be taken to ensure that the LHV or HHV is used consistently in determination of the benchmark and in calculations of monitored performance. Furthermore, if condensing HRUs are used in the system, the HHV should be used in calculations of fuel energy inputs.

\footnotetext{
${ }^{14}$ The $E U F_{V W}$ was introduced by Timmermans (1978) and later elaborated upon by Horlock (1997).
} 
Other variables appearing in Eq. (55) are defined as follows: $Y_{\text {Elec }}$ and $Y_{t h, j}$ represent, respectively, the value per unit of electricity generated (e.g., in $\$ / \mathrm{kWh}$ ) and the value per unit of useful heat (or cooling) provided (e.g., in \$/million Btu) by the jth thermal application technology (e.g., absorption chiller or desiccant unit); and Price $_{F u e l, j}$ is the price of the fuel injected at point $j$ in the system, with the discussion of different fuels versus a single fuel from the immediately preceding paragraph applying. By accounting for the value of products, this metric represents the value of products per unit of expenditure on fuel and has units of $\$$ value of produced energy per $\$$ of fuel consumed. In operating a plant, $E U F_{V W}$ should be maximized to achieve the most economic operation. Because generally $Y_{\text {elec }}>Y_{t h, j}$ for most thermal applications, a CHP plant should be operated to maximize electricity production. If, however, the amount of electricity above on-site requirements cannot be sold to the grid, the electricity production should follow variations in on-site electric load. Changes in the value of $E U F_{V W}$ caused by degradations in CHP system performance would be weighted by their effects on the value of the energy produced. As a result, faults and performance degradations having the greatest dollar impacts would be recognized by larger changes in the $E U F_{V W}$.

Other system-level variables that we propose to separately monitor to provide information useful for diagnosing changes in CHP system efficiency and understanding operating costs are:

- Current rate of useful heating or cooling output, $Q_{t h}\left(\mathrm{~kW}_{\text {th }}\right.$ or Btu/hr)

- Current electric power output, $W_{\text {Elec }}(\mathrm{kW})$

- Current total rate of fuel use, $Q_{\text {Fuel }}=\sum_{j} Q_{F u e l, j}\left(\mathrm{~kW}_{F u e l}, \mathrm{MJ}_{\text {Fuel }} / \mathrm{hr}\right.$, or Btu $\left.\mathrm{Buel}_{\text {Ful }} / \mathrm{hr}\right)$

- Current rate of expenditures on fuel, Cost $_{F u e l}=\sum_{j} Q_{\text {Fuel }, j}$ Price $_{F u e l, j}(\$ / \mathrm{hr})$

Average values of these metrics over various time intervals can also be constructed for each of them, e.g., average daily useful heat output, daily average hourly heat output, total daily heat output, and so forth for the other variables.

These indicators of overall system performance are supplemented with the component performance indicators to enable system-level and finer resolution performance monitoring and potentially fault detection and diagnostics in support of condition-based maintenance of CHP plants.

\section{CHP System-Level Input/Output Diagram}

The input/output diagram for system-level performance monitoring of a CHP system is shown in Figure 28. Arrows at the top of the diagram represent measured inputs, arrows on the left side of the diagram represent fixed inputs (relative to the time between samples of the measured inputs), and arrows at the bottom of the diagram represent outputs. The monitoring algorithms (represented by the box) are based on Eq. (54), Eq. (55) and the expressions for other monitored variables given above. In this diagram, the density, specific heat, and heating value of each fuel stream $(j)$ must be specified. Although the density and heating value of the fuels are assumed to vary slowly compared to the time between samples of the measured inputs and, therefore, are considered fixed inputs, they could be varied by changing their values periodically based on measurement of them or information from the fuel supplier. All individual useful thermal outputs $(j)$ must be specified to ensure proper crediting of outputs and their values $\left(Y_{t h, j}\right)$. 
System-level monitoring provides top-level indicators of the performance of the CHP plant and is supplemented by component monitoring, which provides greater detail and resolution.

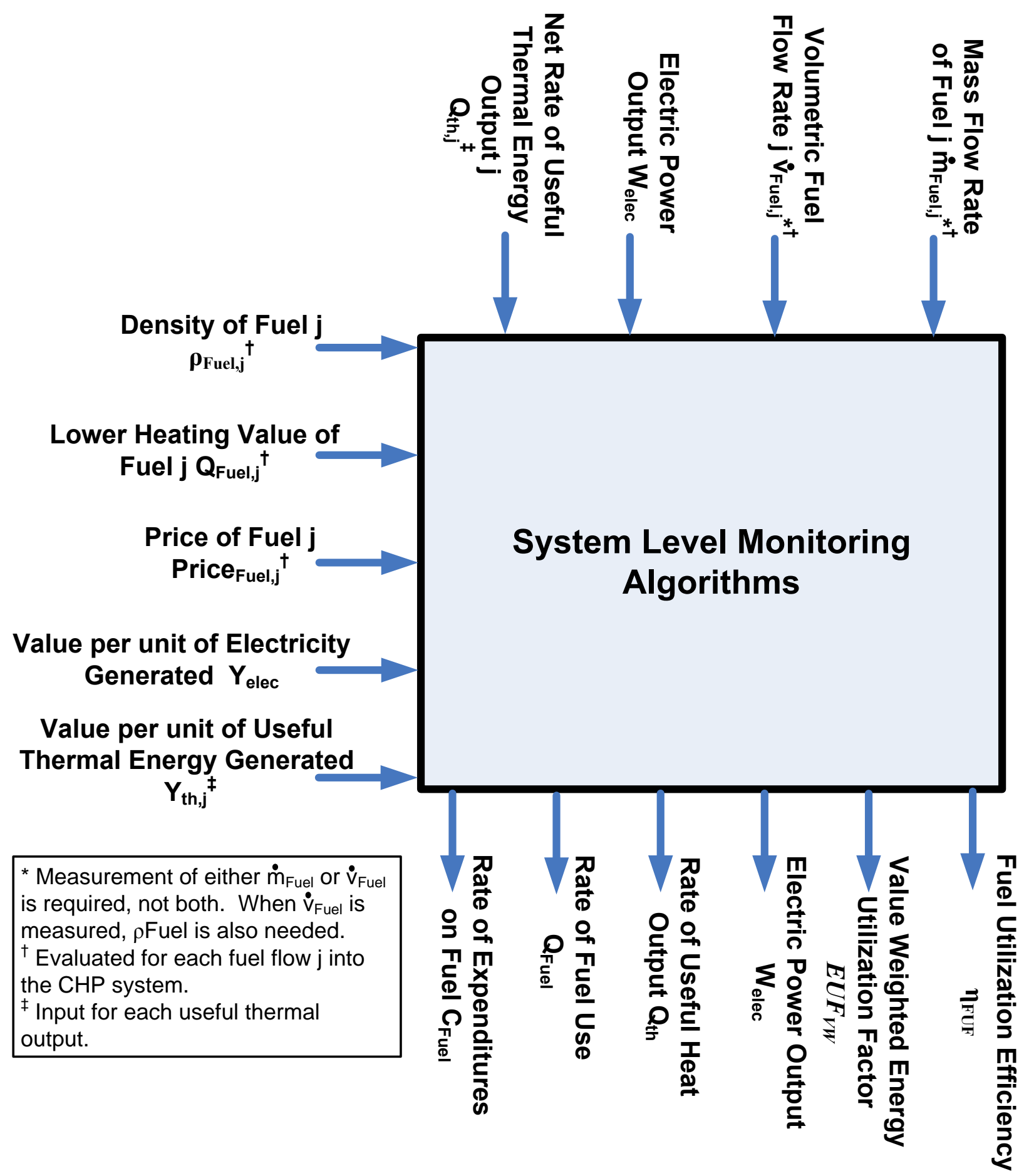

Figure 28 - System level CHP monitoring input/output diagram 


\section{Commissioning and Performance Verification}

Commissioning verification $(\mathrm{CxV})$ is a process by which the actual performance of the individual components in a CHP system and the performance of the CHP system as a whole are verified to comply with the designers' and manufacturers' specified and recommended performance. Furthermore, for new systems, commissioning should include a systematic series of activities, starting in the planning phase and continuing through design, installation, and startup, aimed at ensuring correct operation of the CHP system. Before start-up, the process should include inspection and testing of all components in the CHP system to ensure the correct components are installed, they are installed correctly, and they perform properly. A goal of this project is to automate parts of the process of verifying that commissioning has been done correctly and resulted in a CHP system that meets design and operation expectations. Although $\mathrm{CxV}$ can include active testing of components and sub-systems, in this project the intent is to focus on verifying performance to ensure that the system has been adequately commissioned and to identify components for which further commissioning is still needed when deficiencies are found.

Performance verification focuses on comparing the performance of the system and its major components to their original (commissioned) performance during routine operation of the CHP system. The purpose of performance verification is to ensure that peak performance is preserved during operation of the system and to provide a basis for condition-based maintenance and performance adjustments. When performance significantly deviates from the expected level (baseline), alarms are automatically triggered to alert operators to performance degradation so that actions can be taken to improve system performance and get it back to its expected level.

The $\mathrm{CxV}$ algorithms will provide the logic by which measurements of performance developed for performance monitoring are interpreted relative to performance expectations to identify any deficiencies in performance during initial operation of the CHP system. By verifying the performance of the individual components, deficiencies in overall system performance can be isolated so that follow up efforts can be targeted at the offending components. Some deficiencies may span multiple components of the system. In these cases, controls or other integration issues will be identified as needing rechecking and further commissioning. The performance verification algorithms satisfy a similar function during routine operation of the CHP system after start-up. The outputs of the $\mathrm{CxV}$ and performance verification algorithms are alarms, quantitative indicators of deficiencies, and supporting information to help guide corrective actions.

The rest of this section provides descriptions of the $\mathrm{CxV}$ processes and procedures, equations upon which the $\mathrm{CxV}$ and performance verification algorithms will be based, and input/output diagrams identifying all inputs and outputs associated with the algorithms.

\section{CHP System Commissioning}

Procedures for characterizing the performance of CHP systems and acceptance testing of some generic components used in CHP systems can be found in the literature (Southern Research Institute 2000, 2002, 2004; Connected Energy Corporation 2004). Standards for testing several CHP components are also available (ASME 1984, 1991, 1996, 1997; ANSI/ASME 1981; 
Cooling Tower Institute 2000), and manufacturers provide guidance for initial testing and startup of the components they manufacture, but the authors found no information published in the open literature on the overall commissioning process for CHP systems. Despite the lack of published information, CHP systems should be checked before and during initial operation; the planning and performance of these checking/verification activities in a systematic manner is the process of commissioning. Commissioning of a new CHP system should include the following major activities: ${ }^{15}$

- Develop commissioning plan

- Develop commissioning specifications

- Perform commissioning-focused design review

- Develop installation check lists

- Develop start-up and verification checks

- Develop functional tests

- Observe construction

- Perform checks of installed systems and equipment

- Witness start-up

- Perform functional tests

- Verify compliance with specifications and identify deficiencies

- Correct deficiencies

- Perform pertinent functional tests

- Verify performance

- Approve and report

- Continued commissioning over the life of the system.

When existing systems are commissioned, the steps associated with design are generally not possible, and the process must focus on evaluating the condition, performance and operation of the CHP plant. Using terminology parallel to that used by the building commissioning industry, this process for existing systems is called retro-commissioning and would have the following major activities: ${ }^{16}$

- Develop project objectives

- Review available documentation on the CHP system and historical fuel use and energy production data

- Develop a retro-commissioning plan

- Perform system assessment

- Develop diagnostic monitoring and test plans

- Execute diagnostic monitoring and tests

- Analyze results and identify deficiencies and potential improvements

- Implement repairs and improvements

- Retest and re-monitor to verify performance improvements

- Prepare report

- Resume or continue operation

- Re-commission as needed over life of the system.

${ }^{15}$ Adapted with changes from a description of the building commissioning process in PECI (2006).

${ }^{16}$ Adapted with changes from Haasl and Sharp (1999). 
The algorithms for performance monitoring and $\mathrm{CxV}$ developed in this project will make performance assessment, testing, and verification of performance improvements easier both during initial system start-up and later during operation of the system. Furthermore, the algorithms will provide a basis for automating these processes so they can be done continuously and corrective actions (maintenance) can be implemented when performance degradations necessitate. This will help keep CHP system performance at peak levels and enable continuous CHP system commissioning while the plant operates.

\section{Approach to Commissioning and Performance Verification}

The fuel utilization efficiency and electric power production will be used to monitor overall CHP system performance. The efficiency or effectiveness (as appropriate to the component) and other selected critical parameters will be used to monitor the performance of each of the major components of the CHP system (heat recovery units, chillers, cooling towers, desiccant systems, pumps and fans).

During system start-up, the performance of the overall system and individual components can be compared to manufacturer performance benchmarks to verify that the system and components are installed and operating properly. After the system is operating, a baseline can be empirically developed for each performance indicator from data collected over a "training period." The performance indicators can then be compared to these baselines to determine when performance has degraded significantly. A computer system implementing the algorithms should provide alarms when sufficiently large and statistically significant decreases from baseline performance values are detected, particularly when they persist over time. The performance indicators would always be available to operators to view, trends would be recorded, and alarms would prompt operations staff to investigate and assess whether degradations in performance warrant adjustments to operations or maintenance actions. This information should be presented to the operations staff continually to enable them to make timely decisions, preventing further system performance degradation and potential damage to equipment.

Detection of performance degradation is not as simple as comparing the actual current value of the performance indicator (e.g., fuel utilization efficiency) calculated from the latest values of the measured variables to a single fixed alarm threshold for that performance indicator. Because many of the performance indicators depend on the value of exogenous variables, their benchmarks will vary as the values of the independent exogenous variables change. For example, the fuel utilization efficiency of a turbine varies with ambient temperature. As a result, even when in perfect condition and fully commissioned, its fuel utilization efficiency will vary when the ambient temperature changes. As a result, the baseline for fuel utilization efficiency must be a function of ambient temperature (i.e., a line rather than a point).

The basis for a generic process for verifying proper performance or detecting performance degradation is shown in Figure 29. The performance indicator (efficiency or effectiveness) is some function of one or more independent explanatory variables (V), such as outdoor-air temperature. Given that this function can be determined for the initial, as properly commissioned, performance of the system or component, the current level of degradation is 


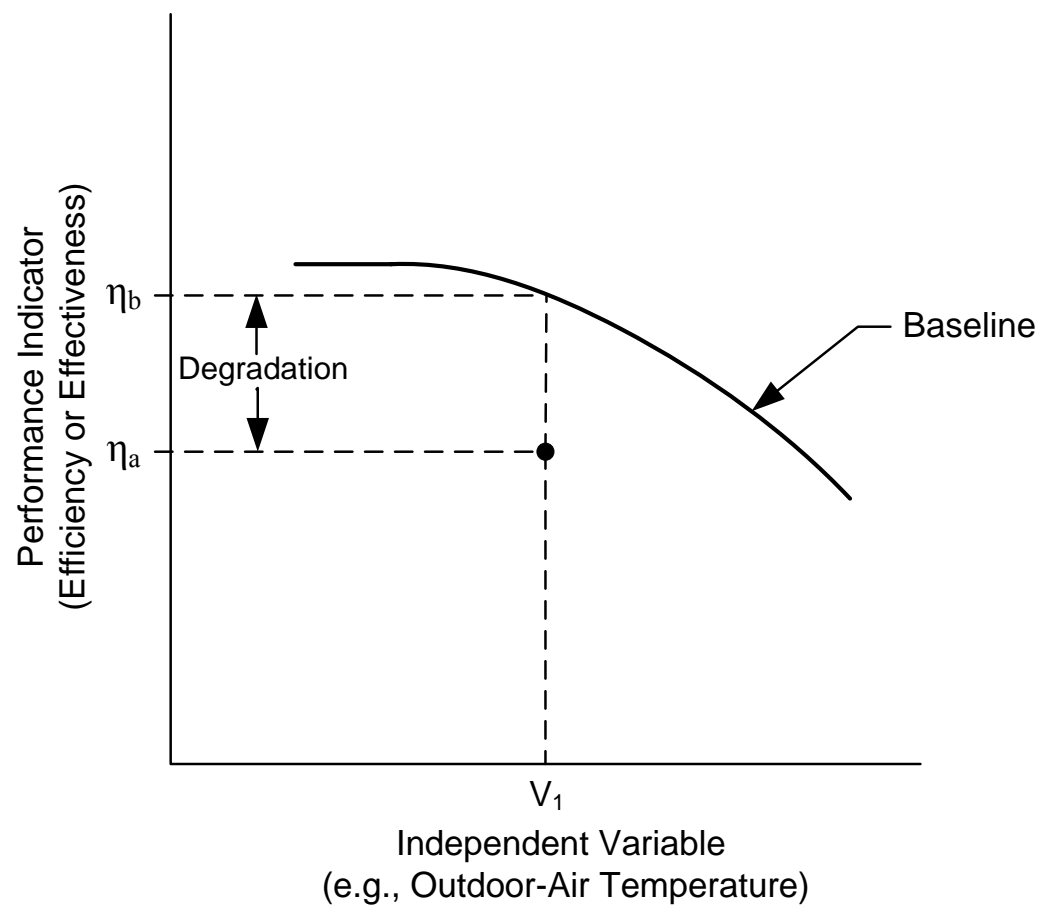

Figure 29 - Basis for generic performance verification and degradation detection process.

determined as the difference between the actual measured value of the performance indicator $\left(\eta_{\mathrm{a}}\right)$ and the baseline value $\left(\eta_{\mathrm{b}}\right)$ corresponding to the value on the baseline for the current value(s) of the explanatory variable(s) $\left(\mathrm{V}_{1}\right.$ in Figure 29$)$. The degree of degradation is the difference between these two values of the performance indicator, i.e.,

$$
\text { Degradation }=\eta_{b}-\eta_{a} \text {. }
$$

The baseline is determined empirically from actual performance data collected while the system is operating properly (presumably, early in its life after commissioning). In practice, however, this line is likely not well defined by two empirical measurements. Instead, measurements are likely to define a "thick line" or "cloud" of points. This is caused by three factors: 1) random error in empirical measurements, 2) the influence of other variables not explicitly accounted for in establishing the baseline, and 3) measurements made during transient operation of the system. Random measurement error is found in all measured quantities, the degree depending on the characteristics of the measuring system (e.g., a sensor and associated electronics). The second factor results when variations in the performance indicator occur from other physical conditions not explicitly included in the baseline function. This will result, for example, if the influence of an exogenous variable is unknown or deemed insufficient to warrant measuring and including in the baseline. An example of the latter may be the influence of ambient humidity on the combustion temperature of the fuel in a turbine. The effect of humidity variations on the actual fuel utilization efficiency may be very small compared to other factors, and, therefore, these variations might be neglected in establishing a baseline. The humidity variations will potentially cause several slightly different values of measured efficiency at each specific outdoor-air temperature. As a result, the data points form a thick line or cloud around an average line representing fuel utilization efficiency versus outdoor-air temperature (see Figure 30). 
(a)

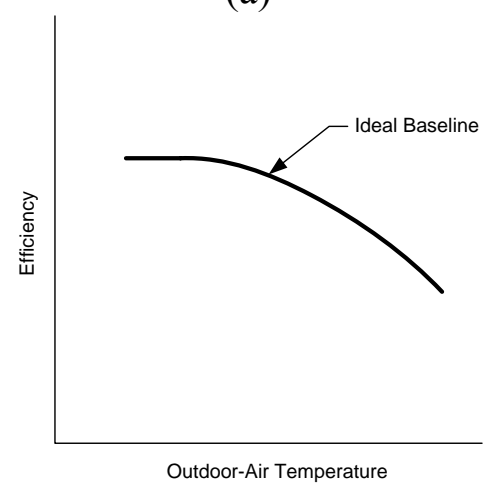

(b)

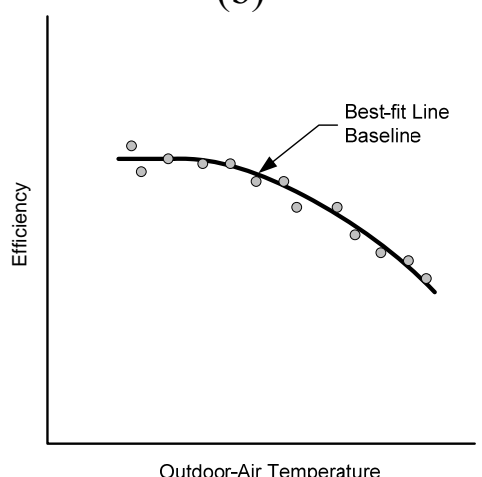

Outdoor-Air Temperature (c)

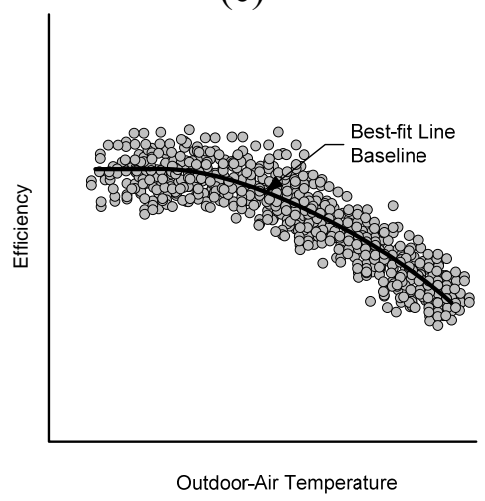

Figure 30 - Effect of non-explicit variables and measurement uncertainty on an empirically determined baseline: a) ideal baseline for efficiency a function of only outdoor-air temperature with perfect measurements, b) baseline developed from a relatively small number of measured points, and c) empirical baseline from a large number of points with significant measurement uncertainty and dependence on other variables.

When two variables have significant impacts on the performance indicator, both should be used to explain variations in the indicator, in which case the line becomes a surface. When more than two variables must be used to establish the baseline, they define a surface in multi-dimensional space. The amount of data required to establish the baseline increases rapidly as the number of variables used to explain variations increases, and a purely empirical method requires more data than can be collected over a reasonable period of time ("training period"). Therefore, for more than about two variables, this purely empirical method becomes impractical, and another method is required. For the components in the CHP systems considered in this project, we expect two or fewer explicit explanatory variables for each of our performance indicators to be sufficient and, as a result, a purely empirical method for establishing performance baselines will be used.

A threshold for the deviation of actual performance from the baseline performance can be used to decide when an alarm should be issued. An alarm is issued when

$$
\left|\eta_{b}-\eta_{a}\right|>\text { Alarm Theshold }
$$

Two primary factors should drive selection of the alarm threshold: 1) ensuring that the probability that Eq. (58) is satisfied is sufficiently large, given uncertainty in the underlying measured data; and 2) ensuring that other factors such as the energy and cost impacts of the deviation observed are sufficient to warrant an alarm to operators. The first is accomplished by statistically accounting for the uncertainty in the baseline and the uncertainty in the measurements of current conditions. By ensuring statistical significance, false alarms are largely prevented. ${ }^{17}$ Once uncertainty is adequately considered, the second is largely based on estimation of impacts and judgment of the significance of those impacts. In setting thresholds, it is important to avoid alarms becoming a nuisance by alerting operators to conditions they

\footnotetext{
${ }^{17}$ Even under the most stringent significance criteria, some false alarms may occur. The probability of a false alarm will approach but not reach zero.
} 
consider insignificant, even when they are statistically significant deviations from the baseline. This is especially important for new technologies, where if they become a nuisance, they will likely be ignored by users. So, for example, a cost threshold for importance of a problem (i.e., performance degradation) might be set and the corresponding deviation beyond statistical significance determined to establish the alarm threshold. In automating this approach in software, thresholds can be made adjustable so users can loosen or tighten them relative to initial default settings to customize the monitoring system's behavior.

\section{A Bin-Based Method for Baseline Performance}

We have found the modeling methodology presented in this section useful in establishing performance baselines for detecting anomalies in energy consumption by buildings (Katipamula et al. 2003) and plan to apply it in this project to CHP performance monitoring. It has the advantage that it can capture both linear and non-linear behavior. The method is based on the concept of data bins borrowed from the field of building energy data analysis. A bin is an interval (bin) of values of an independent variable with which a value of another (dependent) variable is associated. For example, the weather at a location can be characterized by the number of hours per year on average that the outdoor-air temperature falls into $5^{\circ} \mathrm{F}$ bins between some minimum temperature and some maximum temperature, as shown in Figure 31. Similarly, bins can be defined for energy uses that are correlated with outdoor-air temperature (e.g., energy use for cooling a building; see Figure 32).

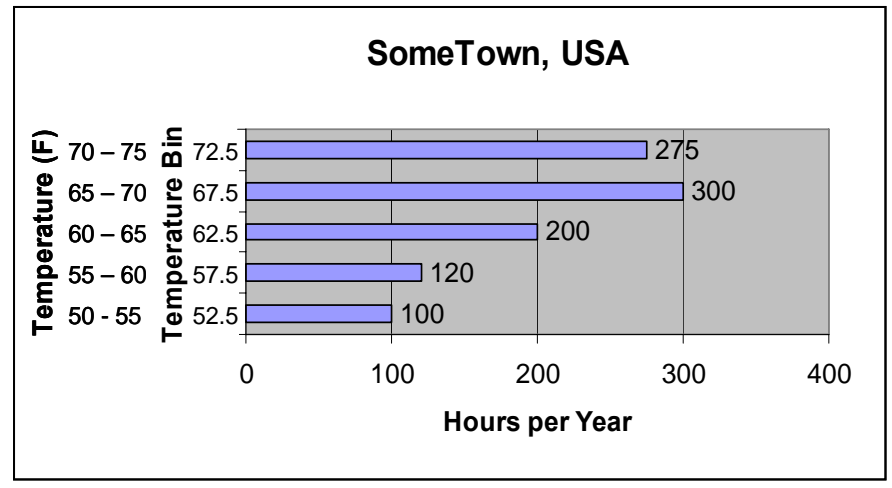

Table of Temperature Bins for SomeTown, USA

Figure 31 - Temperature bins are shown for a fictitious location in the U.S.

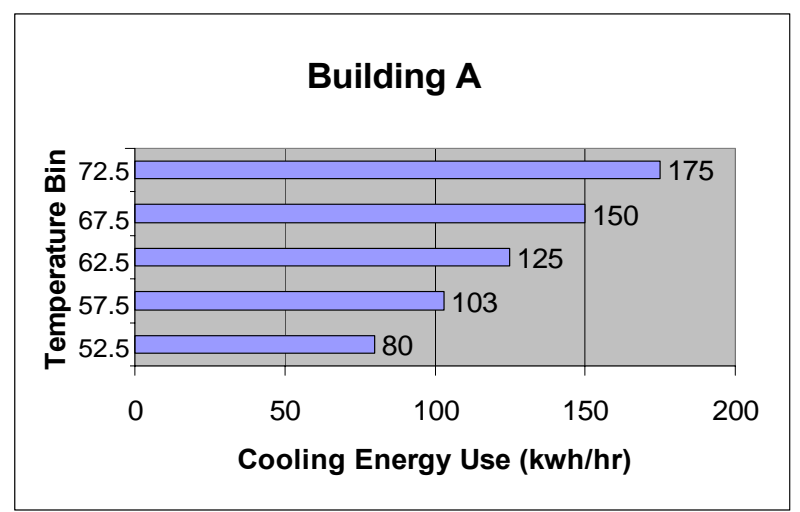

Cooling Energy Bins for Building A

\begin{tabular}{|c|c|}
\hline Bin $\left({ }^{\circ} \mathrm{F}\right)$ & $\mathrm{kWh} / \mathrm{hr}$ \\
\hline 72.5 & 175 \\
\hline 67.5 & 150 \\
\hline 62.5 & 125 \\
\hline 57.5 & 103 \\
\hline 52.5 & 80 \\
\hline
\end{tabular}

Figure 32 - Example of bins for cooling energy use by a building. 
When multiple variables are used to explain the variations in energy use multi-dimensional bins can be used, where a multi-dimensional bin is defined as the intersection of one-dimensional bins based on each of the variables. This is shown in Figure 33 for three-dimensional bins that characterize a variable such as energy use in terms of three explanatory variables. A representative value of the dependent variable is assigned to each bin defined by the ranges of values of the independent variables. For an energy use model, the dependent variable is energy consumption. For an energy production model, for example a turbine, the dependent variable is the amount of energy produced.

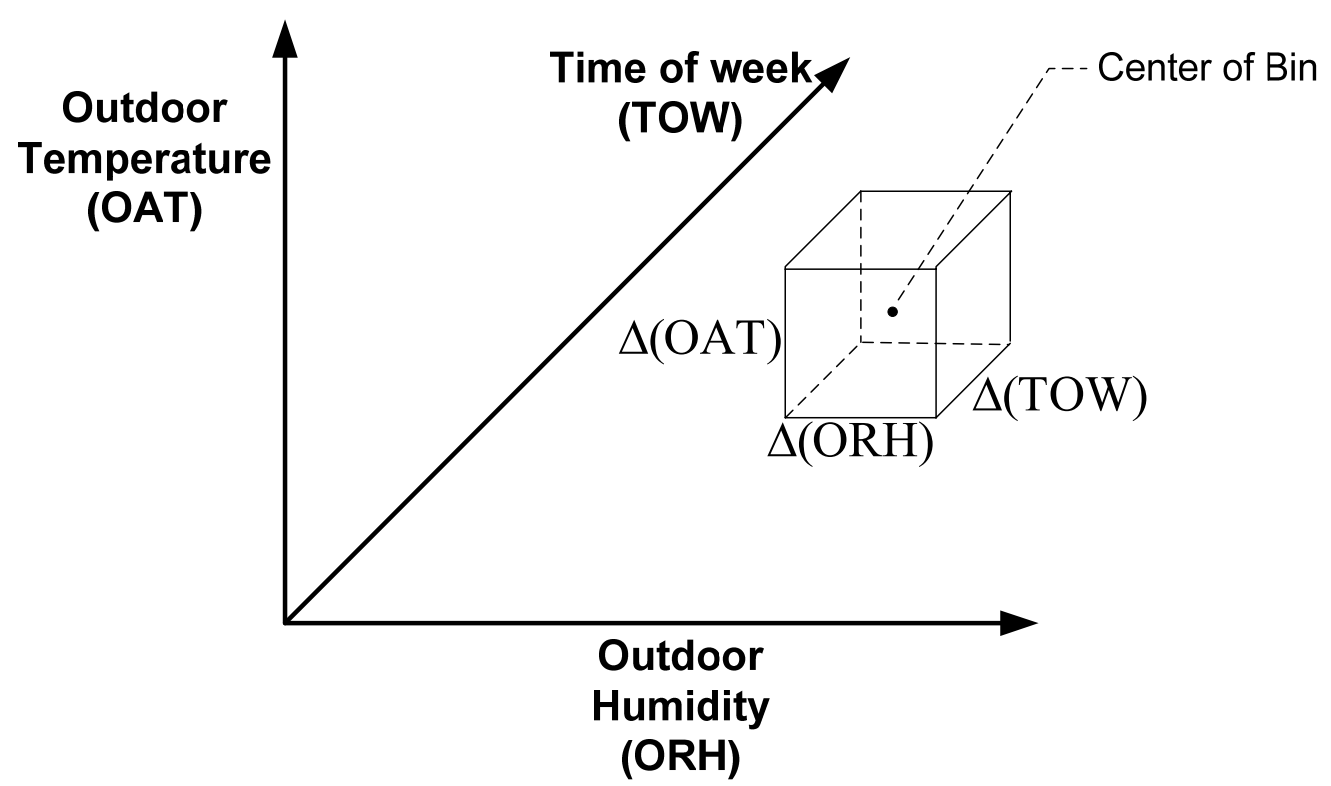

Figure 33. An example three-dimensional binning scheme with bins defined by three explanatory variables: outdoor-air temperature, outdoor-air humidity, and time of week.

The model is "trained" by collecting data empirically and assigning it to bins. Given a sample of empirical data with each set of the sample consisting of a values for a complete set of $\mathrm{N}$ independent explanatory variables $\left(\mathrm{x}_{1}, \mathrm{x}_{2}, \mathrm{x}_{3}, \ldots, \mathrm{x}_{\mathrm{N}}\right)$ and the corresponding measured value of the dependent variable, an $\mathrm{N}$-dimensional model is created by assigning each set of data in the sample to the bin in which the point defined by the values of its independent variables lies. An example bin is shown in Figure 34. When a sufficient number of points have been assigned to each bin, the model is considered fully "trained." A representative value of the dependent variable is then assigned to each bin, completing the model. The median of the values of the dependent variable in the bin makes a good representative value for both large and small numbers of points per bin.

Once the model is trained, it is used to estimate baseline values of the dependent variable [e.g., the CHP system efficiency or the efficiency or effectiveness of an individual CHP component, $\eta_{b}$ in Eq. (57) and Eq. (58)] given a set of measured values for the independent variables. The bin model represents the baseline behavior of the system or component during the training period. 


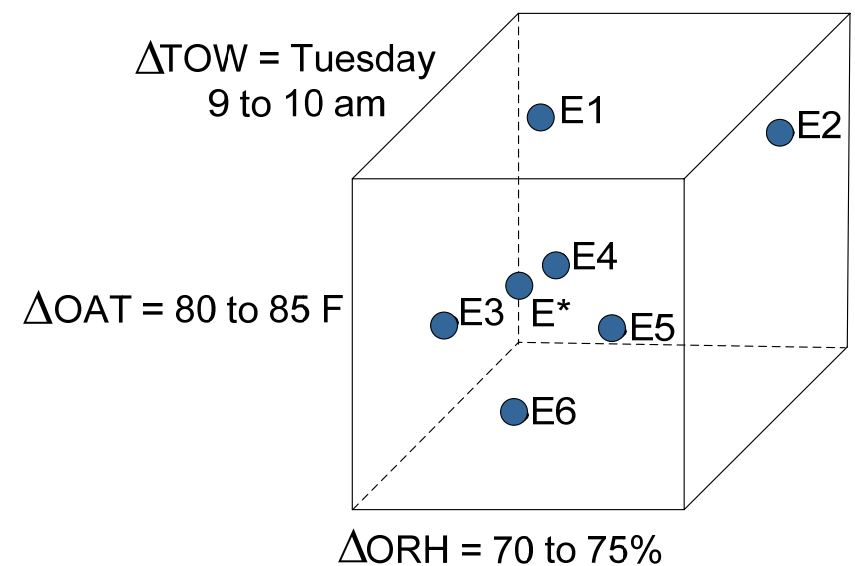

$$
\begin{aligned}
E^{*} & =\text { Representative Value of } E \\
& =\text { Median }(E 1, E 2, E 3, E 4, E 5, E 6)
\end{aligned}
$$

Figure 34 - An example three-dimensional energy bin is shown for outdoor-air temperature (OAT), time of week (TOW) and outdoor relative humidity (ORH) as the independent variables. Points corresponding to sets of independent variable values and their corresponding energy values, $E_{i}$, that fall in the ranges defined by this bin are shown as points inside the bin.

To maximize use of training data and potentially minimize the length of the training period required to obtain adequate data, we introduce the concept of dynamic bins to this approach to modeling. In this approach, the bins are not defined a priori with data assigned to them. Instead, bins are defined as needed around a center point defined by the current values of the independent variables (thus the term "dynamic bins"). Only one bin is defined at a time, as needed. For example, for the independent variables used in Figure 33 and Figure 34, the point might be defined, for example, as 9:30 am on Tuesday (TOW $=57.5)$, outdoor-air temperature (OAT) of $82.5^{\circ} \mathrm{F}$ and outdoor-air relative humidity $(\mathrm{ORH})$ of $72.5 \%$. The coordinates of this bin would then cover the independent variable intervals $\mathrm{TOW}=57.5 \pm \Delta \mathrm{TOW} / 2, \mathrm{OAT}=82.5 \pm \Delta \mathrm{OAT} / 2$ and $\mathrm{ORH}=72.5 \% \pm \Delta \mathrm{ORH} / 2$. For $\Delta \mathrm{TOW}=1$ hour, $\Delta \mathrm{OAT}=5^{\circ} \mathrm{F}$ and $\Delta \mathrm{ORH}=5 \%$, the bin is defined as shown in Figure 34. All values for the independent energy variable for points in the training data set within the limits of this bin are then assigned to the bin.

An example application of this model to energy use by a chiller is shown in Figure 35 and Figure 36. In Figure 35, plots of actual measured energy consumption and corresponding values of the expected energy consumption of a chiller are shown for a 3-month period in 2002. Values of expected energy consumption were generated using a bin-based model and corresponding values for the independent variables during this time period. The top plot in Figure 36 shows the same data with expected energy consumption plotted on top of actual energy consumption, clearly revealing the differences. The bottom plot shows an energy consumption index for the same data defined as the ratio of actual to expected energy consumptions. This plot shows that the chiller is consuming more energy than it would have if maintained in its baseline (training-period) state.

Small circles have been added in the bottom plot of Figure 36 to highlight points at which a diagnostic algorithm assigned alarms to these deviations. These alarms would indicate to system operators that the deviation represents sufficient performance degradation to deserve further assessment.

The bin-based model possesses several characteristics that contribute to its strength for use in establishing performance monitoring baselines. It is conceptually simple and as a result, 

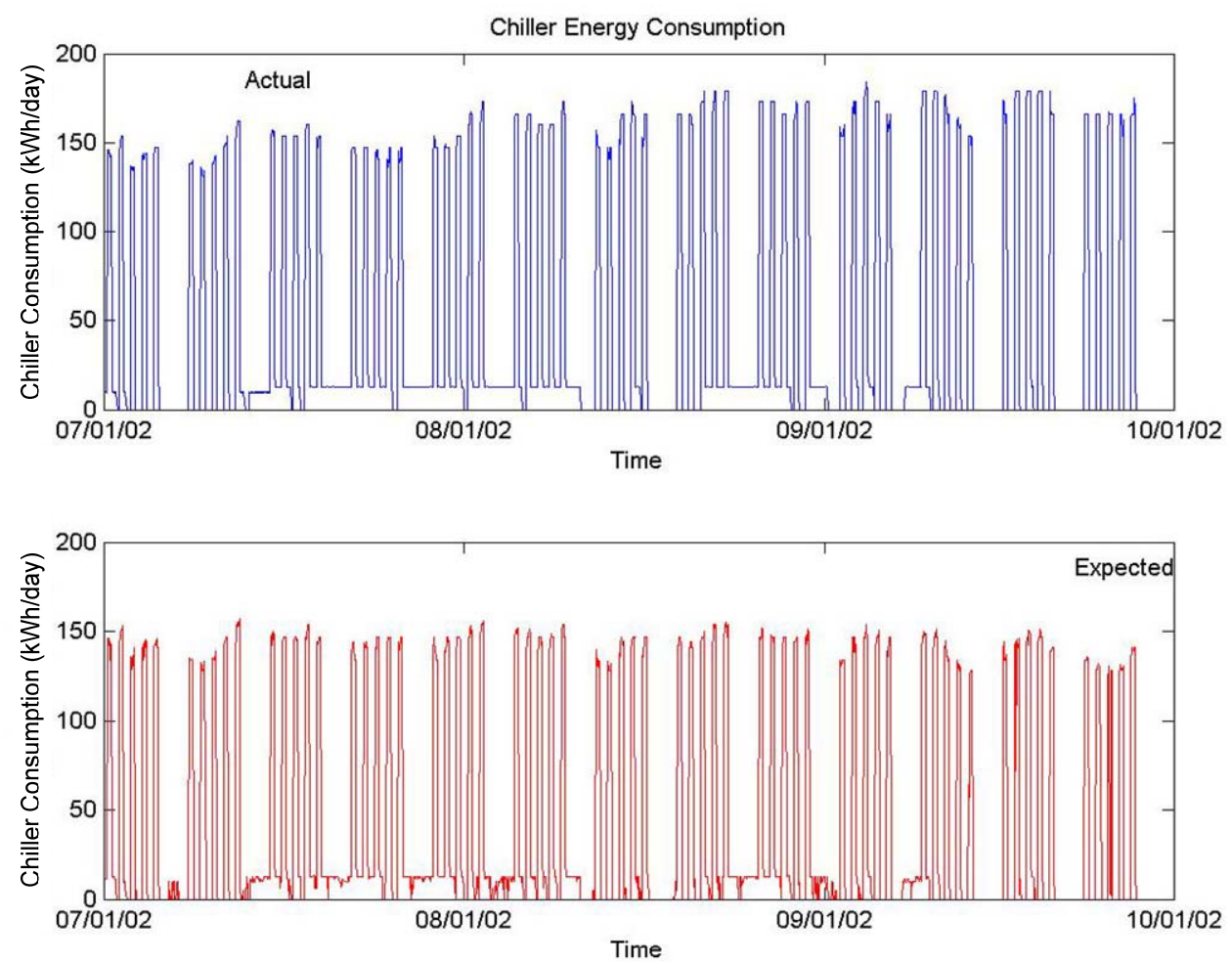

Figure 35 - The actual measured energy consumption (top) and expected energy consumption (bottom) from a bin-based model for a chiller are shown.
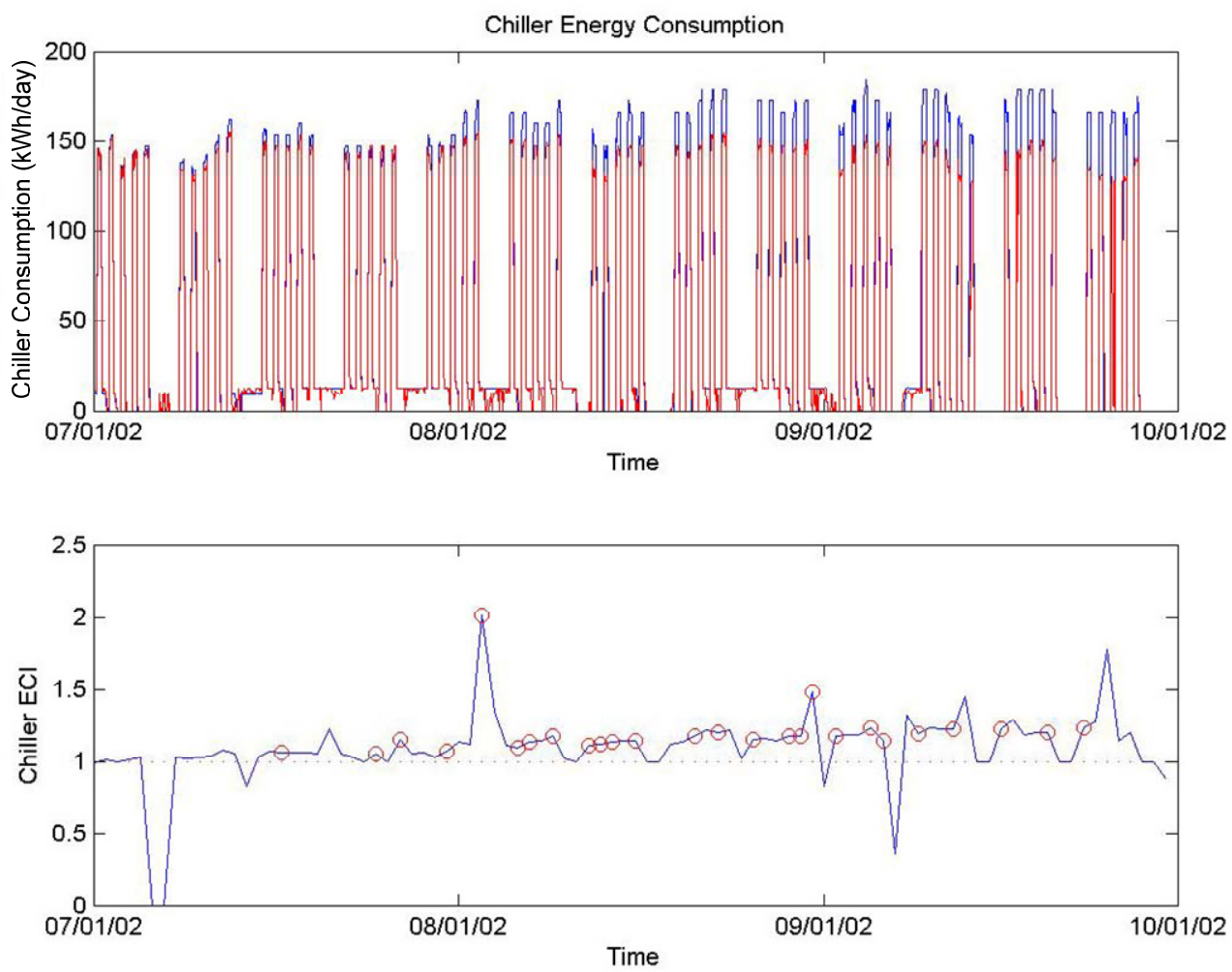

Figure 36 - Actual measured and expected energy consumption (top) and an Energy Consumption Index (bottom) are shown for the chiller in Figure 35. 
potentially appealing to users in the field. Operations staff abhor black boxes that they simply do not understand. A simple model facilitates understanding and provides an initial basis for establishing user trust in the method. Furthermore, this model has proven effective in establishing baselines for other diagnostic problems, i.e., tracking the performance of energy using systems and equipment in buildings. The method is flexible, accommodating whatever independent explanatory variables are appropriate to the system or component, and can be customized to an application's unique characteristics. Bin widths can be adjusted to tune the model to capture features of most importance. Application to building energy tracking has shown that for applications with slowly changing driving conditions (values of independent variables), the model can even be applied usefully while it is still undergoing training. Moreover, the model can capture both linear and non-linear relationships between the dependent and independent variables and transitions from regions of linear behavior to regions of non-linear behavior smoothly.

The model also possesses a few weaknesses that must be noted and assessed during application. When used to establish a performance baseline with which to compare future performance as a means to detect performance degradation, the model will absorb any degradation occurring during the training period. If the degradation is only apparent (i.e., associated with spurious measurements), it will not affect the resulting model, but if the degradation is real, persistent, or part of a trend, it will affect the model, and the model will represent behavior with some degradation present. Therefore, the best training data are measurements made during system/component operation for which performance is known to be good or proper. Accordingly, we recommend that training data be acquired over a time period immediately following verification of system commissioning or re-tuning of system operations, when performance is known (or more likely) to be at its peak.

The bin-based modeling approach is only practical for a small number of variables because the amount of data required for training grows rapidly with the number of independent explanatory variables. We generally use a rough guide of no more than three independent variables and even this depends on the range of each of the variables, the bin dimension for each variable, the frequency of data collection, and the range of operating conditions.

Finally, no physics are captured in the structure of the model. The model has essentially no structure, which makes it flexible, but as a result it has no underlying functional form from which physical relationships are easily derived. Therefore, it has little value to providing underlying knowledge of how and why a system or device behaves the way it does, but this is not the intent of the proposed application, which is merely to establish a baseline for comparison of values of performance indicators in the future to those captured by the baseline.

\section{Input/Output Diagrams}

This section provides the input/output diagrams for the $\mathrm{CxV}$ and performance verification algorithms. 


\section{Commissioning Verification Input/Output Diagrams}

A generic input/output diagram for $\mathrm{CxV}$ is shown in Figure 37. Arrows at the top of the diagram represent inputs based on values calculated in the performance monitoring algorithms for the CHP system or a component. The inputs are the actual values of the performance indicator and the uncertainty of the value. The arrow on the left is a commissioning benchmark $\left(\eta_{\mathrm{Cxb}}\right)$ based on the manufacturer's claimed or warranted performance, which may be for a single operating point (set of conditions) or several points for which the operating conditions are specified. The actual value must be taken at conditions corresponding to the benchmark conditions, or the $\mathrm{CxV}$ algorithm must adjust the value based on measured conditions to the conditions corresponding to the benchmark. The commissioning verification alarm threshold is also a fixed input that establishes the deviation of actual performance from the baseline performance to decide when an alarm should be issued. The arrows at the bottom of the diagram represent the outputs of the $\mathrm{CxV}$ algorithm. The comparison provided by the $\mathrm{CxV}$ algorithm is based on Eq. (58). The generic algorithm applies to all CHP components as well as the overall system.

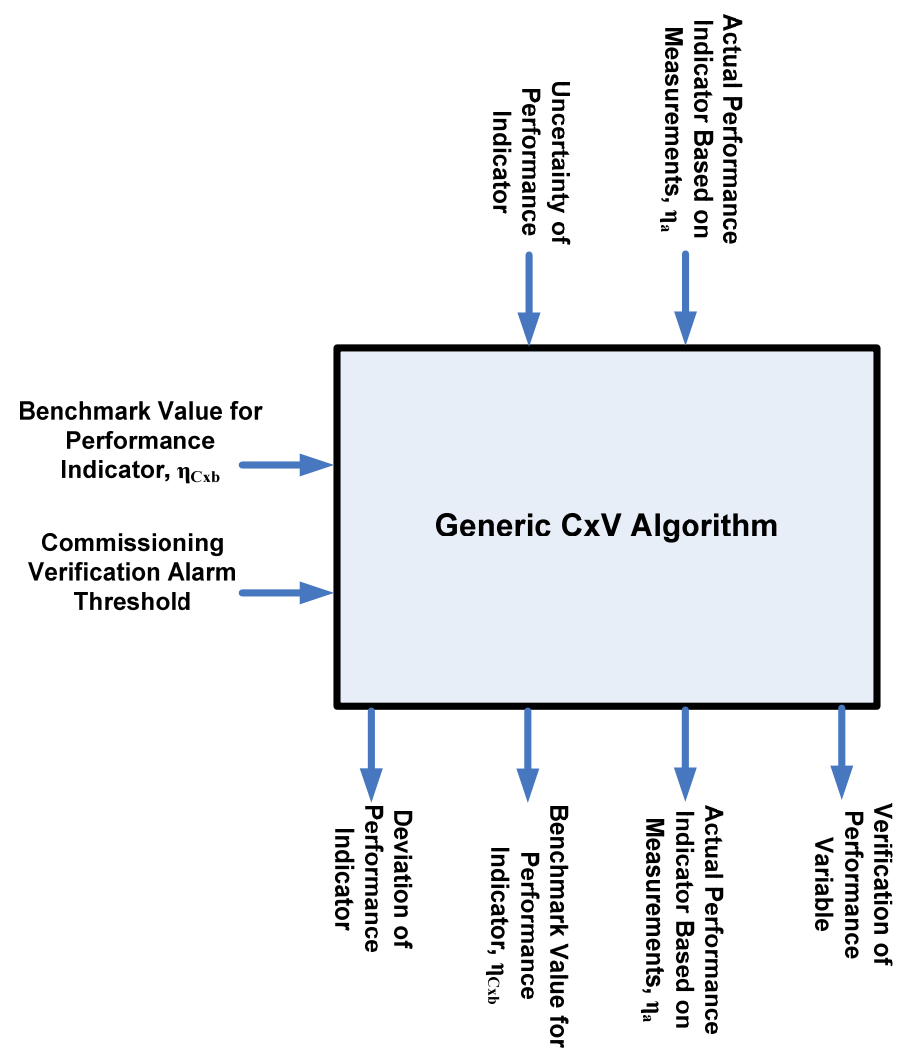

Figure 37 - Input/output diagram for the $\mathrm{CxV}$ algorithms.

When a component or the overall CHP system does not conform to expectations as indicated by the verification of performance variable, the offending component should be re-commissioned to improve its performance. Proper performance can then be verified using the corresponding $\mathrm{CxV}$ algorithm. When the overall CHP system does not satisfy $\mathrm{CxV}$, individual components might be the cause, in which case they individually would not pass verification, or the integration of the components, for example by the control system, may be faulty. After examination and correction, the system should pass $\mathrm{CxV}$. 


\section{Performance Verification Input/Output Diagrams}

A generic input/output diagram for performance verification during routine operation of the CHP system is shown in Figure 38. Measured input variables are shown at the top of the diagram. These include the actual value of the performance indicator based on measured conditions, the values of the measured driving conditions used in the baseline model, and the uncertainties associated with all measured variables. The model itself is part of the performance verification algorithm.

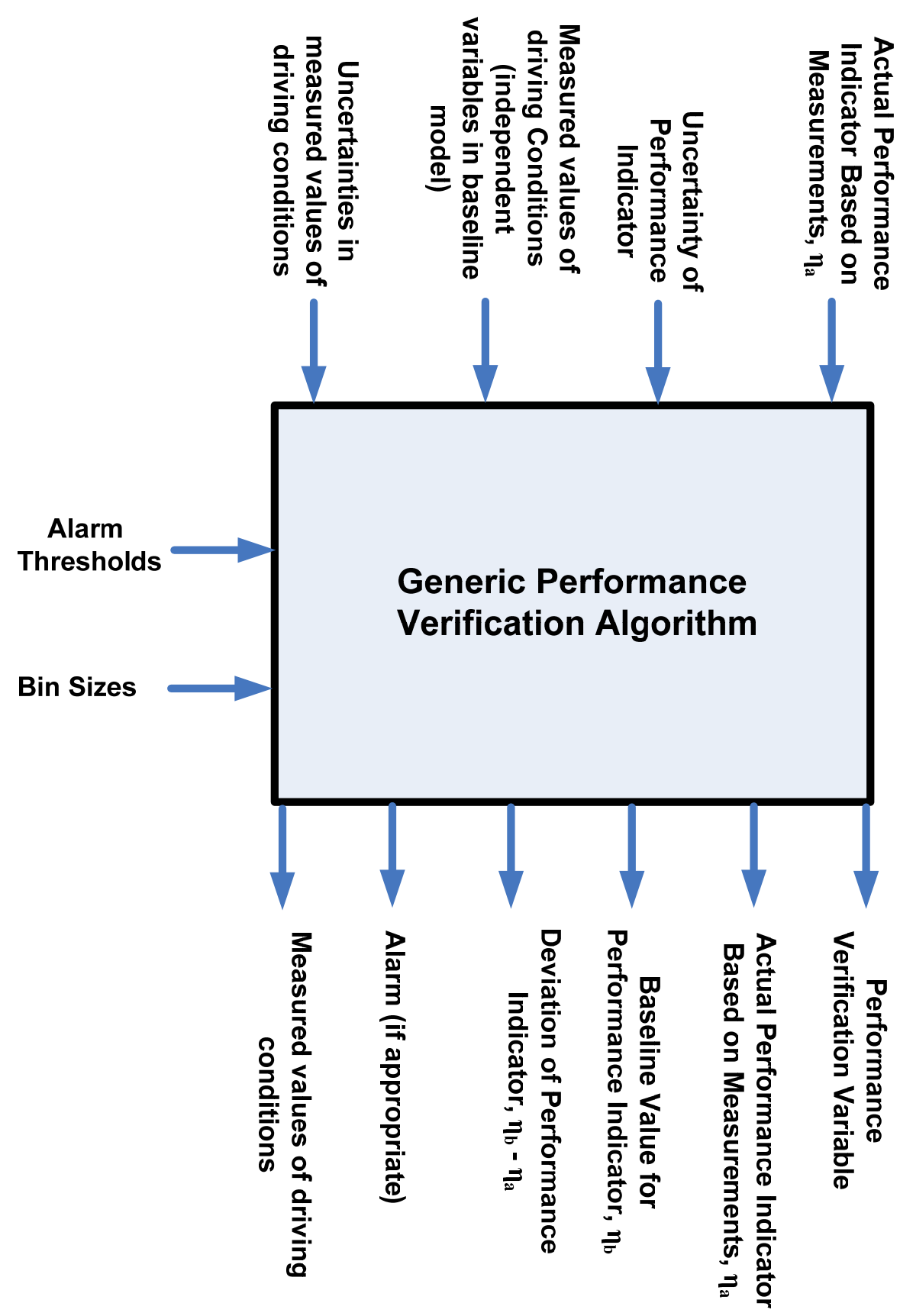

Figure 38 - Generic input/output diagram for performance verification. 
Fixed inputs are shown on the left side of the diagram and are input by the user. The outputs are shown at the bottom of the diagram and include the performance verification variable, which indicates whether the measured value of the performance indicator is sufficiently close to the baseline value for the current conditions, the actual value of the performance indicator, the baseline value for the performance indicator, the deviation of the actual measured value of the performance indicator from its baseline value, an alarm if the deviation exceeds the alarm threshold, and the current values of the driving conditions (independent variables in the baseline model). The bins used for modeling are created on an as-needed basis as part of the performance verification algorithms (the box in Figure 38)

Performance verification could be done on a continuous basis with the variables aggregated (e.g., summed or averaged) over appropriate time intervals. The output will enable system operators to detect unusual degradations in performance, which could indicate immediate operation problems, or gradual degradation over time, which could indicate a need for maintenance, repair, or an adjustment to operations. Alarms are provided to direct operator attention to significant deviations from expected performance. 


\section{CHP Performance Monitoring (PM) and Commissioning Verification (CxV): Algorithm Deployment Scenario}

This section addresses how the algorithms developed in this project could be used in start-up and operation of a CHP system. The algorithms could be deployed in a number of different ways, including embedding them in controllers used to control the CHP components or developing a software application that runs on an independent plant computer platform. In this section, we describe a hypothetical deployment scenario in which the algorithms under development in this project for $\mathrm{CHP}$ system monitoring and $\mathrm{CxV}$ are deployed to monitor and perform verification of start-up operations of a CHP plant on an independent computer platform.

The major elements of the CHP software application as shown in Figure 39 are: 1) a process to record sensor and control data from the CHP system, 2) a database to store the information, 3) a set of processes to pre-process the raw data (e.g., perform quality control, conversions of units, aggregate data over time, etc.) and post the data back into the database, 4) a set of algorithms that are used to process the raw data to generate useful results, 5) a process that allows users to configure the CHP application and view configuration settings using a web browser and 6) a process that enables users to view the results in a web browser.

Many of the implementation details are not discussed here because the scope of the current project is to develop the algorithms, not a tool for deployment. Still we provide this example to illustrate for the reader how these algorithms could be deployed in practice. The algorithms provide the basis for tools that could be developed in a follow-on project or by manufacturers and third-party service providers. We anticipate that most tools developed in the future will be web-based, so users of the tools will not need to install any special software on their computers to either configure the CHP application or review results. We anticipate that the raw data from various sensors and control points in a CHP plant are recorded in a database periodically (for example, at 1 minute to 15 minute intervals); these data are then periodically pre-processed to generate additional (derived) data. The pre-processed data, for example, can be simple aggregations of sub-hourly data into hourly values or calculations of derived engineering quantities (for example, the COP, which is calculated using data from a number of primary sensors). It can also involve calculation of moving averages for certain measured quantities. The results of pre-processing are written back into the database. A set of algorithms, either continuously or periodically, analyzes both the raw and pre-processed data to generate useful information and post it back to the database. Users can then review the results or the system can provide alarms and suggestions to users through the web browser. 


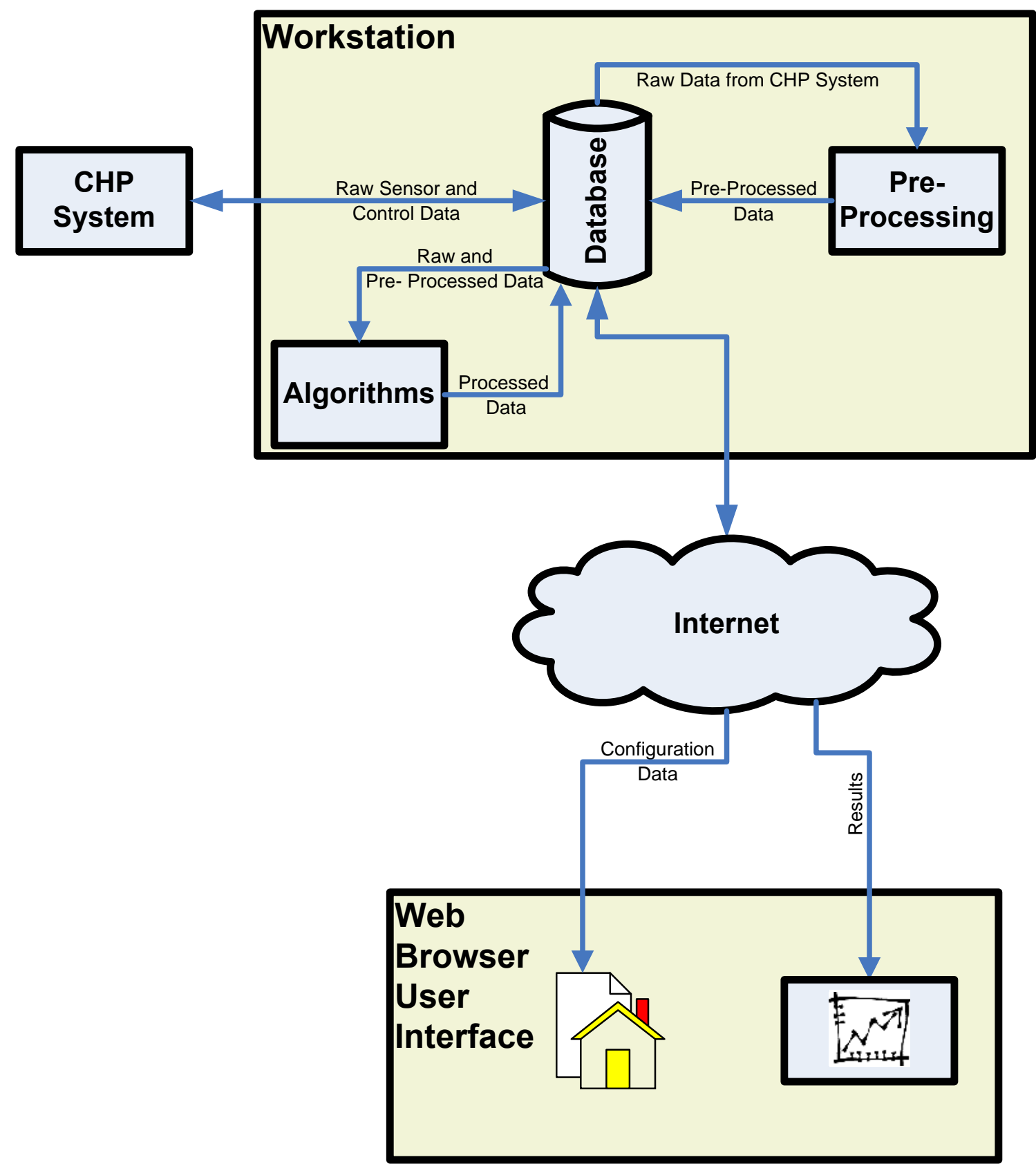

Figure 39 - A potential system architecture for a CHP monitoring and commissioning-verification software system using the algorithms developed in this project. 


\section{CHP Performance Monitoring and Commissioning Verification: Application Scenarios}

In this section, we describe two hypothetical scenarios in which the algorithms under development in this project for CHP system monitoring and $\mathrm{CxV}$ are used in the start-up and operation of a CHP plant. The plant in this scenario uses a small natural-gas-fired turbine as the prime mover with heat recovered from the exhaust to produce hot water. The hot water is used to fire an absorption chiller to provide cooling to a commercial building (see Figure 40). A duct burner fired with natural gas is used to provide supplemental heat to the absorption chiller to meet building needs when cooling demand exceeds the capacity provided by the exhaust alone.

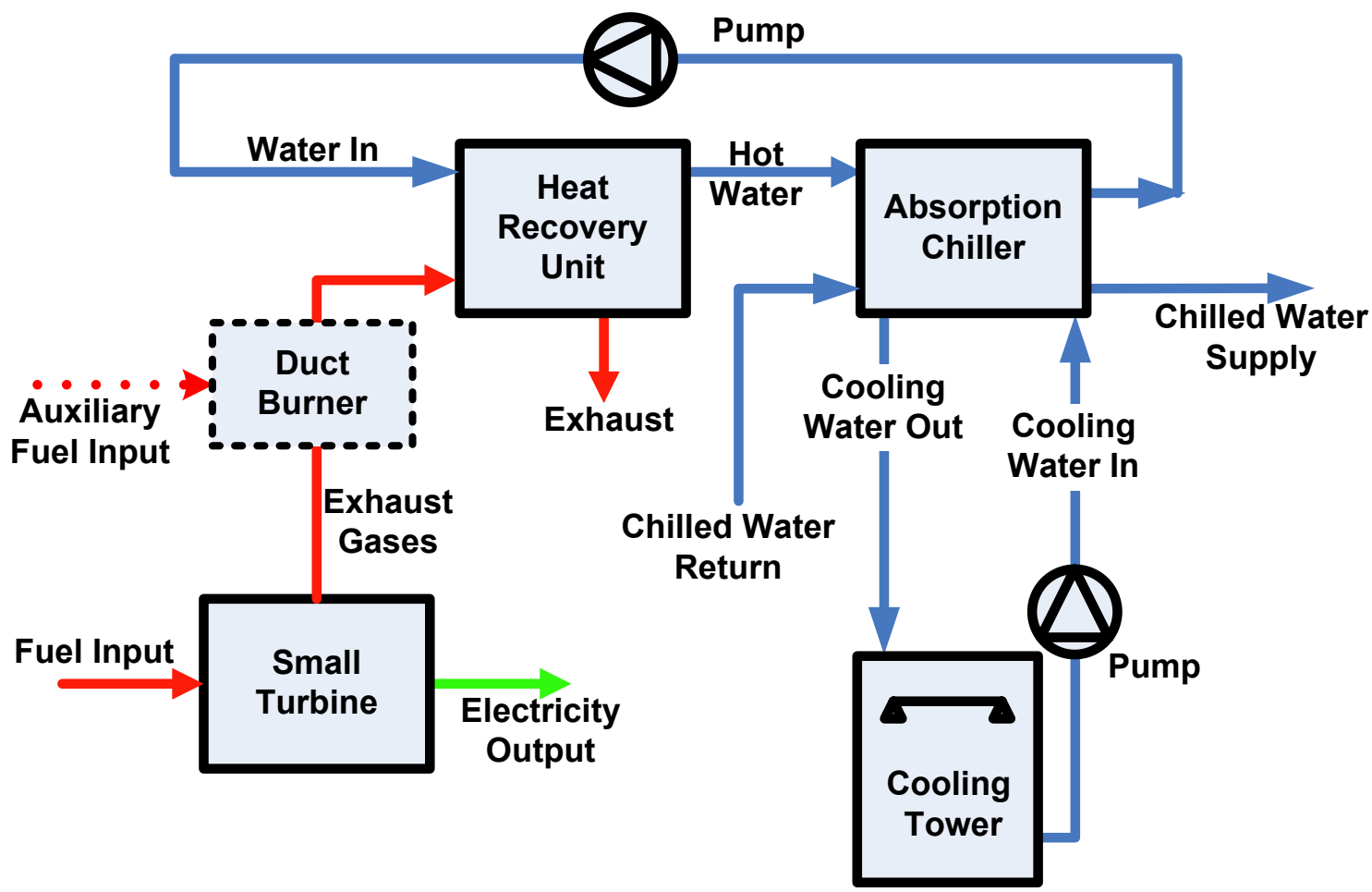

Figure 40 - CHP system used in application scenario.

The CHP system is rated at $1 \mathrm{MW}_{\mathrm{e}}$ and produces about $1.7 \mathrm{MW}_{\text {th }}$ of useful heat, which is available to the absorption chiller in the form of hot water at $257^{\circ} \mathrm{F}\left(\approx 125^{\circ} \mathrm{C}\right)$. Chilled water is supplied by the chiller at approximately $45^{\circ} \mathrm{F}\left(\approx 7^{\circ} \mathrm{C}\right)$ for use in cooling a commercial building. The COP of the absorption chiller is about 0.70 . The local price of natural gas to fuel the turbine and auxiliary duct burner is currently about $\$ 1.00 /$ therm $(\approx \$ 9.50 / \mathrm{GJ})$, and the price of electricity is $\$ 0.10 / \mathrm{kWh}$. The value of the cooling provided (based on comparison to cooling from a vaporcompression air conditioner and electricity at the price indicated) is approximately $\$ 0.035 / \mathrm{kWh}_{\text {th }}$ (\$10.25/million Btu) of cooling.

A scenario describing the use of monitoring is presented first and is followed by a scenario illustrating the use of the commissioning verification process. 
The monitoring system provides continuous streams of data for the following efficiency and effectiveness metrics:

- Value-weighted energy utilization factor, $E U F_{V W}$

- System fuel utilization efficiency, $\eta_{F}$

- Electric generation efficiency, $\eta_{E E}$

- Heat recovery unit effectiveness, $\varepsilon_{H R U}$

- Absorption chiller coefficient of performance, $C O P_{A b C h i l l e r}$

- Cooling-tower efficiency, $\eta_{C T}$

- Cooling-tower electric utilization efficiency, $\eta_{C T}$, Elec

- Cooling-tower pump efficiency, $\eta_{\text {Pump }}$.

In addition, the system provides real-time monitoring for the following conditions:

- Fuel input rate to the turbine, $\rho_{\text {Fuel }} \dot{v}_{\text {Fuel,Turbine }} L H V_{\text {Fuel }}$

- Auxiliary fuel input to duct burner, $\dot{v}_{F u e l, A u x}$

- Exhaust-gas temperature, $T_{\text {Turbine, ex }}$

- Rate of useful heat output, $Q_{t h}$

- Chilled-water supply temperature, $T_{\text {evap }, w, o}$

- Chilled-water return temperature, $T_{\text {evap }, w, i}$

- Temperature of water entering the HRU, $T_{H R U, w, i}$

- Temperature of water leaving the HRU, $T_{H R U, w, o}$

- Exhaust-gas temperature leaving the HRU, $T_{H R U, e x, o}$

- Current electric power output, $W_{\text {Elec }}(\mathrm{kW})$

- Average daily electric energy output, $\int_{0}^{24 h o u r s} W_{\text {Elec }} d t(\mathrm{kWh} / \mathrm{day})$

- Average electric power output over the last $n$ hours, $\int_{t-n}^{t} W_{E l e c} d t / n(\mathrm{~kW})$

- Daily average hourly electric power output, $\int_{0}^{24 h o u r s} W_{E l e c} d t / 24(\mathrm{~kW})$

- Cooling-tower water inlet temperature, $T_{C T, w, i}$

- Cooling-tower outlet temperature, $T_{C T, w, o}$

- Cooling-tower approach, $T_{C T, w, o}-T_{w b}$

- Cooling-tower range, $T_{C T, w, i}-T_{C T, w, o}$

The system monitors these performance parameters and conditions and provides alarms to the operators when conditions deviate significantly from baseline values. A hypothetical sequence of values is shown in Table 2 to illustrate a scenario where monitoring of these parameters assists operators in detecting and correcting a system performance problem much quicker than would be possible without such a monitoring system. Monitoring of an actual system would likely be done using a much shorter time interval than the 30-minute interval used in the table. Thirty minutes has been used for illustrative purposed. 
Conditions at 13:00 are consistent with those for several immediately preceding time steps (values not shown in the table), and the system is running properly. At 13:30, deviations for a few performance variables $\left(C O P_{A b C h i l l e r}, \eta_{C T}, Q_{t h}\right.$, and $\left.T_{C T, w, o}\right)$ from the values at 13:00 can be seen, but their magnitudes are so small that no problems are apparent. In fact, these deviations are all within the range of normal variations likely to be observed during normal, fault-free, operation.

Table 2. Sequence of monitored values for performance parameters and physical conditions.

\begin{tabular}{|c|c|c|c|c|c|}
\hline Time & $13: 00$ & $13: 30$ & 14:00 & $14: 30$ & $15: 00$ \\
\hline $\boldsymbol{E} \boldsymbol{U} \boldsymbol{F}_{V W}$ & 1.12 & 1.12 & 1.07 & 1.12 & 1.12 \\
\hline$\eta_{F}$ & 0.59 & 0.59 & 0.54 & 0.59 & 0.59 \\
\hline$\eta_{E E}$ & 0.27 & 0.27 & 0.27 & 0.27 & 0.27 \\
\hline$\varepsilon_{H R U}$ & 0.63 & 0.63 & 0.54 & 0.62 & 0.63 \\
\hline$C O P_{A b C h i l l e r}$ & 0.70 & 0.68 & 0.60 & 0.68 & 0.70 \\
\hline$\eta_{C T}$ & 0.71 & 0.70 & 0.52 & 0.68 & 0.71 \\
\hline$\eta_{C T, \text { Elec }}$ & 7.0 & 7.0 & 3.5 & 6.5 & 7.0 \\
\hline$\eta_{\text {Pump }}$ & 0.65 & 0.65 & 0.65 & 0.65 & 0.65 \\
\hline $\begin{array}{c}Q_{\text {Fuel,turbine }} \\
=\rho_{\text {Fuel }} \dot{v}_{\text {Fuel,Turbine }} L H V_{\text {Fuel }}(\mathrm{kW})\end{array}$ & 3703 & 3703 & 3703 & 3703 & 3703 \\
\hline $\begin{array}{c}Q_{\text {Fuel,aux }} \\
=\rho_{\text {Fuel }} \dot{v}_{\text {Fuel,AuxiliaryHeat }} L H V_{\text {Fuel }}(\mathrm{kW})\end{array}$ & 0 & 0 & 0 & 0 & 0 \\
\hline$W_{E l e c}(\mathbf{k W})$ & 1000 & 1000 & 1000 & 1000 & 1000 \\
\hline$Q_{t h}\left(\mathbf{k} \mathbf{W}_{\text {th }}\right)$ & 1190 & 1180 & 1000 & 1185 & 1190 \\
\hline$T_{\text {Turbine, ex }}\left({ }^{\circ} \mathbf{F}\right)$ & 620 & 620 & 620 & 620 & 620 \\
\hline$T_{\text {evap,w,o }}\left({ }^{\circ} \mathrm{F}\right)$ & 45.0 & 45.0 & 48.0 & 46.0 & 45.0 \\
\hline$T_{\text {evap,w,i}}\left({ }^{\circ} \mathbf{F}\right)$ & 55.0 & 55.0 & 58.0 & 56.0 & 55.0 \\
\hline$T_{H R U, w, i}\left({ }^{\circ} \mathrm{F}\right)$ & 239 & 239 & 247 & 241 & 239 \\
\hline$T_{H R U, w, o}\left({ }^{\circ} \mathrm{F}\right)$ & 257 & 257 & 258 & 257 & 257 \\
\hline$T_{C T, w, i}\left({ }^{\circ} \mathbf{F}\right)$ & 95 & 96 & 102 & 96 & 95 \\
\hline$T_{C T, w, o}\left({ }^{\circ} \mathrm{F}\right)$ & 80 & 81 & 88 & 82 & 80 \\
\hline$T_{w b}\left({ }^{\circ} \mathrm{F}\right)$ & 74 & 75 & 75 & 75 & 74 \\
\hline$T_{C T, w, o}-T_{w b}\left({ }^{\circ} \mathrm{F}\right)$ & 6 & 6 & 13 & 7 & 6 \\
\hline$T_{C T, w, i}-T_{C T, w, o}\left({ }^{\circ} \mathrm{F}\right)$ & 15 & 15 & 14 & 14 & 15 \\
\hline
\end{tabular}


At 14:00, some substantial changes in performance variables are evident. The value-weighted energy utilization factor has decreased by about 4.5\% (from 1.12 to 1.07 ), not enough to be alarming by itself, but if this persists over the long run, fuel cost increases will be substantial. The fuel utilization efficiency has also decreased from $59 \%$ to $54 \%$, and the effectiveness of the heat recovery unit has decreased from $63 \%$ to $54 \%$ (i.e., by $14 \%$ ), tending to indicate that something is wrong with the heat recovery. The electric generation efficiency has not decreased, but the COP of the chiller has dipped from $68 \%$ to $60 \%$, and most alarmingly, the overall cooling tower efficiency and electric-utilization efficiency of the cooling tower have decreased by $26 \%$ (from $70 \%$ to $52 \%$ ) and $50 \%$ (from 7.0 to 3.5 ), respectively. The output of the chiller has also decreased from $1180 \mathrm{~kW}_{\text {th }}$ to $1000 \mathrm{~kW}_{\text {th }}$. These observations direct operator attention immediately to the cooling tower, which clearly has some sort of problem. Looking at some of the measured variables for the cooling tower reveals that the temperatures of the water entering and leaving the cooling tower have increased by $6^{\circ} \mathrm{F}$ and $7^{\circ} \mathrm{F}$, respectively, further supporting the operator's conclusion that the cooling tower has developed a problem, is not rejecting heat effectively from the condenser water, and is using more electricity to run its fans (known because the condenser pump efficiency has not degraded, leaving only the fans to have caused this increase).

In response to these observations, the operator sends two technicians to inspect the cooling tower. Upon inspection, the technicians find a large piece of cardboard from some sort of container for shipping a large appliance or machine lodged against the air inlet openings to the cooling tower. The cardboard appears to be blocking the flow of air induced by the fans. The technicians surmise that shortly after noon, when a violent wind storm blew through the area, cardboard debris from nearby trash containers must have blown up against the cooling tower and became lodged. To compensate for reduced flow area, the cooling-tower controller began running additional fans, increasing the electric power consumption of the cooling tower and causing the observed substantial decrease in cooling-tower electric efficiency, $\eta_{C T}$, Elec, but with little affect on cooling of the cooling water. As a result, the cooling-tower performance decreased significantly. The technicians remove the cardboard and dispose of it properly. They return to the control room. The entire inspection and repair took about 15 minutes.

Fifteen minutes later at 14:30, the effect of removing the cardboard is clearly apparent in the monitored data. The fuel utilization efficiency has increased back to 59\%. The heat recovery effectiveness is nearly up to its pre-incident level at $62 \%$, and the cooling-tower efficiency and electric utilization efficiency have both nearly fully recovered to pre-event levels, now being $68 \%$ and 6.5 , respectively. The chiller output is also close to fully recovered at $1185 \mathrm{~kW}_{\text {cooling. }}$. The cooling-tower inlet and outlet water also has nearly returned to pre-event temperatures. By 15:00, all parameters indicate full recovery, concluding our performance monitoring scenario.

Without the level of monitoring provided by this project, the cooling-tower problem would likely have persisted for some time, possibly a day, a week, or even longer. Fuel use and costs would have increased, cooling-output would have remained low, and equipment would have run longer and harder. Detection of many different operation faults and causes of degradation are possible with close monitoring. The key is to provide information in real time or short time intervals to enable plant operators to continually know the state of the CHP plant, its major systems and components. 
To illustrate application of the capabilities provided by the $\mathrm{CxV}$ algorithms, we provide the scenario that follows for the system shown in Figure 40. In this case, the scenario focuses on the performance of the prime mover, a small turbine, and the electric generator to produce electricity and waste heat in the exhaust gases as a by-product.

The system manufacturer has rated the turbine at $1 \mathrm{MW}_{\mathrm{e}}$ at which it will produce $1.7 \mathrm{MW}_{\text {th }}$ of heat captured in hot water at $257^{\circ} \mathrm{F}\left(125^{\circ} \mathrm{C}\right)$. The hot water is produced by a matched heat recovery unit. When fired at $80 \%$ of capacity, the manufacturer specification indicates that at an outdoor-air temperature of $60^{\circ} \mathrm{F}\left(\sim 15.6^{\circ} \mathrm{C}\right)$, the turbine-generator will produce $800 \mathrm{~kW}_{\mathrm{e}}$ and 1.36 $\mathrm{MW}_{\text {th }}$ of heat in hot water at $257^{\circ} \mathrm{F}\left(125^{\circ} \mathrm{C}\right)$. Upon initial start-up of the system, after allowing time for the system to reach steady operation at $80 \%$ of full firing rate, the $\mathrm{CxV}$ system reports the following:

- Electrical output, $W_{\text {Elec }}$, is $800 \mathrm{~kW}_{\mathrm{e}}$, which is within the expected range of levels for the current outdoor temperature and fuel firing rate

- Thermal output is $1100 \mathrm{~kW}_{\text {th }}$, which is below the expected range.

Using its diagnostic capabilities, the $\mathrm{CxV}$ system also reports that:

- Turbine exhaust-gas temperature, $T_{\text {Turbine, }, x}$, is $670^{\circ} \mathrm{F}\left(354^{\circ} \mathrm{C}\right)$, higher than expected (which is $620^{\circ} \mathrm{F}$ or $327^{\circ} \mathrm{C}$ )

- Hot water temperature leaving the $\mathrm{HRU}, T_{H R U, w, o}$, is $302^{\circ} \mathrm{F}\left(150^{\circ} \mathrm{C}\right)$, higher than expected (which is $257^{\circ} \mathrm{F}$ or $125^{\circ} \mathrm{C}$ )

and recommends checking control of the variable-speed water circulation pump, which appears to be pumping at a lower rate than necessary.

A technician checks the pump controller and finds that the operating range and calibration are not correct. He replaces the table for these variables in the control code with a table from the manufacturer based on testing the pump in the system (before initial firing). Upon replacing the table and waiting for the system to reach steady operation, the $\mathrm{CxV}$ system reports that operation is as expected. This aspect of operation of the CHP plant has now been corrected and verified by the $\mathrm{CxV}$ system. 


\section{Summary}

This document provides detailed functional specifications for the algorithms for CHP system performance monitoring and commissioning verification, scheduled for development under FY2006 funding. The report identifies 7 generic CHP system configurations for which algorithms will be developed from a total of 10 originally identified in the Scope Specification (Katipamula and Brambley 2006). The report then provides specifications for monitoring individual components present in the seven selected CHP configurations. Each specification includes equations for calculating performance metrics and a diagram showing all fixed inputs, measured inputs, and outputs for the algorithms. An analogous specification is also provided for performance monitoring at the system level.

Commissioning and performance verification are then discussed in some detail that are applicable to both existing and new CHP systems. A method to model system performance and detect degradations is presented along with equations and an input/output diagram. Verification of commissioning is accomplished essentially by comparing actual measured performance to benchmarks for performance provided by the system integrator and/or component manufacturers. The results of these comparisons are then automatically interpreted to provide a conclusion regarding whether the CHP system and its components have been properly commissioned and where problems are found, guidance is provided for corrections.

The report then presents an example of how the monitoring algorithms could be deployed as a stand-alone software package. Scenarios are also provided that illustrate how the algorithms could be used for performance monitoring during operation of a CHP system and as a means for verifying proper commissioning of a CHP system during initial start-up or restart. The report concludes by identifying the next steps in the project. 


\section{Next Steps}

The next step in the project is to develop and document algorithms satisfying the specifications in this document. The algorithms will be documented in the form of "pseudo-computer code" and flow charts in a report. A plan will also be prepared for testing these algorithms, which will be executed in FY2007. Testing will involve implementing the algorithms in computer code, running that code against existing data sets, and comparing the results with known or independently determined performance indicators. The computer code will be research grade, will lack an interface for easy use in the field by plant staff, and will not be suitable for delivery as a tool without significant additional development. Its purpose will be to verify proper performance of the algorithms. 


\section{References}

ANSI/ASME. 1981. Gas Turbine Heat Recover Steam Generators. Performance Test Codes. An American National Standard. ANSI/ASME PTC 4.4-1981. The American Society of Mechanical Engineers, New York.

ASME. 1984. Fans. Performance Test Code. An American National Standard. ANSI/ASME PTC 11-1984. The American Society of Mechanical Engineers, New York.

ASME. 1991. Reciprocating Internal-Combustion Engines. Performance Test Codes. ASME PTC 17-1973, Reaffirmed 1991. The American Society of Mechanical Engineers, New York.

ASME. 1996. Performance Test Code on Overall Plant Performance. STD-ASME PTC 461996. The American Society of Mechanical Engineers, New York.

ASME. 1997. Performance Test Code for Gas Turbines. ASME PTC 22-1997. The American Society of Mechanical Engineers, New York.

Connected Energy Corporation. 2004. Distributed Generation Combined Heat and Power Long Term Monitoring Protocols. Version: Interim. Prepared for the Association of State Energy Research and Technology Transfer Institutions.

Cooling Tower Institute. 2000. Acceptance Test Code-ATC-105 (00) Revised February 2000. Cooling Tower Institute, Houston, Texas.

Energy Nexus Group. 2002. Technology Characterization: Microturbines. Arlington, Virginia. Accessed on May 24, 2006, on the world wide web at http://www.epa.gov/chp/pdf/microturbines.pdf.

Haasl, T. and T. Sharp. 1999. A Practical Guide for Commissioning Existing Buildings, p. 6. ORNL/TM-1999/34. Oak Ridge National Laboratory, Oak Ridge, Tennessee.

Horlock, J.H. 1997. Cogeneration-Combined Heat and Power (CHP), pp. 26-28. Krieger Publishing Company, Malabar, Florida.

Katipamula, S. and M.R. Brambley. 2006. Advanced CHP Control Algorithms: Scope Specification. PNNL-15796. Pacific Northwest National Laboratory, Richland, WA.

Katipamula, S., M.R. Brambley and J. Schein. 2003. Results of Testing WBD Features Under Controlled Conditions. Task Report for the Energy Efficient and Affordable Small Commercial and Residential Buildings Research Program. Project 2.7 - Enabling Tools. Task 2.7.5. Included as part of Final Report Compilation for Enabling Tools, pp. Technical Report P-50003-096-A7. California Energy Commission, Sacramento, California. 
Kovacik, J.M. 1982. “Cogeneration.” Chapter 7 in Energy Management Handbook, pp. 203230, W.C. Turner, editor. John Wiley and Sons, New York.

PECI. 2006. Functional Testing Guide: from Fundamentals to the Field, Section 3. The Commissioning Process. Published on the world wide web at http://www.peci.org/ftguide/ftg/FTG dec052005.htm. Last accessed on June 8, 2006.

Southern Research Institute. 2000. Test and Quality Assurance Plan: Honeywell Power Systems Inc. Parallon ${ }^{\circledR} 75 \mathrm{~kW}$ Turbogenerator. SRI/USEPA-GHG-QAP-10. Greenhouse Gas Technology Verification Center, Southern Research Institute, Research Triangle Park, North Carolina.

Southern Research Institute. 2002. Test and Quality Assurance Plan Combined Heat and Power at a Commercial Supermarket Capstone $60 \mathrm{~kW}$ MicroTurbine ${ }^{\mathrm{TM}}$. SRI/USEPA-GHGQAP-27. Greenhouse Gas Technology Center, Southern Research Institute, Research Triangle Park, North Carolina.

Southern Research Institute. 2004. Distributed Generation and Combined Heat and Power Field Protocol. Version: Interim. Prepared for the Association of State Energy Research and Technology Transfer Institutions. Southern Research Institute, Research Triangle Park, North Carolina.

Timmermans, A.R.J. 1978. Combined Cycles and Their Possibilities Lecture Series, Combined Cycles for Power Generation. Van Karman Institute for Fluid Dynamics, Rhode Saint Genese, Belgium. 